

\section{Editorial Director}

Jan Smets, Member of the Board of Directors of the National Bank of Belgium

\section{Editoral}

On October 11-12, 2012 the National Bank of Belgium hosted a Conference on "Endogenous Financial Risk".

Papers presented at this conference are made available to a broader audience in the NBB Working Paper Series (www.nbb.be).

\section{Statement of purpose:}

The purpose of these working papers is to promote the circulation of research results (Research Series) and analytical studies (Documents Series) made within the National Bank of Belgium or presented by external economists in seminars, conferences and conventions organised by the Bank. The aim is therefore to provide a platform for discussion. The opinions expressed are strictly those of the authors and do not necessarily reflect the views of the National Bank of Belgium.

\section{Orders}

For orders and information on subscriptions and reductions: National Bank of Belgium,

Documentation - Publications service, boulevard de Berlaimont 14, 1000 Brussels.

Tel +32 $22212033-$ Fax +322213042

The Working Papers are available on the website of the Bank: http://www.nbb.be.

(c) National Bank of Belgium, Brussels

All rights reserved.

Reproduction for educational and non-commercial purposes is permitted provided that the source is acknowledged.

ISSN: $1375-680 X$ (print)

ISSN: 1784-2476 (online) 


\title{
Endogenous risk in a DSGE model with capital-constrained financial intermediaries*
}

\author{
Hans Dewachter ${ }^{\dagger}$ and Raf Wouters ${ }^{\ddagger}$
}

Current Version: September, 2012.

\begin{abstract}
This paper proposes a perturbation-based approach to implement the idea of endogenous financial risk in a standard DSGE macro-model. Recent papers, such as Mendoza (2010), Brunnermeier and Sannikov (2012) and He and Krishnamurthy (2012), that have stimulated the research field on endogenous risk in a macroeconomic context, are based on sophisticated solution methods that are not easily applicable in larger models. We propose an approximation method that allows us to capture some of the basic insights of this literature in a standard macro-model. We are able to identify an important risk-channel that derives from the risk aversion of constrained intermediaries and that contributes significantly to the overall financial and macro volatility. With this procedure, we obtain a consistent and computationally-efficient modelling device that can be used for integrating financial stability concerns within the traditional monetary policy analysis.
\end{abstract}

${ }^{*}$ The views expressed in this paper are the authors' and do not necessarily reflect those of the National Bank of Belgium. We would like to thank Michel Julliard for his advice on implementing higher-order perturbation methods in Dynare.

${ }^{\dagger}$ National Bank of Belgium and University of Leuven, hans.dewachter@nbb.be.

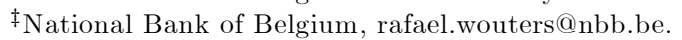




\section{Introduction}

This paper proposes a perturbation-based approach to implement the idea of endogenous financial risk in a standard DSGE macro-model. Recent papers, such as Mendoza (2010), Brunnermeier and Sannikov (2012) and He and Krishnamurthy (2012), that have stimulated the research field on endogenous risk in a macroeconomic context, are based on sophisticated solution methods that are not easily applicable in larger models. We propose an approximation method that allows us to capture some of the basic insights of this literature in a standard macro-model. With this procedure, we obtain a consistent and computationally-efficient modelling device that can be used for integrating financial stability concerns within the traditional monetary policy analysis.

The starting point of this paper is the work of He and Krishnamurthy (2012) in which financial intermediaries are facing occasionally-binding capital constraints. They show that such financial constraints, when activated by some bad economic shocks that deplete the capital base of the intermediaries, lead to a disruptive financial intermediation process and potentially to a systemic risk crisis. In such situations, capital-constrained intermediaries experience a strong increase in the riskiness of their balance sheet position and are forced to adjust their asset and credit evaluation standards. The resulting asset price corrections and credit supply restrictions will feedback to the firms' and households' investment decisions which deteriorate further the macroeconomic environment and raise the probability of a vicious cycle.

Recent papers on the financial crisis and the resulting Great Recession tend to converge on the idea that capital constraints on financial intermediaries are an important factor for understanding the risk attitude of these institutions. Gilchrist and Zakrajeck (2012) relate the predictive power of their bond premium for the business cycle to the risk-bearing capacity of the marginal investors in these bonds. These investors act in a more risk-averse way when their capital becomes impaired which translates in an increase of the bond premium and a reduction in the supply of credit available to potential borrowers. Adrian and Boyarchenko (2012) document that the risk-bearing funding constraint of the intermediaries generates procyclical leverage and strong procyclical dynamics in the intermediated credit. The modelling approach based on capital constraints build also on the older literature of the financial accelerator model (Bernanke, Gertler and Gilchrist (1999)) or collateral constraints (Kyotaki and More (1997)) that has been applied more recently to the financial sector as well (see Gertler and Karadi (2011) or Gertler and Kyotaki (2010)). These models exploit the first-order effects of net worth and credit constraints from default and/or opportunity costs. However, they do not exploit the risk amplification inherent in the global dynamics of these models. Our approach builds also on the literature that illustrates the limits of arbitrage in financial markets due to wealth constraints (Xiong (2001)). It shares with this literature the important message that asset prices during stress periods deviate substantially from their efficient market valuation, i.e. the constraint-free equilibrium price. 
He and Krishnamurthy(2012), and related papers such as Brunnermeier and Sannikov (2012) and Danielsson, Shin and Zigrand (2011), use global solution methods to solve the ordinary differential equations that describe the financial and real decisions of the various economic agents within the context of occasionallybinding constraints that separate distressed states from normal times. This global solution procedure imposes in practice, however, strong limitations on the size of the state vector; in most cases only one state variable is allowed, which hampers a direct implementation of these procedures in a fully-fledged macromodel. Mendoza (2010) uses numerical solution techniques for solving similar setups. These methods can be applied to larger models with a larger state vector, as in Favilukis, Ludvigson and Van Nieuwerburgh (2011). However, these iterative procedures remain very time-consuming and therefore not useful in the context of empirical validation exercises.

In this endogenous risk literature, financial risk is modelled consistently with the stochastic discount factor of the marginal investor. Typically, only financial intermediaries are assumed to invest directly in capital or in firm assets and therefore, these institutions are key to risk pricing. Models with heterogenous agents and limited capital market participation have been able to generate substantial risk premiums as was shown in Danthine and Donaldson (2002), and Guvenen (2009). Along these lines, De Graeve et al. (2010) investigate the time-varying nature of asset price risk in a macro-model that differentiates between shareholder, bondholders and workers. That paper also discusses the interaction between the macroeconomic frictions and asset price risk but it does not consider financial constraints which are central in the new endogenous risk literature. De Graeve et al. (2010) also use local third-order perturbation methods, similar to the ones used in this paper, to investigate the time-varying risk. Recently, there has been a growing interest in the use of higher-order perturbation methods for analyzing the role of risk in macroeconomic models. However, these papers, like Fernandez-Villaverde et al. (2012), concentrate on the role of exogenous risk and stochastic volatility and do not discuss the endogenous risk mechanism that is produced in our model mainly via the leverage constraint on financial intermediaries.

This paper evaluates the risk channel originated by occasionally-binding capital constraints on financial intermediaries in a standard DSGE model. The remainder of this paper consists of four sections. In section 2, we explain the underlying model of He and Krishnamurthy (2012) for capital-constrained financial intermediaries in a continuous-time setting. We discuss the global dynamics of this simple model that treats the real economy as simply as possible. In section 3, we explain how we can replace the occasionally-binding capital constraint by a non-linear but continuous approximation. This approximate model can be solved in a discrete-time setting by local third-order perturbation methods. We compare the results of this approach with the outcomes from the continuous-time model to illustrate the merits and problems of the approximation. In section 4, we implement this non-linear capital constraint on financial intermediaries in a more extensive DSGE model that contains the standard nominal and real frictions. We explain how the capital constraint adds a potentially important risk channel to the transmission mechanism of a standard productivity shock in that model. We illustrate how this endogenous risk 
channel increases the macroeconomic volatility, especially during financial stress periods and how it interacts with the interest rate policy. Finally, section 5 concludes.

\section{Global dynamics in a continuous-time AK economy}

In this section we present a simple, continuous-time, one-sector DSGE model with capital-constrained financial intermediaries. This model fits within the macroeconomic framework to study systemic risk, as proposed by He and Krishnamurthy (2012), (HK(2012)). Specifically, it introduces a reputation-based equity constraint on financial intermediation in an otherwise standard AK production economy. As shown by HK(2012), these models generate endogenous risk, i.e. endogenous dependence of financial and macroeconomic variables on the reputation (leverage) of the financial sector. In line with empirical observation, we find that low-reputation states (where the constraint is becomes binding) are associated with financial distress (high and volatile Sharpe ratios and risk and low capital price levels). However, this type of models has the striking feature of hardly generating a significant impact of reputation (and leverage) on the macroeconomy, i.e. on production or investment. Therefore, we also assess the relevance of financial constraints on the non-financial firm for the amplification of the impact of financial risk (reputation effects). More specifically, we extend the model by introducing, next to the equity constraint on the financial intermediary, a collateral constraint on the non-financial firms. With these additional frictions, we are able to obtain significant links between reputation and macroeconomic quantities. Finally, we also shown that the occasionally-binding capital constraint can be substituted with a continuous approximation. This alternative formulation of the constraint is further exploited in the local approximation method in the next section.

\subsection{The continuous-time AK Model}

\subsubsection{Production, investment and households}

Production is modelled by a standard AK-production technology. Firms employ a level of (effective) capital, $K_{t}$, which given a specific technology (and productivity) $A$, generates a level of output according to the AK framework:

$$
Y_{t}=A K_{t}
$$

The firms pay a fixed proportion of output in the form of the wage bill, $l_{t} w_{t}=l \cdot Y_{t}$ and the remainder of output is paid out to shareholders of the firm in the form of dividends, i.e. $\operatorname{div}_{t}=(1-l) \cdot Y_{t}$.

Following HK(2012), the dynamics of effective capital contain both an endogenous (net investment, $i_{t}-\delta$ ) 
and exogenous component (capital efficiency shocks, $\sigma d Z_{t}$ ):

$$
d K_{t}=K_{t}\left(i_{t}-\delta\right)+K_{t} \sigma d Z_{t}
$$

where $i_{t}$ and $\delta$ denote the investment and depreciation rate, respectively and the instantaneous standard deviation of the capital efficiency shock is given by $\sigma$. The capital efficiency or quality shock is the only exogenous factor in the model. Investments are accompanied by capital adjustment costs, so that the total cost (gross investment) of installing $i_{t} K_{t}$ units of new capital requires $\Psi\left(i_{t}, K_{t}\right)$ units of consumption goods:

$$
\Psi\left(K_{t}, i_{t}\right)=i_{t} K_{t}+\frac{\kappa}{2}\left(i_{t}-\delta\right)^{2} K_{t}
$$

Real investment is undertaken by (risk-neutral) capital good producers, maximizing net profits $q_{t} i_{t} K_{t}-$ $\Psi\left(K_{t}, i_{t}\right)$, with $q_{t}$ denoting the price of capital. The net profits of capital producers are generated by selling the net production of capital goods in the market. Producers maximize profits by choosing optimal investment:

$$
i_{t}=\delta+\frac{q_{t}-1}{\kappa} .
$$

Households maximize expected $(\log )$ utility of the total consumption level, $C_{t}$, subject to the standard budget constraint:

$$
\begin{gathered}
\max _{c_{t}} \int_{0}^{\infty} e^{-\rho t} \ln \left(C_{t}\right) d t \\
d W_{t}=\left(l Y_{t}-C_{t}\right) d t+W_{t} r_{t} d t+\alpha_{t}^{h} W_{t}\left(\frac{d V_{t}}{V_{t}}-r_{t} d t\right),
\end{gathered}
$$

leading to the standard Euler equation:

$$
r_{t}=\rho+E_{t}\left[\frac{d C_{t}}{C_{t}}\right]-\operatorname{Var}_{t}\left[\frac{d C_{t}}{C_{t}}\right] .
$$

Household wealth accumulation consists of two components. First, households derive income out of labor $\left(l Y_{t}\right)$ and earn returns on wealth, $W_{t}$. Households hold wealth either in the form of risk-free bonds, $B_{t}$ or in the form of equity from the intermediary sector, $V_{t}: W_{t}=B_{t}+V_{t}$. Debt is issued by the intermediary sector in the form of risk-free deposits. The return on wealth depends on the allocation of wealth over bonds and equity (i.e. $\alpha^{h}$ ). We assume, following HK (2012), that households use relatively simple investment rules, attributing a fraction $\lambda$ of wealth to the debt household and $(1-\lambda)$ to the equity household. While the debt household invests all attributed wealth in risk-free debt, the equity household invests either in debt or equity of the intermediary sector. The investment share in equity of the latter depends on the reputation of the financial sector, $\mathcal{E}_{t}$ (see next section). If the reputation of the intermediary sector is sufficiently high (i.e. , $\mathcal{E}_{t} \geq(1-\lambda) W_{t}$ ) all wealth of the equity household will be invested in equity $\left(\alpha_{t}^{h}=1-\lambda\right)$, else, reputation acts as an effective upper bound on equity investment $\left(\alpha_{t}^{h}=\mathcal{E}_{t} / W_{t}\right)$. The reputation of the intermediary sector thus effectively acts as an occasionally-binding constraint on household investment:

$$
\alpha_{t}^{h}=\min \left((1-\lambda), \mathcal{E}_{t} / W_{t}\right)
$$




\subsubsection{Financial intermediation, reputation and equity constraints}

Financial intermediaries play a crucial double role in the model, intermediating between the households and the capital market. First, we assume that only financial intermediaries have access to the capital market (and hence become the marginal investor), establishing the need for financial intermediation. Second, households are the final originators of funding of the intermediary sector, either in the form of equity or deposits. The share of equity and deposit financing is determined by the reputation of the financial sector. Figure 1 displays the balance sheets of households and financial intermediaries and contains the implicit assumptions of our set up.

Insert Figure 1

Financial intermediaries raise equity and issue debt to invest in the capital of the producing firms. Denoting the return on equity of the financial intermediary by $d R_{t}^{F I}$, the return on capital by $d R_{t}$ and the leverage (assets over equity) of the financial intermediary by $\alpha^{F I}, \alpha^{F I}=q_{t} K_{t} / V_{t}$, it follows that the return on equity of the financial intermediary is given by:

$$
d R_{t}^{F I}=\alpha_{t}^{F I} d R_{t}+\left(1-\alpha_{t}^{F I}\right) r_{t} d t
$$

with the return on (existing) capital $\tilde{K}_{t}, d R_{t}=d\left(q_{t} \tilde{K}_{t}\right) /\left(q_{t} \tilde{K}_{t}\right)+\operatorname{div}_{t} d t$, following from equations (1) and $(2)^{1}$ :

$$
d R_{t}=\frac{d q_{t}+A(1-l) d t}{q_{t}}-\delta_{t} d t+\sigma d Z_{t}+\operatorname{Cov}_{t}\left[\frac{d q_{t}}{q_{t}}, \sigma d Z_{t}\right] .
$$

Even though households own the financial intermediaries, we assume (as in HK (2012)) that bankers operate and control, independently of household preferences, the investment portfolio of the intermediary optimizing on a reputation-based objective function. Denoting the reputation of the financial intermediary at the micro level by $\varepsilon_{t}$, HK (2012) posit a proportionality between reputation and investment performance:

$$
\frac{d \varepsilon_{t}}{\varepsilon_{t}}=m d R_{t}^{F I}
$$

Positing a direct proportionality between reputation $(\varepsilon)$ and investment performance $\left(\exp \left(m \int d R_{t}^{F I}-\right.\right.$ $\frac{m^{2}}{2} \int\left(d R_{t}^{F I}\right)^{2}$ ) reflects the (widely-held) belief that financial intermediaries can build up reputation and "trust" or "credibility" through the performance of the investment strategy. The better the investment track record of the financial intermediary, the higher its reputation and the confidence of the households in the institution. As mentioned in the previous section, reputation plays a crucial role as it will determine the amount of equity households are willing to hold with the specific intermediary. The higher the

\footnotetext{
${ }^{1}$ Note that the difference between $K$ and $\tilde{K}$ is due to the fact that in the latter new investments are not taken into account as they are not yet part of the investment portfolio. The dynamics for existing capital hence imply zero investments:

$$
d \tilde{K}_{t}=-\tilde{K}_{t} \delta+\tilde{K}_{t} \sigma d Z_{t},
$$
}


reputation, the more households will be investing in the equity of the financial intermediary. The lower reputation, the less inclined households will be to invest in the equity of the intermediary. Reputation hence can act as an occasionally-binding equity constraint on banks' balance sheets. Given the central role of reputation as a pre-condition for equity financing, we model bankers as optimizing reputation by following "growth-optimal" investment strategies for reputation:

$$
\max _{\alpha^{F I}} E\left[d R_{t}^{F I}\right]-\frac{m}{2} \operatorname{Var}_{t}\left[d R_{t}^{F I}\right],
$$

implying the standard optimal investment strategy ${ }^{2}$ :

$$
\alpha_{t}^{F I}=\frac{E_{t}\left[d R_{t}\right]-r_{t}}{m \operatorname{mar} r_{t}\left[d R_{t}\right]}
$$

Aggregating over the reputations at the micro level, by taking into account exit (at rate $\eta_{t}$ ) and entry (at rate $\psi_{t}$ ) of the individual financial intermediaries, we obtain the reputation at the macro level, $\mathcal{E}_{t}$, with:

$$
\frac{d \mathcal{E}_{t}}{\mathcal{E}_{t}}=m d R_{t}^{F I}-\eta_{t} d t+\psi_{t} d t
$$

The level of the macro-reputation plays a crucial role in the allocation of household investment. As explained above, at the aggregate level, equity households invest a share $\left((1-\lambda) W_{t}\right)$ of their wealth in equity as long as the aggregate reputation of the intermediary sector is sufficiently high. The total equity funding of the financial sector by the households is therefore given by the occasionally-binding constraint:

$$
V_{t}=\min \left(\mathcal{E}_{t},(1-\lambda) W_{t}\right) .
$$

Given that the financial intermediary is the only (and marginal) investor in capital, developments in reputation of the financial intermediary will affect risk and risk pricing in the capital market. Specifically, as reputation determines the composition of funding (and hence leverage) of the financial intermediary, it will also affect the required risk premium on the capital market. If the reputation of the financial sector is too low, households will restrict equity funding, and hence the leverage of the intermediary $\left(\alpha^{F I}\right)$, holding all the capital, will increase. Financial intermediaries, however, will compensate the highly leveraged position by requiring higher risk premiums in the capital market (see equation (8)). If the reputation of the financial intermediaries is sufficiently high, equity households are willing to provide a substantial amount of equity financing, decreasing leverage. As a result of the lower leverage of the financial intermediary required risk premiums will be lower. Hence, equation (8) suggests an inverse (positive) relation between reputation (leverage) and risk premiums.

\subsubsection{General equilibrium}

The equilibrium of this economy consists of a set of prices $\left(q_{t}, r_{t}\right)$ and a set of decision rules $\left(C_{t}, \alpha^{F I}\right)$, where (i) the actions should, for given prices, satisfy the respective optimality conditions (i.e. equation

\footnotetext{
${ }^{2} \mathrm{HK}$ (2012), assume that bankers optimize final reputation within a context of exit. This problem is equivalent to maximizing the log of (final) reputation. Taking into account potential exit implies a maximization problem:

$$
\max _{\alpha^{F I}} E \int e^{-\eta t} \ln \varepsilon_{t} d t .
$$
}


(5) and (8)) and (ii) where for given actions and prices, markets should clear. The relevant market clearing conditions are (i) for the goods market:

$$
Y_{t}=C_{t}+\Psi\left(K_{t}, i_{t}\right)
$$

(ii) the financial wealth constraint for the household sector (being the shareholder of the financial intermediaries):

$$
W_{t}=q_{t} K_{t}=V_{t}+\left(W_{t}-V_{t}\right)
$$

and (iii) the capital market clearing (implying that only financial intermediaries invest in the capital market and hold all capital):

$$
\alpha^{F I} V_{t}=q_{t} K_{t}
$$

The latter market clearing condition makes the role of the equity constraint in the equilibrium explicit. Rewriting the latter condition in terms of leverage $\left(q_{t} K_{t} / V_{t}=\alpha^{F I}\right)$ and using the optimal investment condition for financial intermediaries (equation (8)) shows that capital market returns and/or volatility are related to leverage. Increases in leverage (for instance due to a decrease in equity financing of the financial intermediary) are related to either an increase in the expected return on capital or a reduction in the volatility.

Following closely the procedures developed by HK(2012), it can be shown that an equilibrium exists in terms of a single state variable, $e_{t}$, i.e. scaled macro-reputation:

$$
e_{t}=\frac{\mathcal{E}_{t}}{K_{t}}
$$

with dynamics:

$$
d e_{t}=\mu_{e} d t+\sigma_{e} d Z_{t}
$$

Moreover, by conjecturing that the price of capital is a function of the (scaled) reputation of the financial intermediary, i.e. $q\left(e_{t}\right)$, we can rewrite the endogenous variables as a function of this pricing functional and the dynamics of scaled reputation. ${ }^{3}$ Specifically, the return on capital, $d R_{t}$ defined in equation (7) can be reformulated by using the dynamics of $e$ and the conjectured price functional as:

$$
d R_{t}=\left(-\delta+\frac{q_{t}^{\prime} \mu_{e}+1 / 2 q^{\prime \prime} \sigma_{e}^{2}+(1-l) A+q_{t}^{\prime} \sigma_{e} \sigma}{q_{t}}\right) d t+\left(\sigma+\sigma_{e} \frac{q_{t}^{\prime}}{q_{t}}\right) d Z_{t} .
$$

Below we show that $q^{\prime}$, the derivative of the pricing function with respect to reputation, is positive for the calibrations used in this paper. This implies that, in this model, endogenous risk arises as a consequence of changes in the reputation of the financial intermediaries. Equation (11) shows that the impact of exogenous capital efficiency shocks gets amplified. The total amplification effect, however, depends on both the price impact of a typical shock in reputation $\left(q^{\prime} / q\right)$ as well as on the (endogenously determined) size of the reputational shocks, $\sigma_{e}$.

\footnotetext{
${ }^{3}$ The moments of the dynamics of scaled reputation are a function of the characteristics of the pricing functional $q(e)$ and $e$.
} 
The capital price also determines the equilibrium levels of consumption and investment and hence (for $q^{\prime}>0$ ) implies a transmission of reputation effects to the macroeconomy. Using the market clearing condition, equation (i), and the expressions for optimal investment and the production function (equations (4) and (1)), we can express equilibrium consumption and investment (scaled by capital) as:

$$
\begin{aligned}
& C_{t} / K_{t}=\left(Y_{t}-\Psi\left(K_{t}, i_{t}\right)\right) / K_{t}=\bar{A}-\delta-\frac{\left(q_{t}-1\right)}{\kappa}-\frac{\left(q_{t}-1\right)^{2}}{2 \kappa}, \\
& \Psi\left(K_{t}, i_{t}\right) / K_{t}=\delta+\frac{q_{t}-1}{\kappa}+\frac{\left(q_{t}-1\right)^{2}}{2 \kappa} .
\end{aligned}
$$

Given $q^{\prime}>0$, (scaled) investment increases with the reputation of the financial intermediaries; an increase in reputation (decrease in leverage of the financial intermediaries) requires a lower risk premium and increases the capital price, which triggers a positive investment effect (see equation (4)). The increase in investment is compensated by a decrease in consumption, establishing that the consumption and (gross) investment effects counterbalance in this model.

Finally, given the dynamics of consumption, one can obtain the expression for the equilibrium interest rate level by solving for the mean and the variance of the consumption process (see equation (5)). Given that consumption depends on the pricing function $q$, it follows also that the risk-free interest rate depends on the pricing function and hence the reputation state variable.

\subsection{Global dynamics}

Given a calibration of parameters and appropriate boundary conditions, the model can be solved explicitly by using numerical solution techniques for systems of ODEs. Table 1 presents the calibration for the onesector version of the AK model discussed before. Given the fact that the model is highly stylized, we do not aim to fully replicate all empirical moments. Instead, the main goal is to analyze the degree of nonlinearity and endogeneity of risk and the transmission to the real economy for a "reasonable" set of parameters. For the intermediation part, the calibration follows HK (2012). In line with their calibration, we assume the sensitivity of reputation $m$ at 2.5 , which for baseline specification results in sharpe ratios in between 2.0 and 0.1 with an average of around 0.31. Bankers' exit rate $(\eta)$ and the debt share $(\lambda)$ are respectively fixed at 0.13 and 0.5 . We use a lower trigger for entry, i.e. a Sharpe ratio of 2 , $\gamma=2$. As the production side of the model deviates substantially from $\operatorname{HK}(2012)$, significantly different parameters are used. First, we use a substantially lower size for the capital efficiency shock ( $2 \%$ instead of $5 \%$ ) as it will lead to more reasonable values for the implied consumption volatility (at the price of misfitting investment volatility). We use an aggregate productivity parameter $(A)$ of 0.35 . Given the AK production technology, this parameter implies a GDP to capital share of about $1 / 3{ }^{4}$ We assume significant investment adjustment $\operatorname{costs}(\kappa=20) .{ }^{5}$ Finally, the wage bill share in GDP of $60 \%(l=0.60)$

\footnotetext{
${ }^{4}$ Note that our specification, including a wage bill, also allows us to have more reasonable values for the investment and consumption shares in the economy.

${ }^{5}$ The high level of adjustment costs is chosen to strike a balance between the volatility of asset prices and the (capital) price sensitivity of investments. Choosing smaller values of $\kappa$ will increase the price sensitivity, but reduce significantly the
} 
is in line with an average consumption and investment share in GDP of, respectively, around 70\% and $30 \%$.

\section{Insert Table 1}

Figure 2 presents the global dynamics solution for the baseline case. The upper panels present the solution for leverage $\left(\alpha^{F I}\right)$ and access to equity financing $\left(V_{t}\right)$ as a function of scaled reputation. In line with the occasionally-binding constraint, we observe that reputation determines the level (and share) of equity funding of the financial intermediary. For low reputation levels, the level of equity is effectively constrained. This funding constraint also generates a nonlinear impact on leverage, which increases nonlinearly, as reputation decreases. The impact of reputation on funding and leverage is further reflected in the financial variables. Typically, the price of capital increases with the reputation of the financial sector, reflecting the lower risk premium demanded by the financial sector with high reputation. A high reputation of the sector implies that households invest significant amounts of wealth in equity, reducing leverage and hence the risk premium. For low levels of reputation, however, the equity constraint is binding and households reduce equity investment, inducing a higher leverage on the financial sector, implying higher required risk premia on capital and hence a decreasing price. ${ }^{6}$ Note, moreover, that the price sensitivity to reputation becomes larger for lower levels of reputation, illustrating the link between reputation and volatility. The impact of reputation on the return on capital are depicted in the middle panels; low reputation states are characterized by both a high volatility and expected return. ${ }^{7}$ However, the quantitative impact of the endogenous risk remains limited with the range for the price of capital (between 0.9 and 1.1). Moreover, the transmission of the endogenous risk towards the real economy remains limited, with (scaled) consumption and investment relatively stable for different levels of reputation.

Insert Table 2 and Figures 2 and 3

The nonlinear features of the model can be illustrated further by means of simulations. Figure 3 displays the simulated values of the retained variables and overlays these simulation results on the theoretical global dynamics solution. The most relevant observation is that the simulated values are concentrated on a relatively small subset of global dynamics solution. This follows from the fact that the simulations for the scaled reputation remain within a relatively confined interval, i.e. [0,1], suggesting that the dynamics of $e_{t}$ (equation $(10)$ ) are bounded. Note that the effective interval of scaled reputation $(e)$ contains the region where the nonlinearity of the solution is strongest i.e. where the equity constraint

\footnotetext{
volatility (and nonlinearity) in the capital price.

${ }^{6}$ In line with forward-looking markets, prices start to decrease even at reputation levels where the equity constraint does not bind. This happens due to the anticipation of possible future reputation-constrained states, which become more likely as reputation is closer to the threshold.

${ }^{7}$ Although not reported, note that the Sharpe ratio is decreasing in scaled reputation and is significantly higher in the region where the equity constraint is binding.
} 
binds. The nonlinearity of the global solution is therefore relevant in practice. Table 2 presents summary statistics for the volatility of the most important variables, distinguishing between distress and nondistress periods. ${ }^{8}$ We can observe significant nonlinear effects in the volatility of most financial variables (such as intermediary equity $(\mathrm{Eq})$, the Sharpe ratio (SR) or the capital price $(\mathrm{Q})$ ), with higher volatility during the distress periods than in the non-distress periods. However, the endogenous risk effects in the model remain confined to the financial sector, and do not impact on the macroeconomy. More specifically, the nonlinearity is much less marked for the macroeconomic variables, where much less asymmetry is observed between distressed and non-distressed periods. Finally, note that the model does not perform well in replicating the empirical moments.

\subsection{Extensions}

\subsubsection{The role of additional financial constraints}

Although the model generates an endogenous impact of reputation (and leverage of financial intermediaries) on both macroeconomic and financial variables, the quantitative effects remain relatively small. In this section, we assess the relevance of a financial constraint on the non-financial firm for the amplification of the impact of financial risk (reputation effects). More specifically, we extend the model by introducing, next to the equity constraint on the financial intermediary, a collateral constraint on the non-financial firms.

The baseline model is extended by allowing for productivity enhancing production factors, $n_{t}$, which increase the productivity of capital, $A_{t}=\bar{A}+\chi n_{t}$. We assume that firms need to borrow (intra-period) working capital to employ these specific factors. ${ }^{9}$ The total financing costs of employing $n_{t}$ specific factors, i.e. $n_{t} K_{t}$, need to be pre-financed by intra-period loans and require sufficient coverage by collateral (capital) : $n_{t} K_{t} \leq v K_{t} q_{t}$. By assuming that the working capital constraint binds, a direct feedback from financial shocks to productivity and the real economy is obtained:

$$
A_{t}=\bar{A}+\Phi q_{t}, \Phi=v \chi \geq 0
$$

By modelling productivity as a function of $q$, we introduce a direct macro-financial interaction between the asset prices $(q)$ and the real economy $\left(Y=A_{t} K_{t}\right)$. As asset prices decrease, firms will find it more difficult to obtain intratemporal financing for the productivity-enhancing factors and as a consequence will be forced to work at lower productivity levels. This channel will complement other macro-financial

\footnotetext{
${ }^{8}$ We use a similar procedure as HK(2012) who identify stressed and non-stressed periods by the observed sharpe ratio. The distress sample contains the observations with the highest (one-third of the) sharp ratios, while the non-distress sample takes the remaining observations.

${ }^{9} \mathrm{~A}$ detailed and micro-founded analusis of the impact of working capital constraints can be found in Jermann and Quadrini (2012).
} 
linkages which run through financial intermediation. Note that the baseline model is recovered by blocking this feedback channel, i.e. $\Phi=0$.

Insert Figure 4 and Table 3

We solve for the global dynamics of the extended model using the calibration in the baseline model. To incorporate the impact of financial constraints of firms we allow for different strengths of the direct productivity effect, i.e. $\Phi=0.1$ and 0.15 . In order to have comparable overall productivity, the constant productivity component is adjusted to generate the average productivity of the baseline model at a price $q=1$. This implies a value for $\bar{A}=0.35-\Phi$. Figure 4 presents the solution for the retained financial and macroeconomic variables. As can be observed, allowing for a direct price effect increases significantly the scope for nonlinearity in the model relative to the benchmark model $(\Phi=0)$. For low levels of reputation, i.e. when the equity constraint on financial intermediaries becomes binding, the nonlinear impact of reputation (on capital prices, expected returns and volatility) becomes more pronounced and quantitatively relevant. Moreover, significant links between reputation and macroeconomic quantities appear; low levels of reputation are associated with significantly lower production, consumption and investment. Table 3 confirms, through simulation, that the extended model reinforces the nonlinearity in the model; the volatility in the distressed regime increases both in absolute terms as well as relative to the non-distress state. Overall, this exercise suggests that additional frictions on the firm behavior can substantially reinforce the impact of reputation-based equity constraints on macro and financial variables.

\subsubsection{Occasionally- versus continuously-binding equity constraints}

The AK model presented above features an occasionally-binding constraint, reflecting the idea that households restrict equity financing only when the reputation of the financial intermediaries falls below a certain threshold (i.e. the total wealth of the equity household). Although intuitive, occasionally-binding constraints introduce additional complications for solving the model (either analytically or numerically). In this section we replace, within the context of the baseline AK model, the occasionally-binding constraint by an alternative, approximate, continuously-binding constraint. The latter can be justified by similar reasoning as the occasionally-binding constraint.

\section{Insert Figure 5}

The continuously-binding constraint, used as an approximation to the occasionally-binding constraint $\left(V_{t}=\min \left(\mathcal{E}_{t},(1-\lambda) W_{t}\right)\right.$, reflects the idea that as reputation approaches the lower level $\mathcal{E}_{-}$, households increasingly and nonlinearly limit the total equity financing of the financial intermediary and is formally 
modeled as:

$$
V_{t}=\frac{(1-\lambda) W_{t}}{1+\alpha_{\varepsilon}\left(W_{t} /\left(\mathcal{E}_{t}-\mathcal{E}_{-}\right)\right)^{3}}
$$

where the limits for equity depend on the reputation of the intermediary, with $\lim _{W_{t} / \mathcal{E}_{t} \rightarrow 0} V_{t}=(1-\lambda) W_{t}$ and $\lim _{W_{t} / \mathcal{E}_{t} \rightarrow \infty} V_{t}=0 .{ }^{10}$ Figure 5 depicts the global solution of the AK model with the continuouslybinding constraint and compares it to the baseline AK model (with occasionally-binding constraint). Overall, Figure 5 suggests that substituting the occasionally-binding by a continuously-binding (approximating) constraint generates broadly similar global dynamics. Both model versions imply similar price of capital solutions $(q(e))$, which translate in similar solutions for the macroeconomic variables, i.e. investment and consumption. Small differences in leverage and equity can be observed, which arise as a consequence of the approximation errors, which are largest at the kink of the occasionally-binding constraint. This alternative procedure to implement the constraint allows us to work with local approximation methods to solve the model.

\section{A local discrete-time approximation of the AK model}

In this section, we present the results for a discrete-time approximation of the AK model. The discretetime approximation differs in two respects from the continuous-time AK model. First, the minimumconstraint on the household portfolio behavior, which restricts the household investment in risky funds to an upper bound that is given by the reputation of the financial intermediaries, is replaced by a function that relates the share of risky funds in the portfolio to reputation in a highly non-linear but continuous form. Second, this discrete-time model (with the continuous approximation of the constraint) is solved locally around a deterministic steady state. The complete model is approximated around this steady state by a third-order perturbation method as implemented in Dynare. ${ }^{11}$ The advantage of this approximation approach is that it yields a very efficient solution technique that can easily be applied to much larger and more realistic models. The cost is that we make approximation errors. ${ }^{12}$ The main goal of this section is to assess if the approximation method -based on a discrete-time version of the model- is able to capture the most relevant non-linear aspects (for a macro-economic analysis) of the capital constraint on financial intermediaries.

\subsection{Discrete-time AK model}

The discrete-time AK model follows closely the continuous-time version presented above. We only summarize the important equations and indicate if they deviate from the continuous-time version.

\footnotetext{
${ }^{10}$ The values for $\mathcal{E}_{-}$and $\alpha_{\varepsilon}$ are set to respectively 0.02 and 0.025 .

${ }^{11}$ See Julliard and Kamenik (2004).

${ }^{12}$ The accuracy and numerical stability typically depend strongly on the domain over which the model is evaluated and the behavior of the functions over this domain.
} 
Exactly as in the continuous-time version, the production function is described by an AK technology $Y_{t}=A K_{t}$ and it is assumed that the firms are paying a fixed proportion of output to the households in the form of labor income $w l_{t}=l \cdot Y_{t}$ with the remaining surplus being distributed as dividends to the financial intermediaries which are the shareholders in the firm $D_{t}=(1-l) \cdot Y_{t}$. The effective capital stock is determined by a deterministic depreciation rate $\delta$, the i.i.d. capital efficiency shock $\sigma$ and the new investment $i \cdot K: K_{t}=\left(1-\tau-\sigma_{t}\right) K_{t-1}+i_{t-1} K_{t-1}$. Capital adjustment costs and the resulting optimal investment rule are as described in equation (3) and (4).

Households maximize their expected log-utility stream subject to their budget constraint. The standard Euler equation holds for household consumption: $\rho E_{t}\left(C_{t} / C_{t+1}\right)\left(1+r_{t}\right)=1$. As in the continuous-time version, they allocate their wealth over risk-free deposits and risky intermediation funds. Households do not have direct access to capital but only to risky equity and risk-free debt of the financial intermediaries. By assuming that households are less risk-averse than intermediaries, they will systematically prefer to invest in risky financial assets. This difference in relative risk aversion increases further during crisis periods when the capital constraint bites. ${ }^{13}$

The share of wealth invested in risky funds, $\alpha_{t}^{h} W_{t}=V_{t}$, is constrained by the reputation of the intermediary sector. In order to solve the model with standard perturbation methods around a steady state, we replace the occasionally-binding constraint with a continuous non-linear approximation. This function states that the share of risky funds in the household portfolio decreases quickly, but continuously, once the reputation of the intermediary sector, scaled by its total assets, i.e. $\mathcal{E}_{t} / W_{t}$, drops below some minimum confidence level: $\alpha_{t}^{h}=f\left((1-\lambda), \mathcal{E}_{t} / W_{t}\right)$. In line with the continuous-time model, the maximal share of risky funds is restricted to a level of $1-\lambda$, which is reached for high levels of reputation of the financial intermediaries. The exact form of this non-linear function is similar to the one used in section 2.3.2. and is specified below when we consider the implications for the optimal bank behavior.

The reputation process of the intermediary is determined by the history of realized returns on intermediaries equity $\left(\widetilde{R}_{t}\right)$ :

$$
\mathcal{E}_{t}=\mathcal{E}_{t-1}\left(m \widetilde{R}_{t}-\eta\right)
$$

with

$$
\widetilde{R}_{t}=\alpha_{t-1}^{F I} R_{t}+\left(1-\alpha_{t-1}^{F I}\right) r_{t-1}
$$

and

$$
R_{t}=\left(q_{t} K_{t}+D_{t}\right) /\left(q_{t-1} K_{t-1}\right)
$$

where the optimal investment share, $\alpha^{F I}$, is determined by the mean-variance portfolio strategy of the intermediary:

$$
E_{t}\left(R_{t+1}-r_{t}\right)=m \alpha_{t}^{F I} \operatorname{Var}_{t}\left(R_{t+1}\right)
$$

\footnotetext{
${ }^{13}$ This hypothesis on relative risk aversion is not very intuitive, but can represent the large cost of default, distress, confidence for depositors and financial markets.
} 
and given that the intermediaries need to hold the complete capital stock in market equilibrium it follows also that:

$$
q_{t} K_{t}=\alpha_{t}^{F I} V_{t}=\alpha_{t}^{F I} \alpha_{t}^{h} W_{t}=W_{t} .
$$

This condition implies that the funding structure (equity versus deposits) and leverage of financial intermediaries is determined by the household investment decisions, i.e. $\alpha^{F I} \alpha^{h}=1$. Therefore, the constraints imposed on household investment directly impact the funding structure of the financial intermediaries. Combining this condition, $\alpha^{F I} \alpha^{h}=1$, with the $\alpha^{h}$ allocation rule of the households results in a non-linear expression for $\alpha^{F I}$, which is approximated by the following third-order function:

$$
\alpha^{F I}=\frac{1}{1-\lambda}+\alpha_{\mathcal{E}}\left(\frac{q_{t} K_{t}}{\mathcal{E}_{t}-\mathcal{E}_{-}}\right)^{3}
$$

It follows that $\alpha^{F I}$ is equal to the constant share $1 /(1-\lambda)$ during periods where the reputation of the intermediaries is sufficiently high relative to their total assets. When reputation declines and households restrict their investment share in risky funds, the intermediary's balance sheet becomes more risky as their outstanding leverage increases. In response for this increasing leverage pressure, intermediaries will require a higher premium to compensate for this risk and this will result in downward fire-sale prices for asset prices. We use a third-order function in order to have no additional approximation problems when solving the model at third-order. ${ }^{14}$ By selecting appropriate parameters $\alpha_{\mathcal{E}}$ and $\mathcal{E}_{-}$for this function we can approximate locally the occasionally-binding minimum constraint of the continuous problem. This approximation works well within a limited domain of $q_{t} K_{t} / \mathcal{E}_{t} \cdot{ }^{15}$

From the dynamics of reputation (see equation (13)), it follows that the deterministic steady state of the model is undetermined: we can approximate the model around any value of reputation. We select this value $(\mathcal{E}=0.60)$ in such a way that it is located at the center of the stochastic distribution obtained by the third-order simulations of the model. The exit rate is assumed to fulfil the condition $m \widetilde{R}=\eta$. With a first-order approximation, the reputation process will follow a non-stationary process. Under certainty equivalence, there is no role for risk and financial leverage and reputation will not affect the asset pricing decisions. Given a one-time shock to the efficiency of capital, the return on intermediary equity will temporally increase and this will move reputation to a permanently higher level. There is no reason to expect that future returns would adjust to stabilize the reputation process. With a third-order approximation on the other hand, the model fluctuates around a fixed point that is locally stable: with an above average reputation the risk premium is relatively low, and reputation tends to decline again, with a low reputation the required risk premium increases and this helps to restore the reputation over time.

\footnotetext{
${ }^{14}$ Note that this approximation is exact only when all variables entering the function belong to the state vector.

${ }^{15}$ To control better the numerical stability of the simulation, it can be very helpful to separate and to trade-off the two roles of the parameter $m$ that controls both the sensitivity of the reputation process to the realized returns, and thereby increasing the domain of $\mathcal{E}$, and the risk-aversion of the bank which determines the sensitivity of the required risk to $\mathcal{E}$.
} 


\subsection{Simulation results}

We use the same calibration of the parameters as in the baseline version of the continuous-time model except for the exit rate $\eta$ which is set at $m \widetilde{R}=10 \%$. The simulation outcomes are generated with the first and third-order perturbation procedures available in Dynare. The model is approximated around a deterministic steady state with $\mathcal{E}=0.60, \mathcal{E}_{-}=0.20$ and $\alpha_{\mathcal{E}}=0.025$. This steady-state reputation level is close to the critical value of reputation that marks the binding constraint regime in the global solution of the continuous-time model. Moreover, for high reputation, the Sharpe ratio in both the continuousand discrete-time version are very similar and situated close to a lower bound of 0.10 . The calibration implies a relatively low risk level: despite the fact that the exogenous stochastic shock is high from a real macroeconomic perspective, it is not able to generate the high volatility in asset prices or the high risk levels that are typically observed in the financial markets.

\section{Insert Table 4}

From Table 4, it follows that, on average over all periods, the discrete-time model solved with a local approximation method produces a similar volatility for output and capital, approximately equal to $2 \%$, as the continuous-time model solved with global solution methods. Investment is slightly more volatile while consumption behaves somewhat smoother in the continuous-time version (compare Tables 4 and 2). The volatility in financial equity is high, although it remains well below the volatility observed for the continuous-time model, but the volatility in risk, as measured by the standard deviation of the Sharpe ratio, is an order of magnitude lower than in Table 2. The Sharpe ratio is increasing when reputation goes down, but obviously the slope of this relation is much lower for the discrete model than for the continuous-time case, and as a consequence the volatility of the Sharpe ratio is much smaller and less sensitive to the financial reputation as well.

Importantly, the discrete-time model generates a volatility in the asset price, the valuation of the productive capital stock, that is only $50 \%$ of the volatility under global dynamics. There is a risk channel present in the discrete-time model, but the third-order approximation is not able to generate the same strong propagation mechanism as in the continuous-time model.

The covariances between real growth and financial leverage (positive) and risk (negative) display similar signs and correlations as in Table 2. In terms of asymmetry between the distressed and the non-distressed subsamples, there is no difference in the volatility of the real variables. In the continuous-time case too, this difference was very small and pointing in the opposite direction for investment (vol. up in distressed periods) than for consumption (vol. down in distressed periods). However, financial equity displays an important asymmetry across the distressed and non-distressed subsamples and this asymmetry is also 
reflected in the covariance of financial equity with the other variables. Financial equity and asset prices, investment and consumption are highly positively correlated during stress-periods. Financial equity and risk are of course negatively correlated. All these correlations are much lower during normal periods than during stress-periods.

The low volatility in risk (Sharpe ratio) in the discrete model is not explained by the approximation of the financial constraint $\alpha^{F I}$. The volatility in the equity-funds of the financial sector, implied by the discrete-time model, is high with a strong differentiation between distressed and non-distressed periods. This finding suggests that the approximate constraint generates substantial nonlinearity and volatility. The discrete-time model is missing, however, the difference in volatility of the return on capital in the two regimes. This volatility remains constant across regimes in contrast with the results in the continuoustime model. ${ }^{16}$

Note also that there are important differences between the third-order approximation outcomes and the outcomes under a first-order approximation. This difference is a measure for the impact of risk considerations on the volatility in the discrete-time model. Without risk considerations (i.e. in firstorder), all variables in the model fluctuate proportionally to the capital stock adjusted for its efficiency, and neither the short rate nor the risk premium will be affected by the shocks. Moreover, under riskneutrality, the asset price remains constant and the volatility in consumption and investment are identical. The volatility in the intermediary equity is of no interest in this model as there is no pass-through in the risk premium.

It is clear from Table 4 that the local approximation method is able to identify an effect of endogenous risk in the financial sector and that it implies a risk channel from financial leverage towards asset prices and investment. Measured by the volatility in the asset price $(\operatorname{vol}(\mathrm{Q}))$, the magnitude of this channel with the local solution method is half the magnitude observed in the global solution of the continuous-time version. Within the context of this simple AK-model, this effect of the risk channel under both solution methods remains very weak and most of the dynamics remain proportional to the exogenous shock in capital efficiency. The spill-over effects from the health of the financial sector towards the real economy are minor as long as there are no additional frictions on the real side of the model. This finding is in line with HK (2012) who, despite important asymmetries in financial variables, find only a very small asymmetry in the real macroeconomic variables as well.

\section{Insert Figure 6}

\footnotetext{
${ }^{16}$ It follows from equation(11) that the volatility of the return on capital is given by $\left(\sigma+\sigma_{e} q_{t}^{\prime} / q_{t}\right)$ in the continuoustime version. All three components are constant (but non-zero) in the third-order approximation and evaluated at the deterministic steady state: $\sigma$ the exogenous volatility in the shock, $\sigma_{e}$ the elasticity of reputation with respect to the exogenous shock and $q_{t}^{\prime} / q_{t}$ the sensitivity of the asset price with respect to reputation.
} 
The graphs in Figure 6 illustrate the relation between a set of financial and real variables and the reputation of the intermediaries. The figure can be directly compared to the policy functions of the global solution in Figure 3. The exact functional relationships of the global solution are replaced by approximated relationships which is a typical result for the perturbation approach ${ }^{17}$. The relation between leverage and reputation, which is directly imposed by our non-linear portfolio rule that substitutes for the occasionally-binding constraint, holds quite precisely in the simulation results. The relation between intermediaries equity funds and reputation also displays a clear asymmetric behavior: with low reputation the access to equity funds increases more or less one to one with reputation (as in the binding constraint regime), but for higher levels of reputation this relation becomes basically flat.

The relationship between the risk premiums (and analogously for the Sharpe ratio which behaves similarly) and reputation is more complicated. More specifically, the discrete-time model based on the third-order approximation is able to replicate the slope but not the non-linearity in the relation between reputation and risk premium. The second row in Figure 6 illustrates this problem. The graph on the right contains the risk premium that we can calculate based on the non-linear expression for the risk premium $\left(m \alpha^{F I} \operatorname{Var}(R)\right)$ given the series for leverage, $\alpha_{t}^{F I}$, and for the variance of the asset returns. Logically, the required risk premium, calculated in this way, reflects closely the curvature and the asymmetry that is also present in the leverage series, especially because the variance term is constant. The third-order approximation of this relationship, shown in the graph on the left, does retain the downward sloping relationship but not the curvature. The risk premium declines monotonically with the increase in reputation.

Two observations help to explain why we lost the asymmetry in the volatility of risk and asset prices across stressed and non-stressed periods with the local solution method. First, unlike the global dynamics solution, the third-order local approximation is not able to capture the fact that the elasticity of risk aversion to reputation is increasing as reputation is declining. Instead, the method uses the elasticity that applies around the point of approximation $(\mathcal{E}=0.60)$ and keeps it constant. Second, with the local approximation method, the variance of the asset return (shown in the third row of Figure6) remains constant, also fixed at some average level, while there is an extra feedback effect from financial risk towards the variance of asset returns in the global solution. These mechanisms are important in the global solution as they tend to reinforce the endogenous risk channel when reputation is declining. With the local solution, we evaluate the endogenous risk channel at some intermediate level and we are missing part of the internal propagation effect within the financial sector. We capture the relation of risk to reputation up to first-order (risk is a linear function of the state vector) but we are missing the higherorder characteristics of this relation.

Note, however, that the relation between leverage and equity of the intermediaries on the one hand, and risk, asset prices and investment on the other, remains highly non-linear also in the local approximation

\footnotetext{
${ }^{17}$ See Den Haan and De Wind, (2012) for a discussion of these problems of third order approximation methods
} 
solution, as can be observed from the correlations in Table 4. When reputation is high, these financial ratios are basically constant and unrelated to the other variables. It is only when stress in the financial sector increases that these ratios become volatile and display an increasing correlation with the other variables.

The increase in risk aversion during periods of low reputation (restricted capital access) also translates in lower asset prices. Again the relation between asset prices and reputation is linear and is missing the curvature from the global solution. The investment ratio is following precisely the asset price, but its impact on output is tempered by the crowding-out effect on consumption. In the financially-constrained states, which are also typically states with low capital efficiency, the risk-free rate is low, which implies a high consumption-share level and a low expected consumption growth rate. Note that the risk premium (downward sloping in reputation) dominates the impact of the risk free rate (upward sloping in reputation) on the asset pricing.

We also observe that the domain of (scaled) reputation that the model simulations are visiting, is very similar in both the discrete- and the continuous-time version. This region is much more limited compared to the simulations in $\mathrm{HK}(2012)$ because the volatility in the exogenous shock is much smaller.

\section{Capital-constrained intermediaries in a fully-specified DSGE model}

In this section, we show how the non-linear propagation effect of capital-constrained financial intermediaries, approximated with a third-order perturbation method, can easily be incorporated in a more extensive DSGE model with the standard nominal and real frictions. The results indicate that these financial constraints generate a significant risk channel which reinforces the traditional transmission mechanisms in macroeconomic models. The risk management of financial intermediaries which are facing time-varying capital constraints induces important risk-premiums in asset and credit pricing. With financial constraints that become more stringent during economic downturns, this endogenous risk channel is potentially an important source of macro-economic instability.

First, we briefly introduce the model setup and its calibration. Second, we discuss the contribution of the risk channel to the macrodynamics in terms of financial and real volatility. We do this by comparing the outcomes under the first-order approximation, disregarding all risk consideration, with the outcomes under the third-order approximation. This difference is used as a measure for the contribution of the endogenous risk channel. The importance of this risk channel depends crucially on the capital constraint that the intermediaries are facing in crisis periods. Then, we run a counterfactual simulation 
for the post-war US economy using a model-consistent and quantitavely-realistic productivity shock as the exogenous driving process. By doing so, we illustrate how the model can be used to identify the magnitude and timing of the endogenous risk and how this risk contributed to the business cycle. From a monetary policy perspective, the model allows to evaluate how the policy decisions affect inflation and output objectives through both the traditional transmission mechanism and the risk considerations of the financial intermediaries.

\subsection{The DSGE model}

The specification of the macroeconomic block of our model follows closely the standard DSGE models (CEE 2005, SW 2003-2007). The nominal and real frictions present in these models yield a framework that is able to produce a significant transmission mechanism for the shocks originating in the financial and the monetary sector of the economy. These frictions are important for our exercise in which we want to show the potentially important (reinforcing) role of the risk channel for decisions in the real economy. In order to concentrate on the non-linear dynamics that are caused by the risk considerations, we use a linear approximation for the price and wage equations in our model. As explained recently by Fernandez-Villaverde et al. (2012), the curvature in the profit function of the firms can give rise to important non-linearities in the price setting with an impact on the markup and production decisions as well. By avoiding the non-linear effects in the other blocks of the model, we can consider the difference between the first- and third-order solution of the model as a good measure for the risk-channel only.

Households maximize the expected utility flow:

$$
E_{0} \sum_{t=0}^{\infty} \beta^{t} U\left(C_{t}, L_{t}\right),
$$

where the instantaneous utility function depends now on both consumption and labor effort, and is specified along the GHH-type (Greenwood, Hercowitz and Huffman (1988)). With these preferences, we eliminate the wealth effect on labor supply which is a useful feature for obtaining stronger propagation effects. The final consumption good is defined as an aggregate basket over a continuum of differentiated goods. Households offer differentiated labor services. We also allow for an external habit effect to introduce a more realistic dynamic profile in the aggregate demand response:

$$
U\left(C_{t}, N_{t}\right)=\frac{\left(C_{t}-h C_{t-1}-\psi L_{t}^{\phi}\right)^{1-\sigma}}{1-\sigma}
$$

Households maximize their expected utility subject to the budget constraint: 


$$
W_{t}=w_{t} L_{t}-C_{t}+\frac{r_{n, t-1}}{1+\pi_{t}} W_{t-1}+\alpha_{t-1}^{h} W_{t-1}\left(\widetilde{R}_{t}-\frac{r_{n, t-1}}{1+\pi_{t}}\right)-\Psi\left(K_{t}, i_{t}\right)
$$

Households earn the real wage bill $(w L)$ and pay for consumption and net-investment. They allocate their wealth over deposits, that pay a nominal interest $\left(r_{n}\right)$, and intermediary equity funds that earn the real risky rate $(\widetilde{R})$. Household wealth and its components, $W=B / r_{n}+V$, are expressed in real terms in this equation. The allocation rule is similar as in the previous section, with households turning away from risky investments $\left(V=\alpha^{h} W\right)$ when the reputation of the intermediaries relative to their total assets is declining. Consumption follows from the standard euler condition: $\rho E_{t}\left(U_{c, t+1} / U_{c, t}\right)\left(r_{n, t} /\left(1+\pi_{t+1}\right)\right)=1$.

Households decide on their nominal wage as a markup over the marginal rate of substitution and wage stickiness is introduced via a Calvo model, allowing for partial indexation of wages to past inflation. As motivated before, we use the linearized expressions for the optimal wage setting process in order to avoid the higher-order effects that result from the curvature in the Dixit-Stiglitz aggregator. This wage-setting model reduces to the following expression for nominal wage inflation $\pi_{w}$ :

$$
\pi_{w, t}-\iota \pi_{t}=\beta\left(\pi_{w, t+1}-\iota \pi_{t-1}\right)-\kappa_{w} \lambda_{w, t}
$$

where $\lambda_{w}$ is the wage markup over the marginal rate of substitution between consumption and labor effort $w / m r s$, and $\iota$ captures the degree of indexation.

Firms maximize the present value of the dividend stream using the intermediaries' pricing kernel (with $\lambda$ the marginal utility of reputation):

$$
E_{0}\left[\sum_{t=0}^{\infty} \beta^{t} \frac{\lambda_{t}}{\lambda_{0}} D_{t}\right]
$$

subject to the following production technology, demand function for the individual firm's output $Y_{t}^{*}$, and capital accumulation process:

$$
\begin{gathered}
Y_{t}=Z_{t} K_{t}^{\alpha} N_{t}^{(1-\alpha)}-\Psi, \\
Y_{t}^{*}=\left(\frac{P_{t}^{*}}{P_{t}}\right)^{-\varepsilon} Y_{t}, \\
K_{t+1}=(1-\delta) K_{t}+i_{t} K_{t} .
\end{gathered}
$$

Dividends are defined as total sales income minus the wage bill and net of depreciation allowance $D_{t}=$ $Y_{t}-w_{t} N_{t}-\delta K_{t}$ all expressed in real terms ${ }^{18}$. Firms produce with a Cobb-Douglas technology, see equation (18), that contains a fixed cost which exactly offsets the price mark-up consistent with the assumption

\footnotetext{
${ }^{18}$ Note that this definition of the dividend flow and the corresponding expressions for the return on capital and risky intermediary equity imply that households pay for the investment expenditures, even though the decision to invest is based on asset prices that are determined by the intermediaries' required return.
} 
of free entry. The total factor productivity $Z_{t}$ follows a standard autoregressive process with persistence $\left(\rho_{z}\right)$ and standard error $\left(\sigma_{z}\right)$. Prices $\left(P_{t}^{*}\right)$ are set as a markup over the expected marginal cost according to the Calvo model. The retained linear expression for price inflation is the basic New-Keynesian Phillips curve written in terms of the price markup: $\pi_{t}=\beta \pi_{t+1}-\kappa_{p} \lambda_{p, t}$. Optimal labor demand is realized at the point where the marginal product of labor equals the wage plus the mark-up: $w_{t} \lambda_{p, t}=m p l_{t}$. The capital adjustment cost and the optimal investment decision presented in equation (3) and (4) are still valid. In the sensitivity section below, we will also consider a collateral constraint on the working capital of the firms similarly to the constraint discussed in the continuous-time model of section 2 .

The equations describing the behavior of the financial intermediaries remain exactly the same, except that all aggregates should now be interpreted explicitly in real terms. The capital constraint on intermediaries is approximated by the highly non-linear function in reputation relative to total assets, i.e. equation (17). The realized return that drives reputation is the real return: $\widetilde{R}_{t}=\alpha_{t}^{F I} R_{t}+\left(1-\alpha_{t}^{F I}\right) r_{n, t-1} /\left(1+\pi_{t}\right)$. The required return on assets and the reputation dynamics are still as given by equation (16) and (13) .

The model is closed with the goods market clearing condition, $Y_{t}=C_{t}+\Psi\left(K_{t}, i_{t}\right)$, and a basic inflation targeting rule for monetary policy: $r_{n, t}=\overline{r_{n}}+r_{\pi}\left(\pi_{t}-\bar{\pi}\right)$. With this simple rule, we avoid the need for defining an output-gap concept in the model.

\subsection{Calibration}

The parameter values that determine the behavior of the financial intermediaries are the same as discussed in section 3. This applies also for the parameters of the household and firm block that are common with the simple AK-model of section 3 unless explicitly mentioned. For the additional parameters, we use standard values from the literature which are summarized in Table 5 . The annual discount rate $(\beta)$ is set at 0.96 and the steady-state returns are defined consistently with this parameter. The depreciation rate $(\delta)$ is assumed to be $10 \%$. The elasticity of intertemporal substitution for the households $(\sigma)$ and the inverse of the Frish labor elasticity $(\phi)$ are both set equal to one. The habit parameter is equal to 0.3 , which is lower than most estimates but better suited for a GHH-utility function. The CD-labor share $(\alpha)$ is set at 0.6. Higher values of the labor share can further increase the volatility of profit and dividends which should also increase the size of the risk premium in the stochastic economy. The capital adjustment cost is set at a value of 25 which produces a realistic relative volatility of consumption and investment in our model. This value is different from the previous section and its role will be considered in the sensitivity section. The price and wage inflation have a moderate sensitivity to their respective markups with wages behaving more sticky $\left(\kappa_{w}=0.02\right)$ than prices $\left(\kappa_{p}=0.10\right)$. Wages are partially indexed to price inflation $(\iota=0.5)$. The fixed cost in production is equal to $20 \%$ of output and this choice also determines the average markup in price setting and the corresponding elasticity of substitution between 
individual goods. Fixed costs and nominal stickiness are important in the model as determinants of the amount of operational risk, that is the risk directly related to the volatility of the dividend flow paid out by the firms. Finally, monetary policy is responding to inflation deviations from target with an elasticity of 1.5 as in the standard Taylor rule. In the sensitivity analysis we will further illustrate how the results depend on some of these parameter assumptions. Finally, note that we approximate the model around a steady state reputation of $\bar{\varepsilon}=1$. This value is again selected as being close to the center of the stochastic distribution of the reputation process in third-order simulations of the model.

Insert Tables 5 and 6

The parameters of the autoregressive process for the productivity shock are based on a rudimentary estimation strategy of the first-order approximation of the model. In this procedure, we set all the parameters at their calibrated parameters and we estimate only the stochastic structure. The estimation is based on four quarterly time series from the post-war US economy (1955Q1-2011Q2): the growth rate expressed per capita of GDP, consumption, investment and hours worked. In addition to the parameters of the tfp process, which is the only fundamental shock that we consider, we also allow for four i.i.d. measurement errors, one for each of the observable series, to overcome the singularity problem in estimation. The standard errors of these measurement errors is estimated together with the standard error and persistence of the tfp-process. The results are summarized in Table 6 .

The estimated productivity shock explains more than $80 \%$ of the quarter-to-quarter growth rate in per capita GDP and investment, and slightly more than $50 \%$ of the growth in consumption and hours worked. By considering only one fundamental shock, the estimation procedure most likely tends to overestimate the weight given to the tfp-process as driver of the business cycle. Still, we consider these results as yielding a plausible calibration for our exogenous shock, which we interpret in this exercise as a proxy for the various sources of macroeconomic risk. The magnitude of this volatility of the fundamental shock is essential as it will determine the amount of risk in the economy. In the counterfactual simulation exercise that we consider in section 4.3.3, we will also exploit the time series of the tfp process to generate counterfactual simulations to illustrate the cyclical profile of the endogenous risk channel implied by our model. 


\subsection{Simulation outcomes and irf analysis}

\subsubsection{Simulation outcomes}

Table 7 summarizes the simulation statistics for the extended DSGE model. The simulated model is a quarterly model but the statistics are reported on an annual basis. Again, this table contains four columns: the first three document the statistics averaged over respectively all periods, the $33 \%$ distressed periods and the $66 \%$ non-distressed periods (classified by the implied Sharpe ratio), the fourth column contains the statistics for the first-order solution of the model in which no risk considerations are active. It is not surprising that the DSGE model is able to generate a richer dynamic structure for the main macrovariables than the simple AK-model studied before. Remember that the volatility in this model is generated with an estimated calibration of the single exogenous shock: that is a tfp-innovation with a quarter-to-quarter standard error of $0.75 \%$. This stands in contrast with the relatively large capital quality shock (which basically acts as a tfp-shock in the AK-context with a standard error of 2.0\%) that we considered in the simple model. Clearly, the additional real and financial frictions that we consider in this model are able to produce a significant propagation channel for the exogenous shock.

Let us first concentrate on the average statistics over the complete cycle and compare the results from the third-order approximation with the outcomes under first-order. The volatility of output growth is $2.78 \%$ under the third-order solution while it is $2.25 \%$ under first-order. This means that risk considerations increase the overall volatility in the growth rate of output with $25 \%$ over the cycle. This increase in volatility is mainly produced by the larger fluctuations in investment with a standard error of 8.40 under third-order versus 5.23 under risk-neutrality, which is an increase of $60 \%$. The volatility in the growth rate of the capital stock, which is directly related to the investment level, also increases by $50 \%$. The volatility of consumption growth on the other hand is very similar across the two solution methods and illustrates the strong consumption smoothing desire of the households.

Similar to the models considered before (all based on the same simple capital adjustment cost schedule), investment is moving proportional to the market price of capital $\mathrm{Q}$ and this variable serves as the main transmission channel of financial risk towards the real sector of the economy. Risk considerations increase the volatility of this asset price, equivalent to the value of the capital stock, by almost $60 \%$ compared to the risk-neutral outcome. For risky financial equity funds the increase in volatility is even larger (243\%) with a volatility increasing from 8.37 to 20.36 .

Note also that the statistics of the DSGE model are more in line with the empirical observed volatilities (given in Table 2) than the simple model. The nominal and real frictions in the model and the interaction with the risk channel clearly improve the realism of the model.

Table 7 also summarizes how the model performs in terms of financial stress, measured by the Sharpe 
ratio and the volatility in financial equity. The DSGE model produces a significant amount of asymmetry in the volatility of financial risk: in the low risk regime the Sharpe ratio has a volatility of $1.68 \%$, while in the high risk regime this volatility increases to $7.20 \%$. This asymmetry is also obvious in the price fluctuations of financial equity and in the covariance of these financial equity prices with the market price of capital and investment. This covariance is close to zero in tranquil periods while it rises quickly in the high-risk regime. Under high financial stress, the value of equity of the financial intermediation sector declines rapidly, increasing the risk aversion and the Sharpe ratio of the sector that acts as marginal investor and therefore determining the price of risk in this economy. As a consequence, the market price of capital drops significantly below its risk-neutral value and this further depress real investment. While this asymmetry in volatility is very obvious for the financial variables, it is much smaller for the volatility in asset prices and in real variables. As discussed in the previous section, the local approximation method is missing part of the internal propagation within the financial sector. The asymmetry in asset prices and real variables that we observe in the DSGE model is not induced by financial risk consideration but rather by the asymmetric features of the operational risk in the real sector of the economy (fixed costs, habit etc.). These features of the model also imply that the volatility of the expected return on capital is now also time-varying and countercyclical.

Insert Table 7 and Figure 7

To further document the dynamics implied by the DSGE model with financial risk, we also consider Figure 7 that relates the important macrovariables to the reputation of the financial intermediary, similar to Figure 3 for the continuous-time and Figure 6 for the simple, discrete-time AK-model. The impact of the reputation is again most obvious for the leverage ratio of the intermediaries. The non-linear portfolio rule does still provide an acceptable approximation for the occasionally-binding capital constraint: as the reputation declines, the access to risky equity financing is quickly disappearing for the intermediaries. This financial leverage determines the risk aversion of the intermediaries as measured by the Sharpe ratio and the required risk premium for holding assets or providing capital to the firms. The risk premium increases quickly as the reputation declines. This higher risk premium also depresses the market price of capital and this price directly determines the investment decision. Consumption is clearly more robust against declines in the reputation-state but the crowding-out effect that was obvious in the simple model, in the form of a negative relation, is clearly no longer present in a DSGE model with endogenous labor and various real and nominal frictions active.

From the graphs in Figure 7, it follows that the approximation problems for the relation risk-reputation which we discussed for the simple AK-model are also present in this context. The third-order approximations produces a linear relation between risk and reputation while the exact equation implies a convex relation. The amount of risk is, however, significantly larger in the DSGE model than in the AK-model. There are two important reasons for this result. First, the real propagation mechanism in the model with 
frictions is larger than in the simple model which increases the volatility in the economy despite the fact that the volatility in the exogenous shock is much smaller. Second, several frictions in the DSGE model augment the operational risk in the model and make the dividend flow much more volatile than aggregate output or consumption. It is this volatility in dividends which is crucial for the valuation of capital and asset prices.

While the slope of the relationships depicted in Figure 7 has remained comparable to those for the simple models (see Figures 3 and 6), it is also obvious that the relations are much more dispersed here. As we observed for the simple AK-model, there is the influence of the higher-order approximation that introduces noise to the exact-functional relationships which are typically holding in the continuous-time solution. In addition, the extended model has a larger state vector which weakens the one-to-one relation between the macrovariables and the reputation state. The DSGE model also introduces more complex dynamic interactions between the variables with additional leads and lags in the cross-correlation structure and these are difficult to capture with the contemporaneous scatter plots.

\subsubsection{Impulse response analysis}

With a third-order approximation, impulse response functions (irfs) depend on the state of the economy. Therefore, we consider irfs around three different states: a state with high reputation, low reputation and intermediate reputation. Because we consider only one exogenous driving force, these states also correspond with respectively, a boom, recession, and normal business cycle situation. In order to identify the specific contribution of the risk channel, we also consider the irfs under a first-order approximation where risk considerations and financial intermediation are not playing any active role in the asset evaluation or credit supply decision of the intermediaries.

\section{Insert Figures 8 and 9}

From Figures 8 and 9, it follows immediately that the impact of a productivity shock is much larger and much more persistent during periods of financial stress with low reputation. Average or high reputation states do not make an important difference for the irfs. This illustrates that the solution method is able to generate an important amount of asymmetry across states of the economy, despite the limits of our third-order approximation that we discussed before. Moreover, all irfs under third-order differ significantly from the irfs under first-order.

First, we can consider the impact of the productivity shock on the reputation of the financial intermediary. This important state variable reacts very differently in the four situations considered. Under first-order, the reputation follows a non-stationary process: following a negative productivity shock, the reputation 
decreases and remains at this level. In this case, the balance sheet composition does not affect the risk appreciation of the intermediaries. As a consequence, reputation, and its effect on the household supply of equity funds to the financial intermediaries that follows from our functional approximation of the constraint, do not affect the real decisions of firms or households. With risk and real decisions left unaffected, there is no stabilisation mechanism for reputation. This mechanism is very different under third-order with reputation, and the resulting capital constraint, playing an active role in the risk appreciation of the financial intermediaries. In normal and boom periods, reputation follows a strongly mean-reverting process displaying some oscillations. A very different outcome is observed during periods of increased financial tension with risk being highly sensitive to shocks. In these situations, the response of reputation has important and persistent effects on the rest of the economy. With financial intermediaries being constrained to access additional equity funds, the leverage becomes very sensitive and, in case of a negative shock, the higher leverage drastically increases the risk aversion of the financial intermediary. After the initial decrease in the return, during the period when the negative shock is realized, the intermediaries require a substantial higher risk compensation to build up reputation and capital again. Following a one standard deviation tfp-shock during a financially distressed period, the required risk premium by the intermediaries for holding assets on its balance sheet increases by some $16 \mathrm{bp}$. This increase is quite persistent and it takes several years to disappear. The persistence in the risk spread reflects the time it takes to restore the reputation and equity base. In terms of asset price valuation, this increased spread generates a price decrease of almost $3 \%$ on impact. This asset price effect does not only depend on the risk premium. The two other determinants are the expected dividend flow and the risk-free rate. These variables depend on the overall macro reaction as discussed below.

The profile of the risk premium dynamics for the case of low or intermediate financial stress is complex. The third-order approximation generates a quite volatile risk premium reaction on impact, similar in size to the outcomes in the financial stress period. But this effect is very short-lived and returns to a much lower level after less than one year. ${ }^{19}$ If we look at the implications for the asset price valuation, we see that in the short run there is still a significant risk effect on the price, which can be measured by comparing the irfs with the outcomes under first-order. But after one year, this difference becomes very small.

The asset price is the main transmission variable to the real economy: with the elasticity of investment to the asset price determined by the capital adjustment cost. The response of investment is twice as large in risky situations compared to the first-order approximation: investment drops with $5 \%$ against $2.5 \%$ on impact. In calm periods, the additional effect of the risk channel relative to the risk-neutral case is more moderate and short-lived. Consumption is affected much less and its response is relatively

\footnotetext{
${ }^{19}$ As explained before, the third-order approximation contains only a linear relation between risk and the state vector and is therefore not able to generate strong asymmetries for the impact effect on risk. But the overall dynamics of the model contain of course highly non-linear interactions and these are responsible for the strong asymmetries in the dynamic adjustment following after the shock. Note also that the irfs for the risk premium, calculated with the exact non-linear function $m \theta \operatorname{Var}(R)$, display a strong asymmetry even on impact.
} 
similar independent of the state of the economy. Two compensating forces are at work here: the stronger negative income effects from the risk channel is offset by a positive substitution effect that is induced by the expected persistent decrease in the risk-free real interest rate which is the relevant rate for households consumption decisions. In our monopolistic competitive context with sticky prices, the short-run reaction of output is determined by the sum of the two demand components with a dominant weight for consumption. The wage bill of the firm is more resistent reflecting both the presence of increasing returns to scale due to the fixed-costs in production, that smoothes the short-run labor demand, and the stickiness in nominal wages. The combination of these features, which we can consider as sources of operational risk, together with the fact that dividends start from a low level in recessions, result in a highly volatile dividend response, especially during periods with low reputation.

When financial constraints are active, the procyclical effect of the risk channel on aggregate demand puts also significant pressure on the inflation process. While inflation is positively affected by the short-run impact of lower productivity on the marginal cost, it turns negative after few quarters when lower demand is deepening the recession. The impact of the risk channel on inflation, represented by the difference in the third and first-order irfs, can become quite substantial and generating a larger interest rate decline by the central bank in order to stabilize inflation. The magnitude of these effects are considerable: the decrease in the short rate is of the same magnitude as the increase in the risk premium and is also relatively persistent. These results suggest that there is potentially an intense interaction between the risk channel and the behavior of the short rate that is controlled by the central bank. This decline in the short rate can also be interpreted as a risk sharing mechanism between intermediaries and households: households accept a lower interest rate on deposits and in that way they support the return of the intermediaries and therefore their reputation. The risk premium, the short rate and the dividend process together determine the asset price response. Financial and operational risk reinforce each other in this complex transmission mechanism. In the sensitivity section we will further illustrate the contribution of the different assumptions in the calibration for these outcomes.

\subsubsection{Counterfactual simulation of the risk contribution to the business cycle}

By combining the impulse response functions with the estimated model-consistent productivity shocks over the post-war US data (1955-2011), we can run a counterfactual simulation in which we assume that these productivity shocks were the only determinant of the business cycle and calculate the implied endogenous risk behaviour according to the model. We concentrate our discussion on the role and the magnitude of the risk channel. We identify this risk channel again as the difference between the simulated variables, expressed in deviation from the stochastic fixed point, under first and third-order.

Insert Figures 10 till 12 
Figure 10 presents the exogenous total factor productivity process as filtered by the estimated first-order model based on the four macro-time series as discussed in section 4.1. By construction, this tfp-process captures the main business cycle fluctuations and displays a marked decline during each of the NBER recessions. As discussed before, our procedure may exaggerate the role of the tfp-process as the sole driver of the business cycle. But this simple identification strategy allows us to run a counterfactual experiment that gives a first indication of the potential role of the endogenous risk over the business cycle without requiring a complete specification of the multi-factor stochastic structure. The estimated profile of the tfp-process is reflected in all other financial and real variables but what is of interest in this exercise is the contribution of the endogenous risk process in this macroeconomic response which we can appreciate by comparing the outcomes under the two approximation methods.

The other graphs in Figures 10 collect the main results for the financial variables: only the third-order outcomes are shown here because these variables have no meaningful role in a risk-neutral context. The reputation/total asset ratio and even more outspoken the leverage ratio of the financial institutions, which is directly affected by the non-linear capital constraint, are very sensitive to the macroeconomic downturns. Both series display a strongly asymmetric behavior in the sense that their reaction is much more pronounced during periods of recessions while they behave much smoother during normal or booming business cycle periods. Binding capital constraints also force the intermediaries to become more risk averse with Sharpe ratios shooting up. The risk premium that intermediaries require for holding capital assets doubles during recessions and typically fluctuate between $1 \%$ and $2 \%$. The implied returns for risky equity funds of the financial intermediaries are much more sensitive as they also compensate for the risk of financial leverage.

As discussed before, in this standard DSGE model without additional financial frictions constraining households or firms, the valuation of the capital stock serves as the main transmission variable between the financial and the real economy. The risk aversion of the financial intermediaries (being marginal lenders to the firms) is directly affecting this asset price. The extra volatility in asset prices is substantial and leads to significant underpricing/overpricing during recessions/booms. This illustrates again what we noted already before, namely that the third-order approximation tends to reduce the asymmetry in the transmission of financial risk towards the real economy. Investment decisions, see Figure 11, mirror exactly the asset price valuation. In terms of investment level, the risk channel as captured by the third-order approximation contributes to overaccumulation during booms and underinvestment in recession. During the recent Great Recession, the risk channel is responsible for some extra $10 \%$ of the total simulated decline of $25 \%$.

In terms of output and inflation, see Figure 12, the contribution of the risk channel is small as measured by the difference between the third and first-order simulations. But one should be careful before concluding from this observation that the risk premium does not play an important role for the overall macrodynamics. The underlying effect of the risk premium is to a large extent compensated by the real 
short-term interest rate adjustment: in a recession, the risk premium goes up and exerts extra downward pressure on aggregate demand and inflation which the central banks systematically tries to mitigate by cutting the short rate in order to stabilize inflation fluctuations. On the other hand, during booms (with low risk premiums) the model predicts that the central bank will react more restrictively due to the low risk appreciation and corresponding overheating of the economy. The small visible impact of risk on aggregate output therefore masks the important channel of endogenous risk in the transmission channel of the tfp shock.

\subsection{Sensitivity analysis}

In this section we analyze in greater detail the functioning of the risk channel through a series of sensitivity tests related to model assumptions and parameter calibrations. Some key results are displayed in Table 8. The baseline model corresponds to the DSGE model explored in the previous section.

\section{Insert Table 8}

The first row in Table 8 summarizes some important volatility properties of the third-order approximation of the model. The risk contribution is calculated as the difference between the volatility of third-order and the first-order approximation expressed in percentage of the third-order volatility. For the baseline model, this risk channel accounts for almost $60 \%$ of the volatility in intermediary equity funds and more than one third of the volatility in asset prices and investment. For output this contribution is substantial lower with $17 \%$ and for consumption this share is very small and even negative because its volatility is smaller under third-order. As discussed in the previous section, this small impact on consumption follows from the interaction between the risk channel and the monetary policy reaction. Considering again the case of a negative productivity shock, the risk channel contributes to the negative response of aggregate demand via its direct impact on asset prices and investment. Therefore, by moving aggregate demand more in line with the declining potential, the inflationary pressure and corresponding monetary policy reaction will be mitigated. By reducing the inflationary pressure, the risk channel substitutes to some extent for the restrictive monetary policy response. With a less restrictive monetary policy, consumption will also decline less following the negative productivity shock.

The second row provides the outcomes for the same model with a higher sensitivity of reputation to the intermediaries' return ( $m=2.75$ instead of 2.5 ). The higher volatility in reputation works exactly like a higher risk aversion: intermediaries will require higher risk premiums in stress-periods and this will lead to extra volatility in asset prices. Intermediaries will be more often and more severely constrained in their access to outside equity funds. Increasing leverage and risk pushes the intermediaries to higher required returns and to sell assets at lower prices. Via asset prices, the volatility spills over to the real 
economy.

The strong risk channel in our DSGE model is almost exclusively generated by the intermediaries constraint. To illustrate this argument further, we consider two variants in which we either completely eliminate the intermediaries as active price setters, or we keep the financial constraint on capital constant at the steady state value. In the first setup, we are in a representative agent context where it is the households' stochastic discount factor and risk aversion that determines asset prices. In the second case, we solve the model around a constant financial leverage level of $\alpha^{F I}=2.5$. This is exactly the deterministic steady-state level around which we take the approximation but well above the lower bound, for tranquil periods, that is imposed by our non-linear approximation of the capital constraint.

In the representative agent pricing model, the risk channel is basically absent. With a log-utility function and the relatively smooth aggregate consumption process as inputs in the stochastic discount factor, the risk premiums are too small to matter significantly for asset pricing. With financial intermediaries constantly constrained at the average leverage, there is a significant amount of risk which explains the high average Sharpe ratio in this case. But the required risk premiums are almost constant and do not depend on the level of reputation of the intermediaries. With a constant leverage, the volatility in intermediaries equity returns will be smoother and no longer dependent on the state of the economy. By avoiding the asymmetric dynamics in leverage and high risk outcomes, the contribution of risk on average will be lower as well.

The RBC-version is an experiment in which we eliminate several of the nominal and real frictions in the DSGE model. In particular, we eliminate the price and wage stickiness, the habit persistence and the fixed-cost/markup in the model. These frictions introduce more complex and more realistic dynamic properties in the model. They also generate stronger transmission mechanisms in the model and they reinforce the size of the risk channel. Without these features, the amount of risk is reduced by a factor of two and the contribution of the risk channel is less than $10 \%$ even for asset prices and investment. Without significant nominal and real frictions active in the model, financial risk is much less distorting for the macroeconomy.

The capital adjustment costs also play a very important role in the amplification of the risk channel. While normally a higher adjustment cost increases the volatility of asset prices and reduces the volatility in investment, this mechanical relation is overturned in our model by the amplification of the risk channel. Higher adjustment costs have such a strong effect on the volatility of the asset prices that this effect dominates the lower elasticity of investment to the asset price. In our calibration we had to limit the adjustment cost to relatively low levels (25 in the baseline and 30 in this experiment) in order to avoid too high volatility in asset prices and investment. ${ }^{20}$ This exercise provides convincing evidence on the strength

\footnotetext{
${ }^{20}$ Increasing further the adjustment cost parameters and the asset price volatility leads to more frequent numerical instabilities during simulation with the third-order approximation methods.
} 
of the amplification mechanism between endogenous financial risk and the real investment response in a properly specified DSGE model.

The interdependence between monetary policy and the risk channel is further illustrated by running a variant with a more strict inflation targeting policy rule. Such a policy rule introduces more volatility in output and demand in order to close the output gap and to stabilize inflation. This explains why such a policy leads to higher risk and more real volatility. But from our discussion above, where we explained that the risk channel is substituting for the monetary policy stabilisation of inflation, it follows immediately that the risk channel helps to stabilize inflation and reduces the need for strong interest rate responses. Therefore, with the risk-channel active the volatility in consumption will be reduced.

Finally, we consider a model version where not only financial intermediaries are restricted by financial constraints but also firms. More in particular, we assume that firms are permanently restricted by a working capital constraint. Following Mendoza (2010) or Jermann and Quadrini (2010), firms need intraperiod loans to finance their wage bill and their loan capacity is restricted by a fraction of the value of their capital stock. When firms are credit constraint along these lines, two additional equations should hold: the wage bill is restricted to a fraction of the the values of the capital stock $\left(w L=\mu_{c} Q K\right)$ and the demand for labor will be further restricted by the Lagrange multiplier $\left(\lambda_{c}\right)$ of the additional constraint $\left(w \lambda_{p, t} \lambda_{c, t}=m p l\right)$. This setup is very similar to the constraint that we have considered in the continuous time model. There we showed that with a strong feedback mechanism from the financial asset prices to the real economy, we could easily amplify the endogenous risk channel in the He and Krishnamurthy model. Here too, this financial constraint on firms increases the link between asset prices and the production decision. As output expands more easily during periods when production potential is high, consumption can also expand more. In this context, the effects of the risk channel are also more equally spread over the different demand components with a smaller impact on investment but a larger and positive effect on consumption.

\section{Concluding remarks}

The paper evaluates the role of a non-linear capital constraint on financial intermediaries (as a proxy for occasionally-binding constraints) in an otherwise standard DSGE model. The model is solved by a third-order perturbation approach. We identify a substantial role for the risk channel. When the capital constraints are most stringent, financial intermediaries that act as marginal investors in the capital market, apply substantial higher risk premiums in evaluating asset prices. These depressed asset prices reduce the investment incentives and aggravates further the macro-economic context. The risk channel contributes significantly to the overall financial and macro volatility. 
We plan to extend the empirical application and allow for different type of shocks including financial shocks that affect the balance sheet of the intermediaries. Note that independent financial shocks, as such, do not ativate the risk channel directly, but by changing the portfolio structure of the intermediaries, these shocks will change the risk channel of other shocks. This extension would also break the close link between financial distress and macroeconomic downturns that applies in the simulations in this paper that are driven by only one fundamental shock. An exhaustive empirical validation of the role of the risk channel in this macro-finance models should be possible by using particle filter techniques to evaluate the likelihood of the model. In that context, it will be crucial to have very efficient solution methods for the higher-order approximation methods.

A fourth-order solution method should be tested in order to obtain asymmetric effects of the risk channel on asset prices and investment responses. Following the logic that a second-order approximation delivers constant risk, a third-order approximation generates risk that is linear in the state vector, it follows that a fourth-order approximation should capture the asymmetry in risk with higher sensitivity of risk to reputation in stressed periods and a clear lower bound on the sensitivity during high reputation states. This procedure should allow us to approximate better the solution outcomes from more time-consuming collocation methods.

Our analysis of the risk effects have exclusively been concentrated on the business cycle implications of risk by considering deviations from the stochastic fixed point. The risk considerations in these models have also important effects on this stochastic state around which the cycles are oscillating. The magnitude of these effects can be quite large and the dynamics between different stochastic steady states in case of policy changes or other structural changes might be very informative for optimal policy analysis.

The model should be extended with additional frictions on the financial intermediation process that reflect liquidity and maturity risks and that implies a more realistic balance sheet composition of both financial intermediaries, firms and households. Capital constraints are important but are not able to explain all the stylized facts of the financial crisis and produce sometimes counterfactual results, for instance in terms of procyclical leverage (see Adrian, Colla and Shin (2012)). A more exhaustive model should also need to model the option for borrowers to switch between bank financing and market financing (Adrian and Boyarchenko (2012) or De Fiore and Uhlig (2011)), allow for additional liquidity risk/constraints and consider different types of financial intermediaries where some are behaving as VaR-investors while other might act as mean-variance investors. 


\section{References}

[1] Adrian, T. and N. Boyarchenko, (2012), "Intermediary Leverage Cycles and Financial Stability", FRB of New York Staff Report No. 567.

[2] Adrian, T., Colla, P., and H.S. Shin, (2012), "Which Financial Frictions? Parsing the Evidence from the Financial Crisis of 2007-9", NBER Chapters, in: NBER Macroeconomics Annual 2012, Volume 27, NBER.

[3] Bernanke, B. S., Gertler, M. and Gilchrist, S., (1999),."The financial accelerator in a quantitative business cycle framework", Handbook of Macroeconomics, in: J. B. Taylor \& M. Woodford (ed.), Handbook of Macroeconomics, edition 1, volume 1, chapter 21, pages 1341-1393 Elsevier.

[4] Brunnermeier, M. and Y. Sannikov, (2012), "A Macroeconomic Model with a Financial Sector", mimeo.

[5] Christiano, L.J., Eichenbaum, M. and C. L. Evans, (2005), "Nominal Rigidities and the Dynamic Effects of a Shock to Monetary Policy", Journal of Political Economy, vol. 113, No. 1, 1-45.

[6] Danielsson, J., Shin, H. S. and J.-P. Zigrand, (2011), "Balance Sheet Capacity and Endogenous Risk", FMG Discussion Papers dp665, Financial Markets Group.

[7] Danthine, J.-P., and J.B. Donaldson, (2002), "Labor Relations and Asset Returns", Review of Economic Studies, vol 69, 41-64.

[8] De Fiore, F. and H. Uhlig, (2011), "Bank Finance versus Bond Finance," Journal of Money, Credit and Banking, Blackwell Publishing, vol. 43(7), 1399-1421.

[9] De Graeve, F., Dossche, M., Emiris, M., Sneessens, H. and Wouters, R., (2010), "Risk premiums and macroeconomic dynamics in a heterogeneous agent model," Journal of Economic Dynamics and Control, vol. 34(9), 1680-1699.

[10] Den Haan, W.J. and J. De Wind, (2012), "Nonlinear and Stable Perturbation-Based Approximations", mimeo.

[11] Favilukis, J., Ludvigson S. and S. Van Nieuwerburgh, (2011), "Macroeconomic Implications of Housing Wealth, Housing Finance, and Limited Risk-Sharing in General Equilibrium", mimeo.

[12] Fernandez-Villaverde, J., Guerron-Quintana, P., Rubio-Ramirez, J.F. and M. Uribe, (2011), "Risk Matters: The Real Effects of Volatility Shocks", American Economic Review, vol. 101(6), 2530-61.

[13] Fernandez-Villaverde, J., Kuester, K., Guerron, P. and J. Rubio-Ramirez, (2012), "Fiscal Volatility Shocks and Economic Activity", mimeo.

[14] Gertler, M. and P. Karadi, (2011), "A model of unconventional monetary policy," Journal of Monetary Economics, Elsevier, vol. 58(1), 17-34. 
[15] Gertler, M. and N. Kyotaki, (2010),"Financial Intermediation and Credit Policy in Business Cycle Analysis", in Handbook of Monetary Economics, Volume 3A, edited by Benjamin Friedman and Michael Woodford, Amsterdam: Elsevier.

[16] Greenwood, J., Hercowitz Z. and G. W Huffman, (1988),"Investment, Capacity Utilization, and the Real Business Cycle", American Economic Review, vol. 78(3), 402-17.

[17] Gilchrist, S. and E. Zakrajšek, (2012),."Credit Spreads and Business Cycle Fluctuations", American Economic Review, vol. 102(4), 1692-1720.

[18] Guvenen, F., (2009), "A Parsimonious Macroeconomic Model for Asset Pricing", Econometrica, vol. 77 , No. $6,1711-1740$.

[19] He, Z. and A. Krishnamurthy, (2012), "A Macroeconomic Framework for Quantifying Systemic Risk", mimeo.

[20] Jermann, U and V. Quadrini, (2012), "Macroeconomic Effects of Financial Shocks", American Economic Review, vol. 102(1), 238-71.

[21] Kiyotaki, N. and Moore, J., (1997),."Credit Cycles", Journal of Political Economy, vol. 105(2), pages $211-48$.

[22] Julliard, M. and O. Kamenik (2004), "Solving Stochastic Dynamic Equilibrium Models: A k-Order Perturbation Approach", mimeo.

[23] Mendoza E.G., (2006), "Lessons from the Debt Deflation Theory of Sudden Stops", American Economic Review, Papers \& Proceedings.

[24] Mendoza E.G., (2010), "Sudden Stops, Financial Crises, and Leverage", American Economic Review, American Economic Association, vol. 100(5), 1941-66.

[25] Smets, F. and R. Wouters, (2003), "An Estimated Dynamic Stochastic General Equilibrium Model of the Euro Area", Journal of the European Economic Association, vol. 1(5), 1123-1175.

[26] Smets, F. and R. Wouters (2007), "Shocks and Frictions in US Business Cycles: A Bayesian DSGE Approach", American Economic Review, vol. 97(3): 586-606.

[27] Xiong, W., (2001), "Convergence Trading with Wealth Effects: An Amplification Mechanism in Financial Markets", Journal of Financial Economics 62, 247-292. 
Table 1: Calibrated parameters of the model ( in Per annum terms)

\begin{tabular}{|l|l|c|}
\hline Parameter & Description & Baseline \\
\hline Production & & \\
\hline$\sigma$ & Capital efficiency shock & 0.02 \\
$\delta$ & Depreciation rate & 0.10 \\
$\kappa$ & Adjustment cost & 20 \\
$\bar{A}$ & Productivity constant & 0.35 \\
$\phi$ & Productivity price feedback & 0 \\
$l$ & Wage share & 0.60 \\
\hline Intermediation & & \\
\hline$m$ & Reputation sensitivity & 2.50 \\
$\lambda$ & Debt share & 0.50 \\
$\eta$ & Banker exit rate & 0.13 \\
$\gamma$ & Entry Sharpe ratio & 2 \\
\hline Other & & \\
\hline$\rho$ & Discount rate & 0.02 \\
\hline
\end{tabular}

Table 2: Simulation of Baseline model: Summary statistics (in Percent)

\begin{tabular}{|l|c|c|c|c|c|}
\hline & \multicolumn{3}{|c|}{ Baseline model } & \multicolumn{1}{c|}{ Data } \\
\hline \hline & Total & Distress & Non-distress & Distress & Non-distress \\
\hline Vol(Eq) & 32.63 & 42.66 & 19.72 & 31.48 & 17.54 \\
$\operatorname{Vol}(\mathrm{I})$ & 2.47 & 2.23 & 2.07 & 8.05 & 6.61 \\
$\operatorname{Vol}(\mathrm{C})$ & 1.86 & 1.41 & 1.66 & 1.71 & 1.28 \\
$\operatorname{Vol}(\mathrm{SR})$ & 19.95 & 23.87 & 2.30 & 60.14 & 12.72 \\
$\operatorname{Vol}(\mathrm{K})$ & 2.03 & 1.64 & 1.78 & - & - \\
$\operatorname{Vol}(\mathrm{Y})$ & 2.03 & 1.64 & 1.78 & - & - \\
$\operatorname{Vol}(\mathrm{Q})$ & 1.00 & 1.26 & 0.62 & - & - \\
$\operatorname{Cov}(\mathrm{Eq}, \mathrm{I})$ & 0.64 & 0.83 & 0.37 & 1.31 & 0.07 \\
$\operatorname{Cov}(\mathrm{Eq}, \mathrm{C})$ & 0.43 & 0.48 & 0.28 & 0.25 & 0.03 \\
$\operatorname{Cov}(\mathrm{Eq}, \mathrm{SR})$ & -1.72 & -2.88 & -0.01 & -6.86 & -0.14 \\
$\operatorname{Cov}(\mathrm{Eq}, \mathrm{Q})$ & 0.31 & 0.50 & 0.12 & - & - \\
\hline
\end{tabular}

Notes: This table presents summary statistics (volatility and covariances) for the simulated annual growth rate of equity (EQ), investments (I), consumption (C), capital (K), output $(\mathrm{Y})$ and capital price $(\mathrm{Q})$. For the Sharpe ratio (SR) the level is used. The data reported in the table are taken from $\mathrm{HK}(2012)$. The definition of distressed and nondistressed periods is based on the observed Sharpe ratio: the distressed period is defined as the $33 \%$ highest realizations of the Sharpe ratio. 
Table 3: Simulation of extended model $(\Phi=0.15)$ : summary statistics (in percent)

\begin{tabular}{|l|c|c|c|c|c|}
\hline & \multicolumn{3}{|c|}{ Alternative model $(\Phi=0.15)$} & \multicolumn{2}{c|}{ Data } \\
\hline \hline & Total & Distress & Non-distress & Distress & Non-distress \\
\hline $\operatorname{Vol}(\mathrm{Eq})$ & 36.98 & 53.59 & 14.55 & 31.48 & 17.54 \\
$\operatorname{Vol}(\mathrm{I})$ & 3.20 & 3.08 & 2.56 & 8.05 & 6.61 \\
$\operatorname{Vol}(\mathrm{C})$ & 2.97 & 2.82 & 2.39 & 1.71 & 1.28 \\
$\operatorname{Vol}(\mathrm{SR})$ & 21.00 & 22.35 & 1.11 & 60.14 & 12.72 \\
$\operatorname{Vol}(\mathrm{K})$ & 2.07 & 1.68 & 1.75 & - & - \\
$\operatorname{Vol}(\mathrm{Y})$ & 3.03 & 2.87 & 2.44 & - & - \\
$\operatorname{Vol}(\mathrm{Q})$ & 2.53 & 3.02 & 1.71 & - & - \\
$\operatorname{Cov}(\mathrm{Eq}, \mathrm{I})$ & 0.84 & 1.42 & 0.26 & 1.31 & 0.07 \\
$\operatorname{Cov}(\mathrm{Eq}, \mathrm{C})$ & 0.77 & 1.30 & 0.24 & 0.25 & 0.03 \\
$\operatorname{Cov}(\mathrm{Eq}, \mathrm{SR})$ & -1.58 & -2.69 & 0.03 & -6.86 & -0.14 \\
$\operatorname{Cov}(\mathrm{Eq}, \mathrm{Q})$ & 0.78 & 1.40 & 0.21 & - & - \\
\hline
\end{tabular}

Notes: This table presents summary statistics (volatility and covariances) for the simulated annual growth rate of equity (EQ), investments (I), consumption (C), capital (K), output (Y) and capital price (Q). For the Sharpe ratio (SR) the level is used. The data reported in the table are taken from HK(2012). The definition of distressed and nondistressed periods is based on the observed Sharpe ratio: the distressed period is defined as the $33 \%$ highest realizations of the Sharpe ratio.

Table 4: Simulation of discrete-time baseline model: summary statistics (in Percent)

\begin{tabular}{|l|c|c|c|l|c|c|}
\hline & \multicolumn{2}{|c|}{ Baseline model - 3e order } & 1e order & \multicolumn{2}{c|}{ Data } \\
\hline \hline & Total & Distress & Non-distress & Total & Distress & Non-distress \\
\hline Vol(Eq) & 17.11 & 23.90 & 9.44 & 7.94 & 31.48 & 17.54 \\
$\operatorname{Vol}(\mathrm{I})$ & 2.22 & 2.18 & 2.23 & 1.96 & 8.05 & 6.61 \\
$\operatorname{Vol}(\mathrm{C})$ & 1.88 & 1.86 & 1.90 & 1.96 & 1.71 & 1.28 \\
$\operatorname{Vol}(\mathrm{SR})$ & 2.56 & 2.81 & 0.58 & 0.00 & 60.14 & 12.72 \\
$\operatorname{Vol}(\mathrm{K})$ & 1.98 & 1.95 & 1.99 & 1.96 & - & - \\
$\operatorname{Vol}(\mathrm{Y})$ & 1.98 & 1.95 & 1.99 & 1.96 & - & - \\
$\operatorname{Vol}(\mathrm{Q})$ & 0.51 & 0.49 & 0.50 & 0.00 & - & - \\
$\operatorname{Cov}(\mathrm{Eq}, \mathrm{I})$ & 0.21 & 0.40 & 0.12 & 0.15 & 1.31 & 0.07 \\
$\operatorname{Cov}(\mathrm{Eq}, \mathrm{C})$ & 0.18 & 0.36 & 0.10 & 0.15 & 0.25 & 0.03 \\
$\operatorname{Cov}(\mathrm{Eq}, \mathrm{SR})$ & -0.54 & -1.11 & -0.01 & 0.00 & -6.86 & -0.14 \\
$\operatorname{Cov}(\mathrm{Eq}, \mathrm{Q})$ & 0.04 & 0.07 & 0.02 & 0.00 & - & - \\
\hline
\end{tabular}

Notes: This table presents summary statistics (volatility and covariances) for the simulated annual growth rate of equity (EQ), investments (I), consumption (C), capital (K), output (Y) and capital price (Q). For the Sharpe ratio (SR) the level is used. The data reported in the table are taken from He and Krishnamurthy (2012). The definition of distressed and non-distressed periods is based on the observed Sharpe ratio: the distressed period is defined as the $33 \%$ highest realizations of the Sharpe ratio. 
Table 5: Parameter CALibration

\begin{tabular}{lllllllllllllllll}
\hline \hline$\beta$ & $\delta$ & $\sigma$ & $h$ & $\phi$ & $\alpha$ & $\kappa$ & $\kappa_{p}$ & $\kappa_{w}$ & $\iota$ & $\Psi$ & $r_{\pi}$ & $\bar{\pi}$ & $\lambda$ & $m$ & $\bar{\varepsilon}$ & $\underline{\varepsilon}$ \\
\hline 0.96 & 0.10 & 1.0 & 0.3 & 1.0 & 0.6 & 25 & 0.10 & 0.02 & 0.5 & 0.20 & 1.5 & 0.0 & 0.5 & 2.5 & 1.0 & 0.2 \\
\hline \hline
\end{tabular}

Table 6: Estimated STANDARD ERRORs OF DSGE MOdEL (FIRST-ORDER APPROXIMATION)

\begin{tabular}{llllll}
\hline \hline$\sigma_{z}$ & $\rho_{z}$ & $\sigma_{\text {GDP }}$ & $\sigma_{\text {inv }}$ & $\sigma_{\text {cons }}$ & $\sigma_{\text {hours }}$ \\
\hline 0.0075 & 0.95 & 0.48 & 0.58 & 1.19 & 0.45 \\
\hline \hline
\end{tabular}

Table 7: Simulation of DSGE model: summary statistics (in Percent)

\begin{tabular}{|c|c|c|c|c|}
\hline & \multicolumn{3}{|c|}{ DSGE model - third-order } & 1e order \\
\hline & Total & Distress & Non-distress & Total \\
\hline $\operatorname{Vol}(\mathrm{Eq})$ & 20.36 & 24.28 & 13.43 & 8.37 \\
\hline $\operatorname{Vol}(\mathrm{I})$ & 8.40 & 8.90 & 8.17 & 5.23 \\
\hline $\operatorname{Vol}(\mathrm{C})$ & 1.27 & 1.13 & 1.19 & 1.31 \\
\hline $\operatorname{Vol}(\mathrm{SR})$ & 6.16 & 7.20 & 1.68 & 0.00 \\
\hline $\operatorname{Vol}(\mathrm{K})$ & 0.45 & 0.30 & 0.32 & 0.31 \\
\hline $\operatorname{Vol}(Y)$ & 2.78 & 2.80 & 2.77 & 2.25 \\
\hline $\operatorname{Vol}(\mathrm{Q})$ & 5.20 & 5.42 & 5.08 & 3.31 \\
\hline $\operatorname{Cov}(\mathrm{Eq}, \mathrm{I})$ & 0.74 & 1.50 & 0.37 & 0.41 \\
\hline $\operatorname{Cov}(\mathrm{Eq}, \mathrm{C})$ & 0.12 & 0.15 & 0.08 & 0.08 \\
\hline $\operatorname{Cov}(\mathrm{Eq}, \mathrm{Q})$ & 0.42 & 0.92 & 0.20 & 0.25 \\
\hline $\operatorname{Cov}(\mathrm{Eq}, \mathrm{SR})$ & -1.18 & -2.07 & -0.08 & 0.00 \\
\hline
\end{tabular}

Notes: This table presents summary statistics (volatility and covariances) for the simulated annual growth rate of equity (EQ), investments (I), consumption (C), capital (K), output $(\mathrm{Y})$ and capital price $(\mathrm{Q})$. For the Sharpe ratio (SR) the level is used. The data reported in the table are taken from He and Krishnamurthy (2012). The definition of distressed and non-distressed periods is based on the observed Sharpe ratio: the distressed period is defined as the $33 \%$ highest realizations of the Sharpe ratio. 
Table 8: Sensitivity analysis: the Contribution of Risk COnsiderations in the Volatility of MACROECONOMIC AND FINANCIAL VARIABLES

\begin{tabular}{|c|c|c|c|c|c|c|}
\hline & $\mathrm{SR}$ & $\mathrm{Vol}(\mathrm{Eq})$ & $\mathrm{Vol}(\mathrm{Q})$ & $\mathrm{Vol}(\mathrm{inv})$ & $\mathrm{Vol}(\mathrm{C})$ & $\mathrm{Vol}(\mathrm{Y})$ \\
\hline \hline baseline & 29.87 & 20.35 & 5.20 & 8.40 & 1.27 & 2.78 \\
risk contribution & $100 \%$ & $59 \%$ & $36 \%$ & $38 \%$ & $-3 \%$ & $19 \%$ \\
risk aversion interm. $=2.75$ & 32.81 & 37.19 & 5.58 & 9.02 & 1.31 & 2.88 \\
risk contribution & $100 \%$ & $72 \%$ & $40 \%$ & $41 \%$ & $-2 \%$ & $20 \%$ \\
representative agent & 5.77 & - & 3.34 & 5.30 & 1.34 & 2.29 \\
risk contribution & $100 \%$ & - & $0 \%$ & $0 \%$ & $0 \%$ & $0 \%$ \\
constant leverage = 2.5 & 32.64 & 6.99 & 4.46 & 7.13 & 1.35 & 2.69 \\
risk contribution & $100 \%$ & $29 \%$ & $25 \%$ & $26 \%$ & $0 \%$ & $14 \%$ \\
RBC-version & 19.59 & 7.14 & 2.14 & 3.40 & 1.66 & 2.15 \\
risk contribution & $100 \%$ & $-12 \%$ & $9 \%$ & $9 \%$ & $-7 \%$ & $0 \%$ \\
inv.adj.cost = 30 & 34.25 & 73.84 & 6.49 & 8.66 & 1.30 & 2.74 \\
risk contribution & $100 \%$ & $87 \%$ & $42 \%$ & $43 \%$ & $3 \%$ & $22 \%$ \\
mon.pol.inflation reaction $=3$ & 31.98 & 24.62 & 5.45 & 8.81 & 1.51 & 3.10 \\
risk contribution & $100 \%$ & $60 \%$ & $36 \%$ & $37 \%$ & $-19 \%$ & $13 \%$ \\
financial constraints on firms & 30.41 & 11.70 & 4.99 & 8.01 & 3.47 & 4.67 \\
risk contribution & $100 \%$ & $15 \%$ & $23 \%$ & $24 \%$ & $12 \%$ & $17 \%$ \\
\hline
\end{tabular}

Notes: The risk contribution is defined as the part of volatility explained by risk considerations and is computed as the difference in volatility under the third and first-order approximations. 
Figure 1: BALANCE SHEEts of Households AND FinANCIAL INTERMEDIARIES

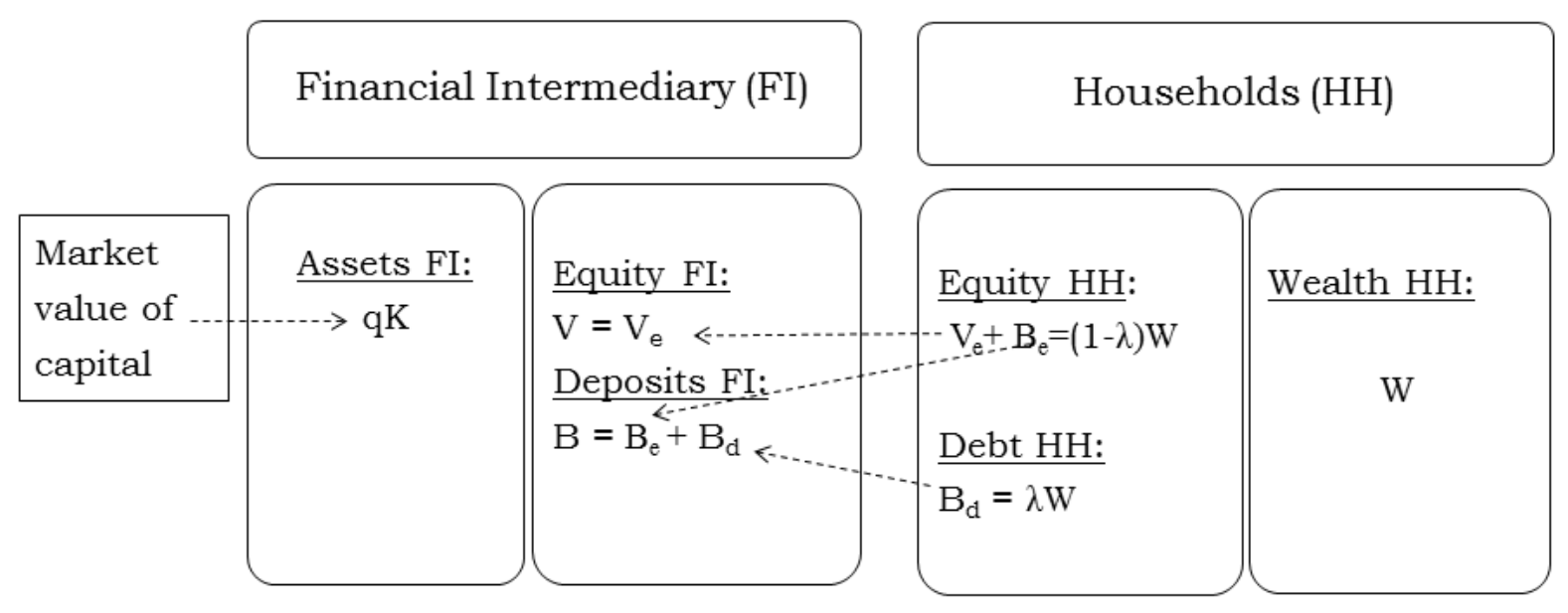


Figure 2: Global solution of the baseline AK model

Leverage $\left(a^{F}\right)$

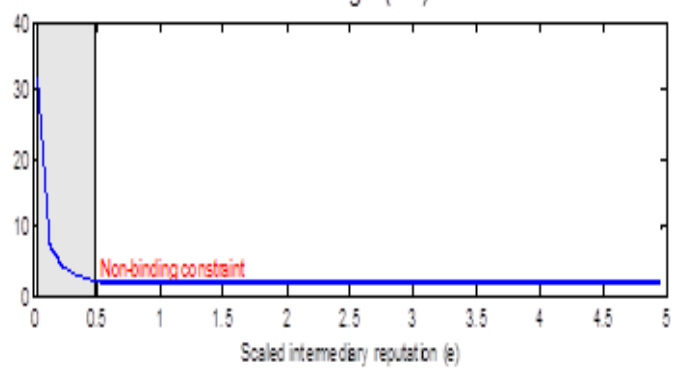

Risk premium (EdR-rdt)

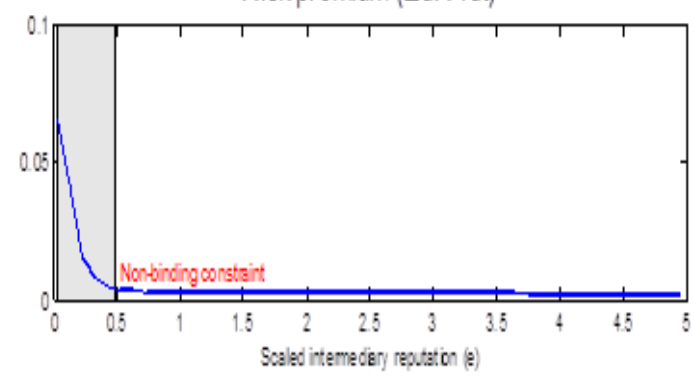

Asset price (Q)

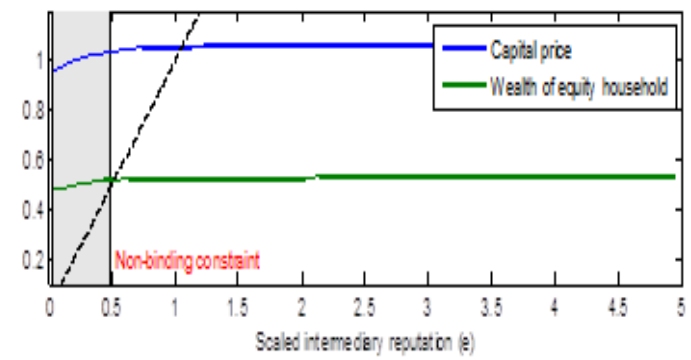

IK

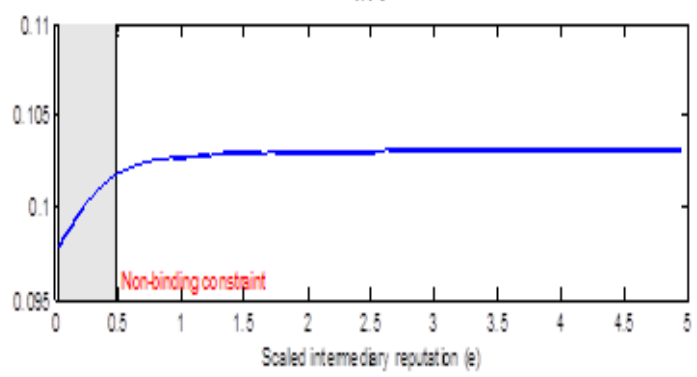

Equity(V)

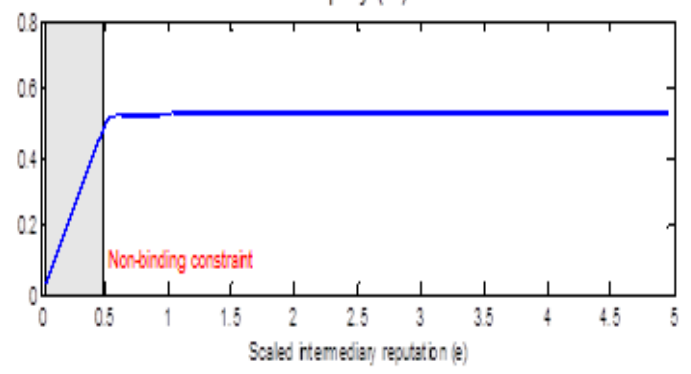

Interest rate (r)

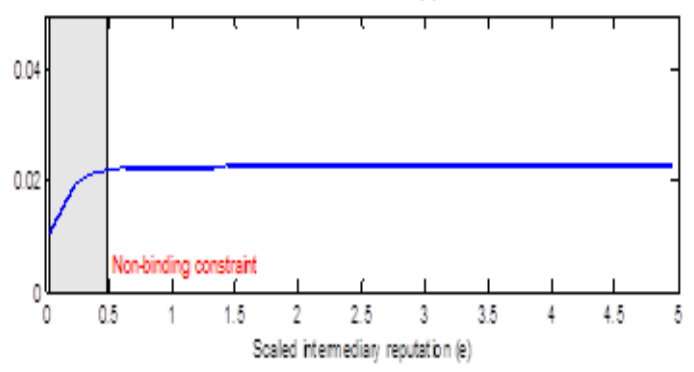

Volatility return on capital(Std(dR))

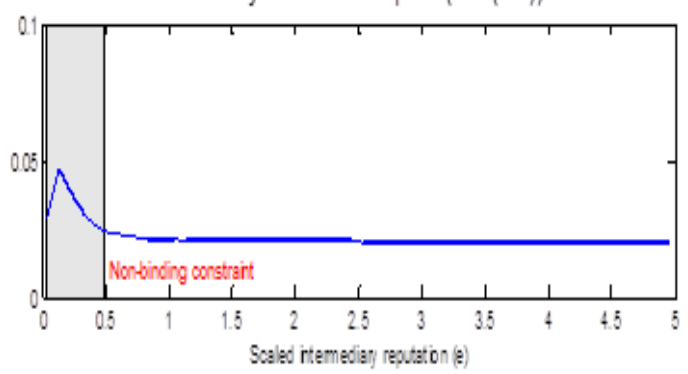

$\mathrm{CIK}$

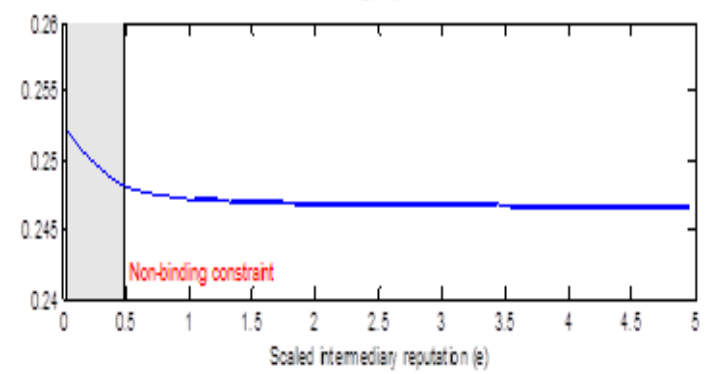


Figure 3: Global solution of the baseline AK model
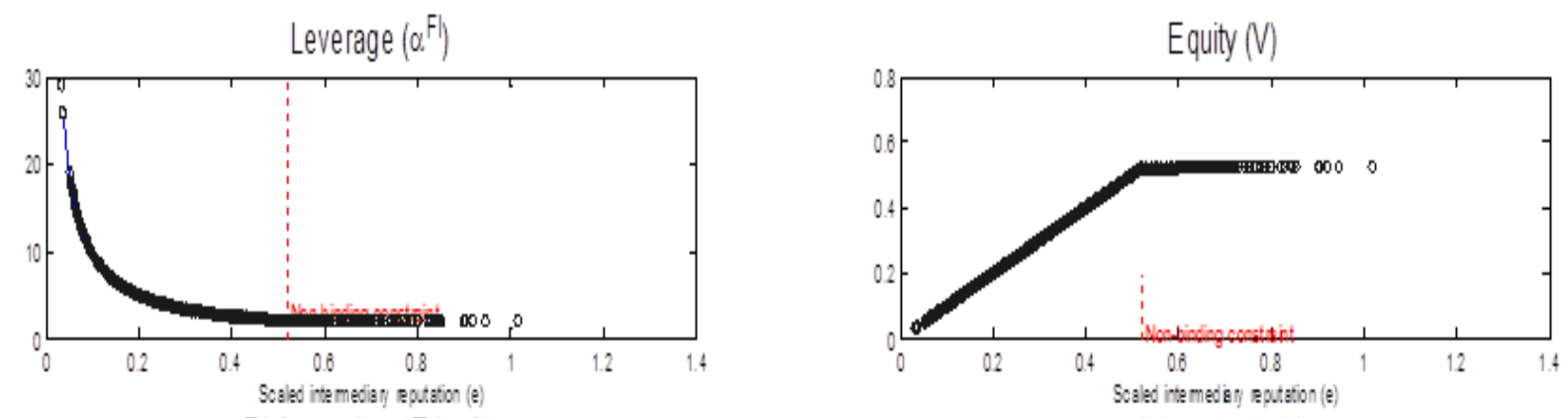

Risk premium (Edr-rdt)

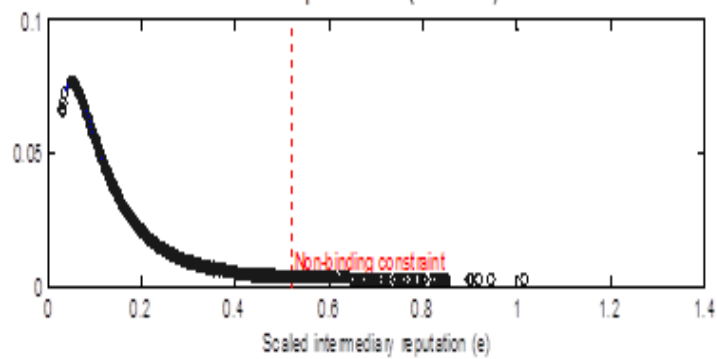

Interest rate (r)

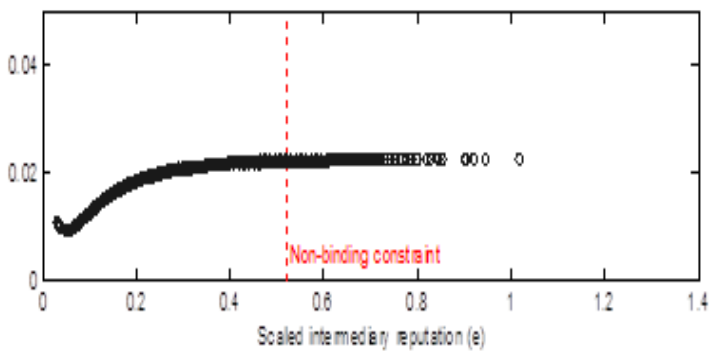

Asset price $(Q)$

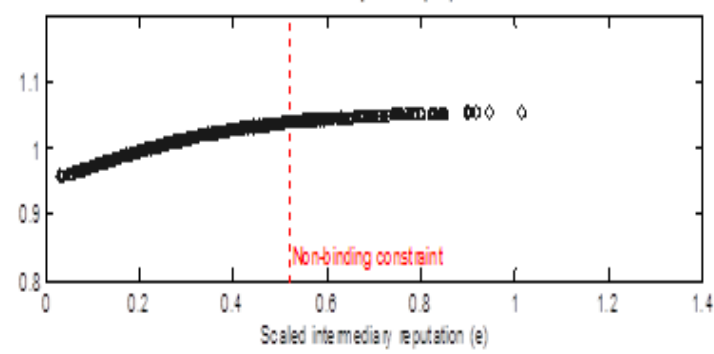

Volatility return on capital (Std(dR))

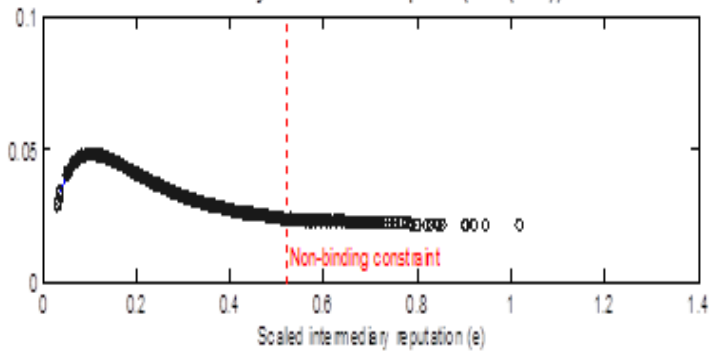

$\mathbb{1} K$
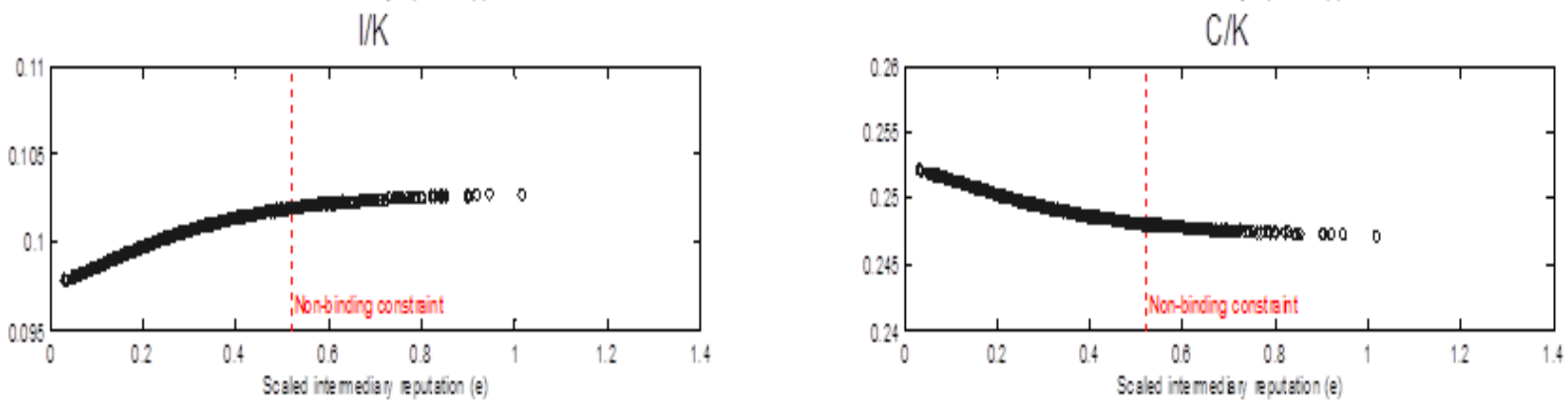
Figure 4: Comparing GLobal Dyamics of AK model Under baseline AND ALternatives

Leverage $\left(\alpha^{F}\right)$

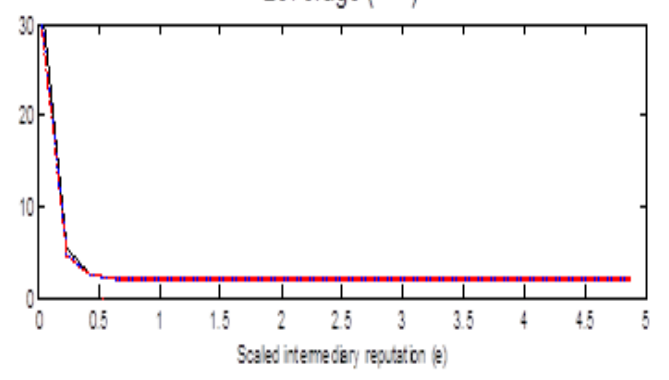

Risk premium (Edr-rdt)

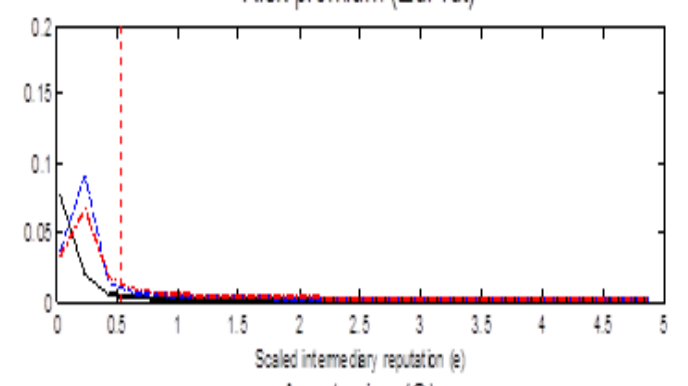

Asset price (Q)

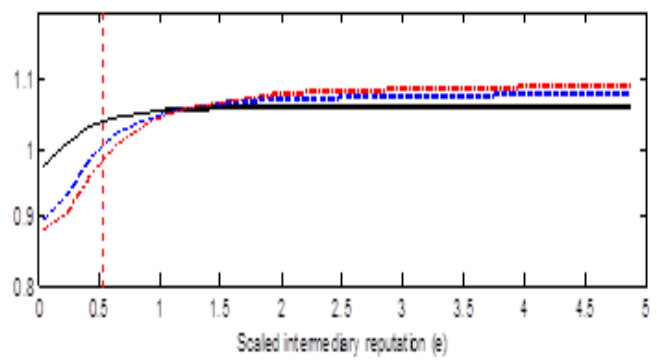

$\mathbb{I K}$

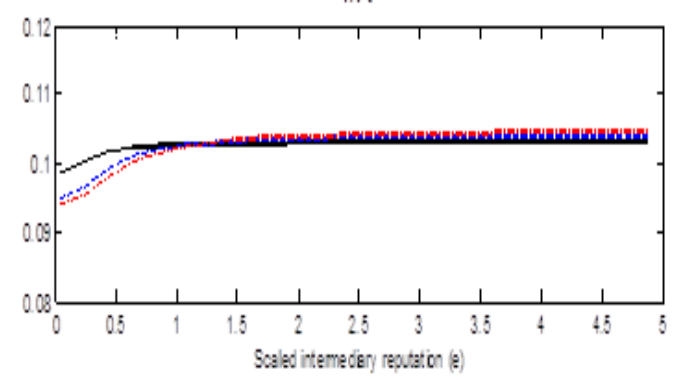

Equity(V)

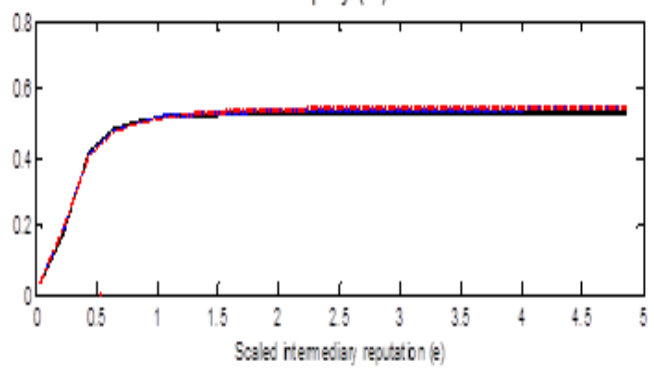

Interest rate (r)

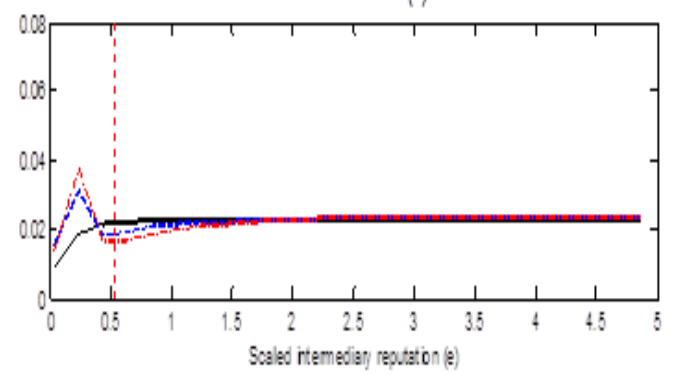

Volatility return on capital (Std(dR))

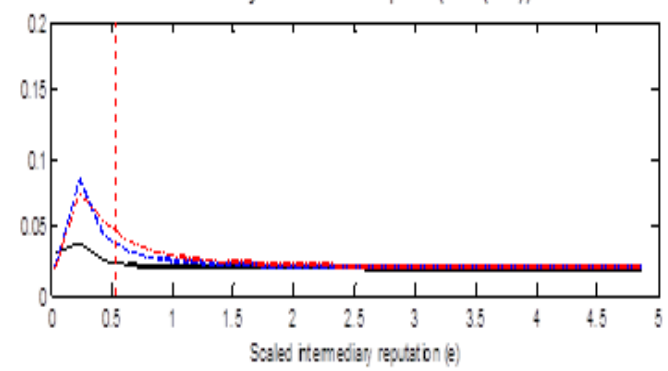

$\mathrm{CIK}$

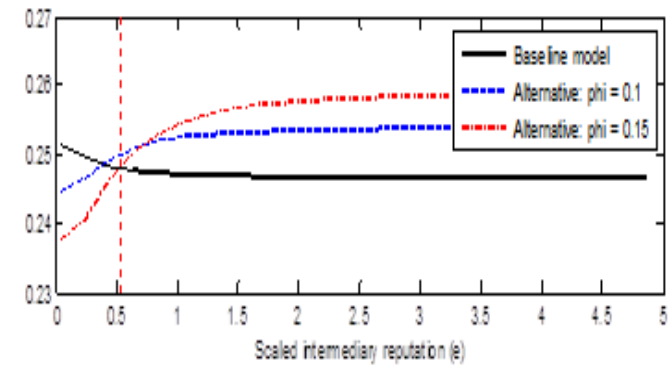


Figure 5: Comparing SOlutions Under Global dynamics AND APPROXIMATION BASED ON CONTINUOUS CONSTRAINT
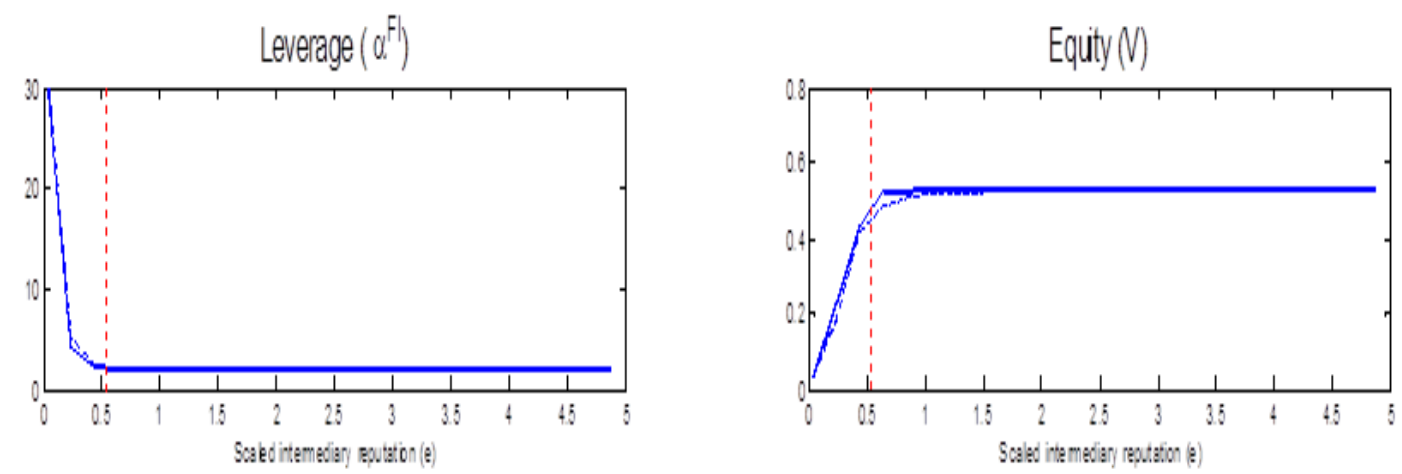

Risk premim (EdR-rdt)

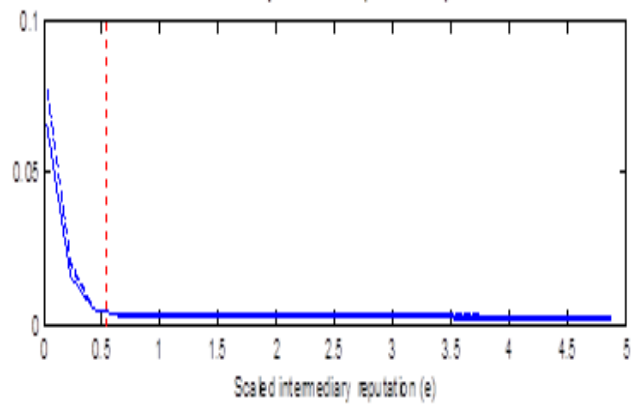

Interest rate (r)

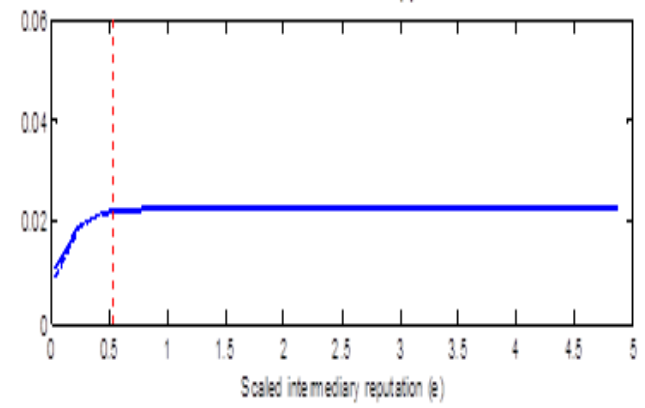

Asset price (Q)

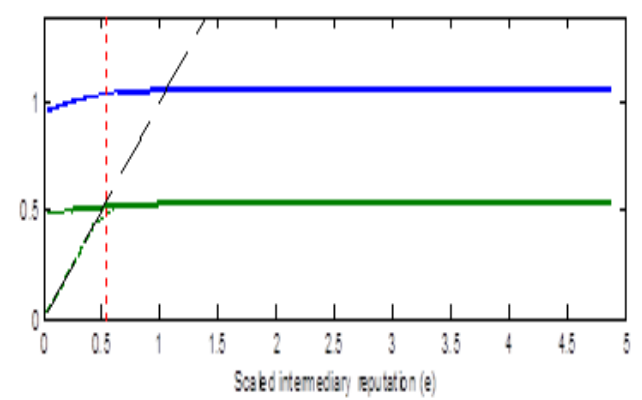

Volability returnon capital (Std(R))
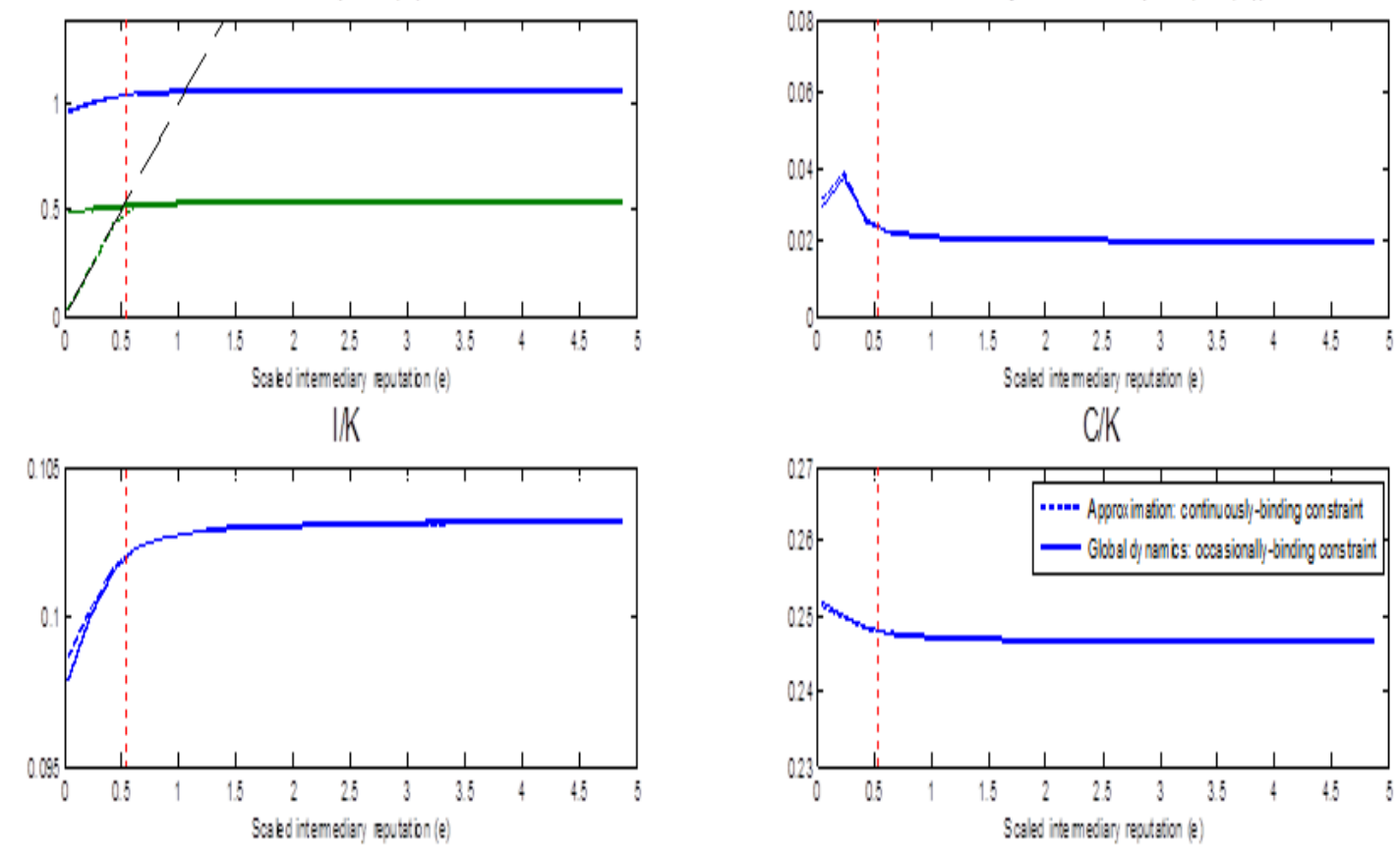
Figure 6: Simulation-based solution of Baseline discrete-time AK model
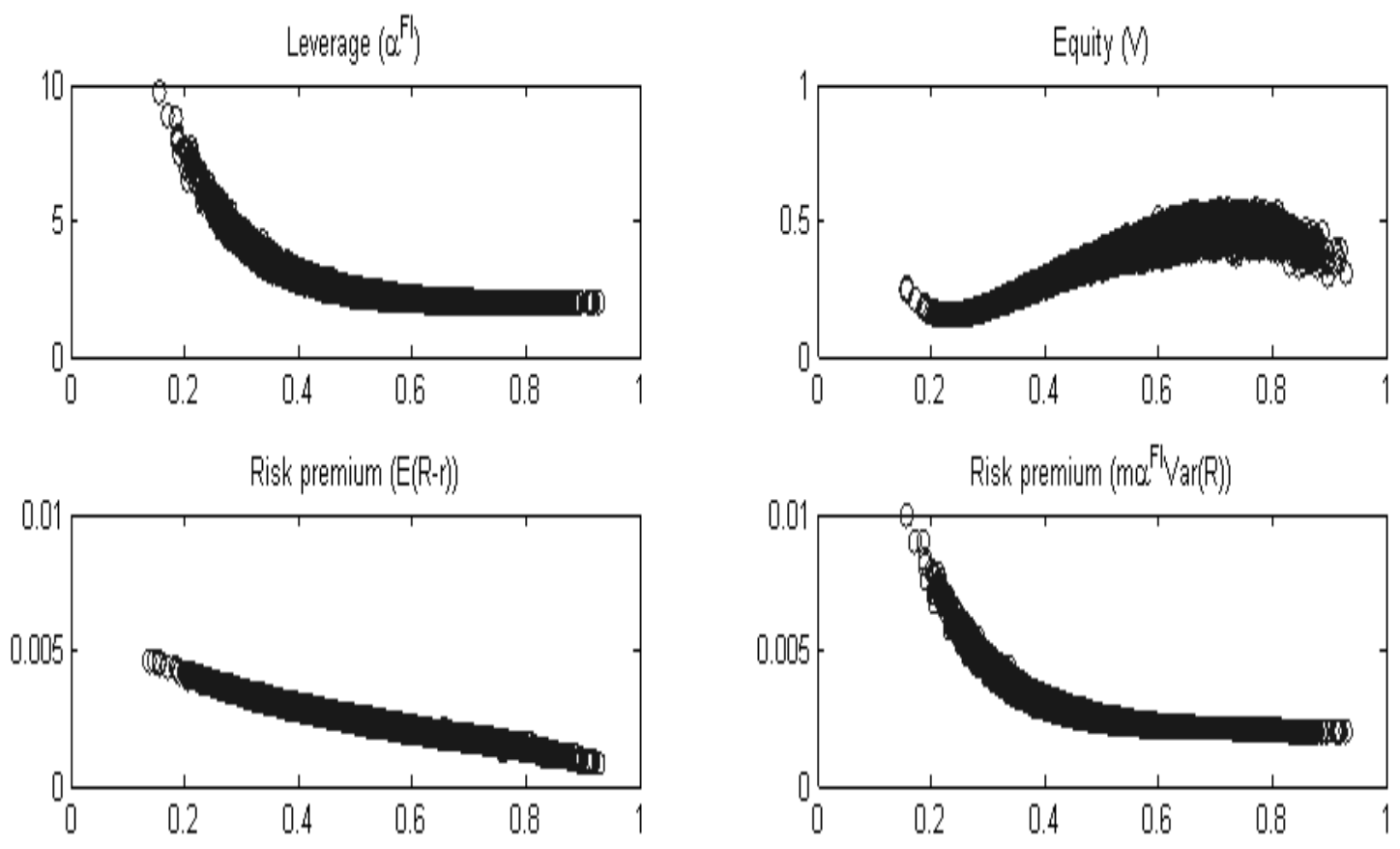

Asset price (Q)

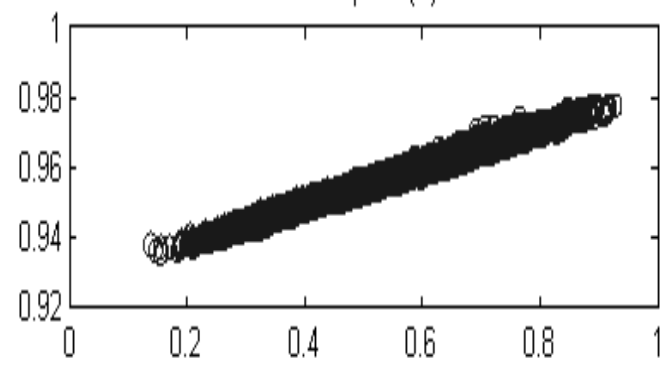

Volatility retumn on capital (Std(R))
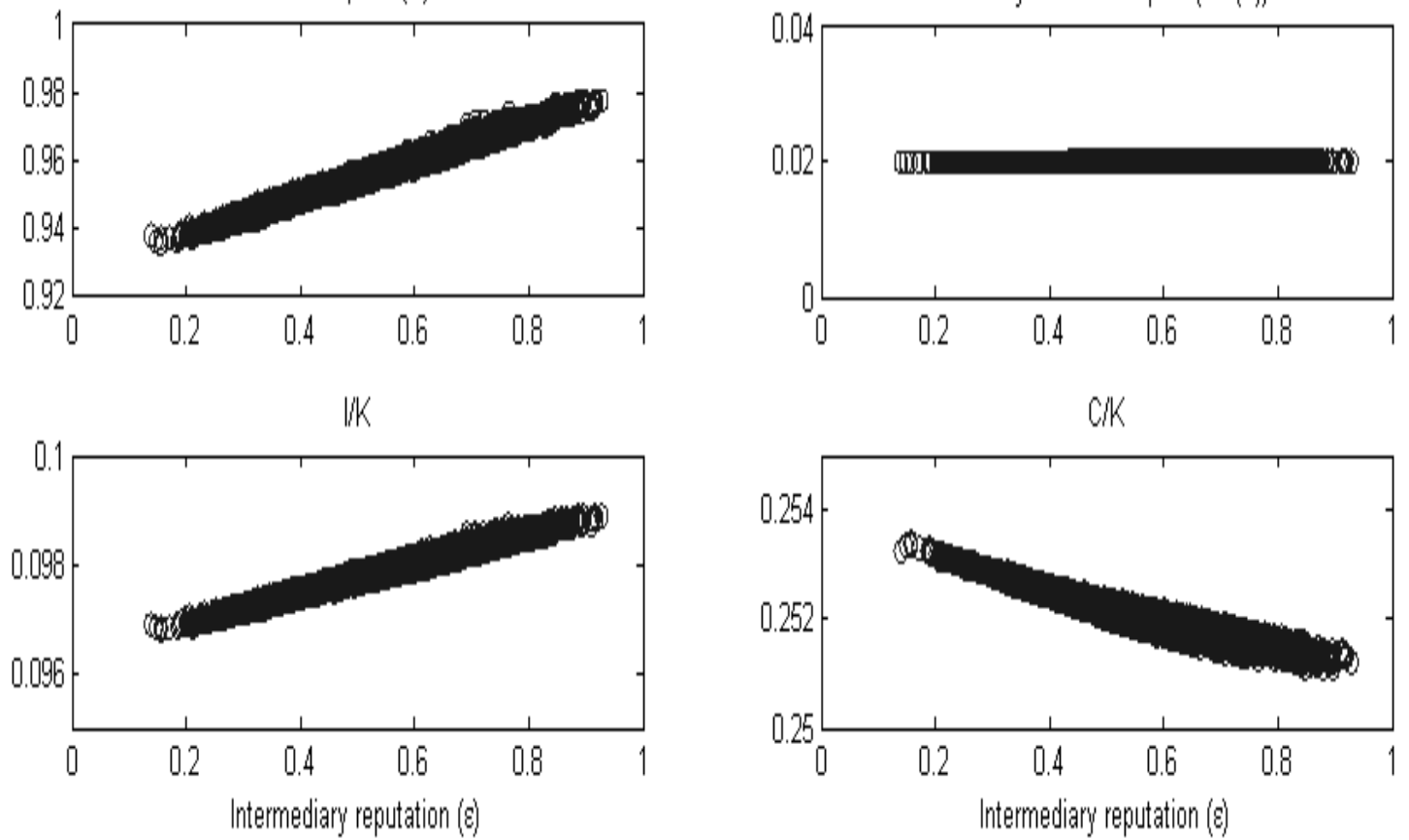
Figure 7: Simulation-based solution of DSGE model
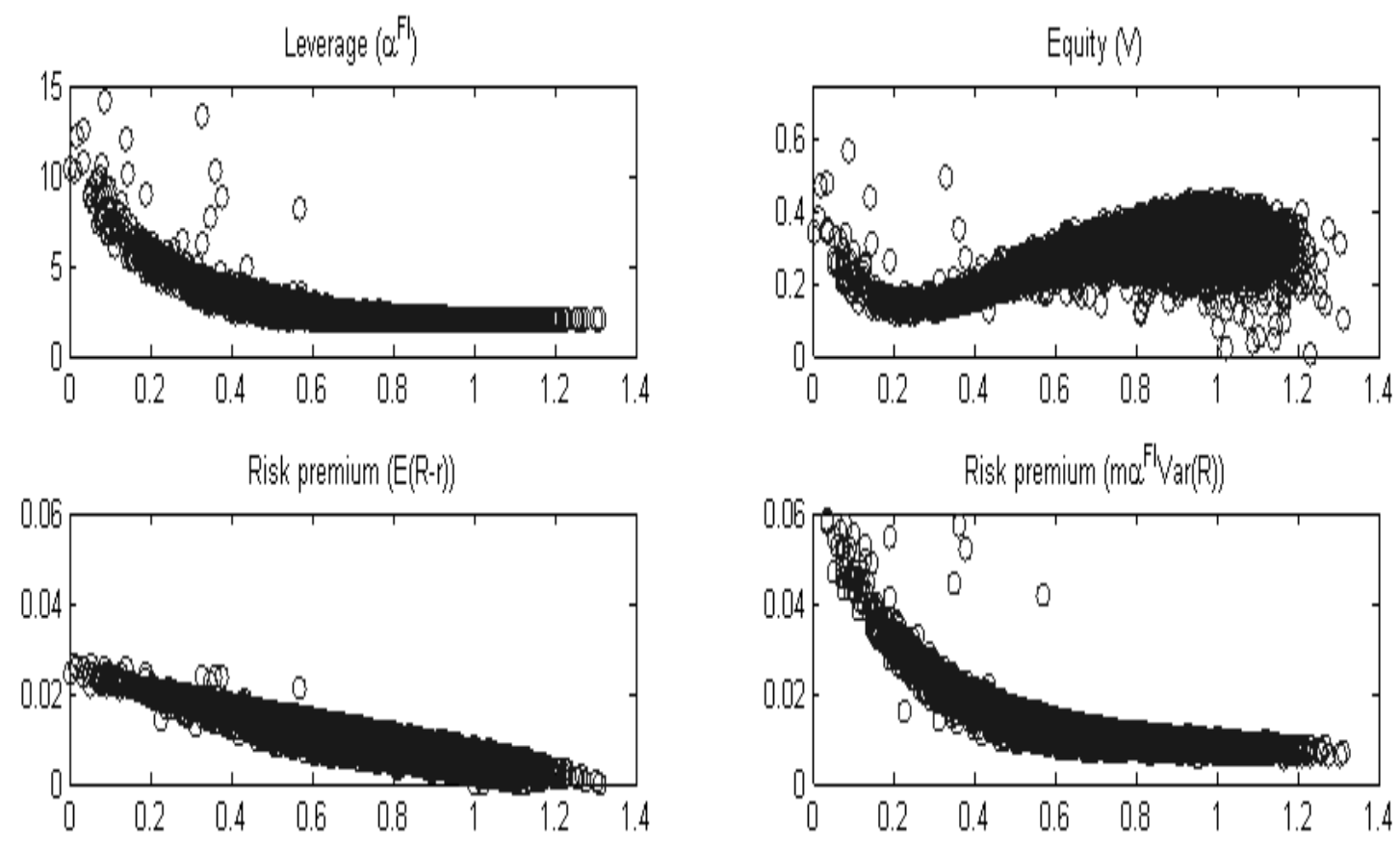

Asset price (Q)
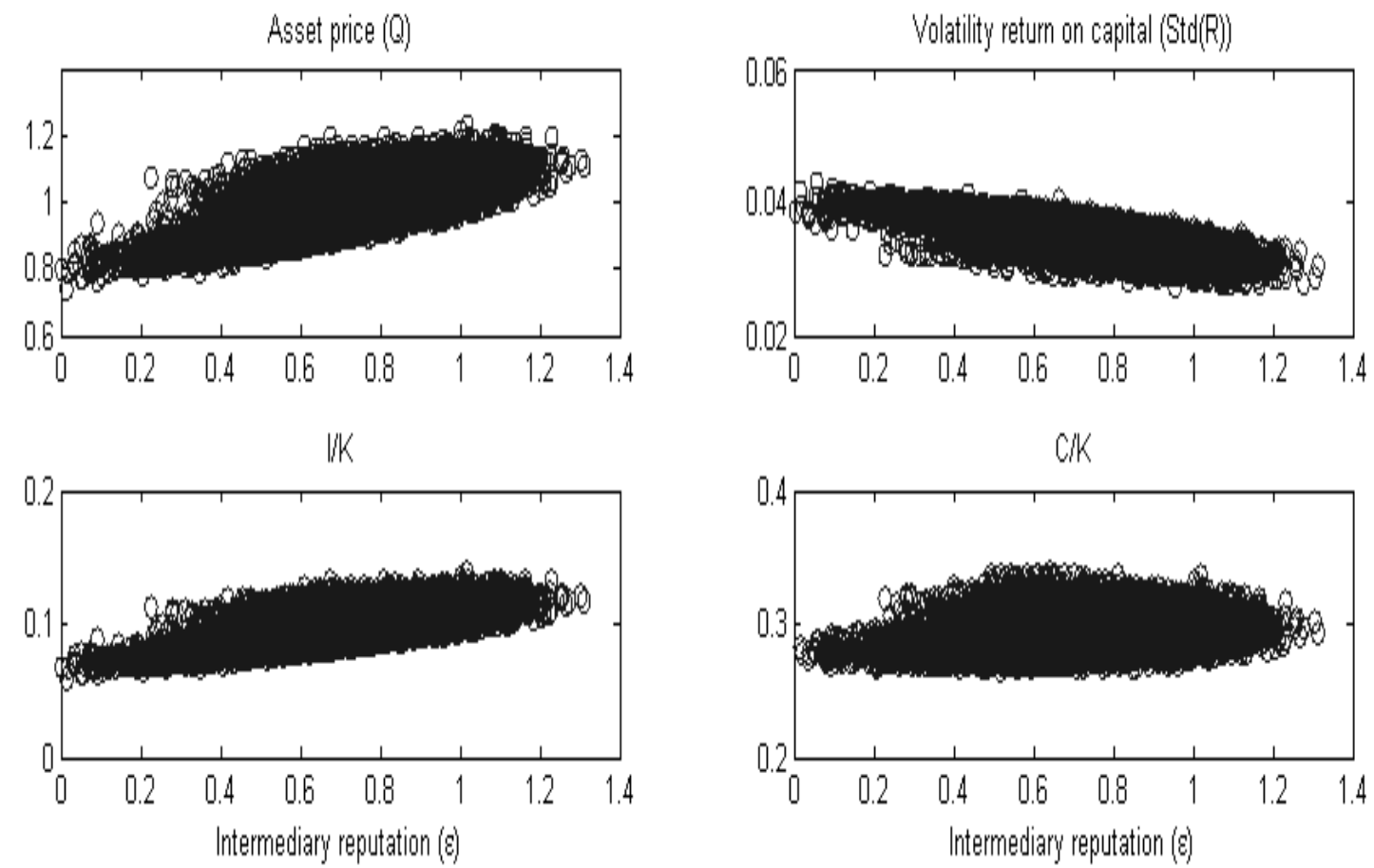
Figure 8: IRF ANALYSIS OF THE DSGE MODEL: FINANCIAL VARIABLES
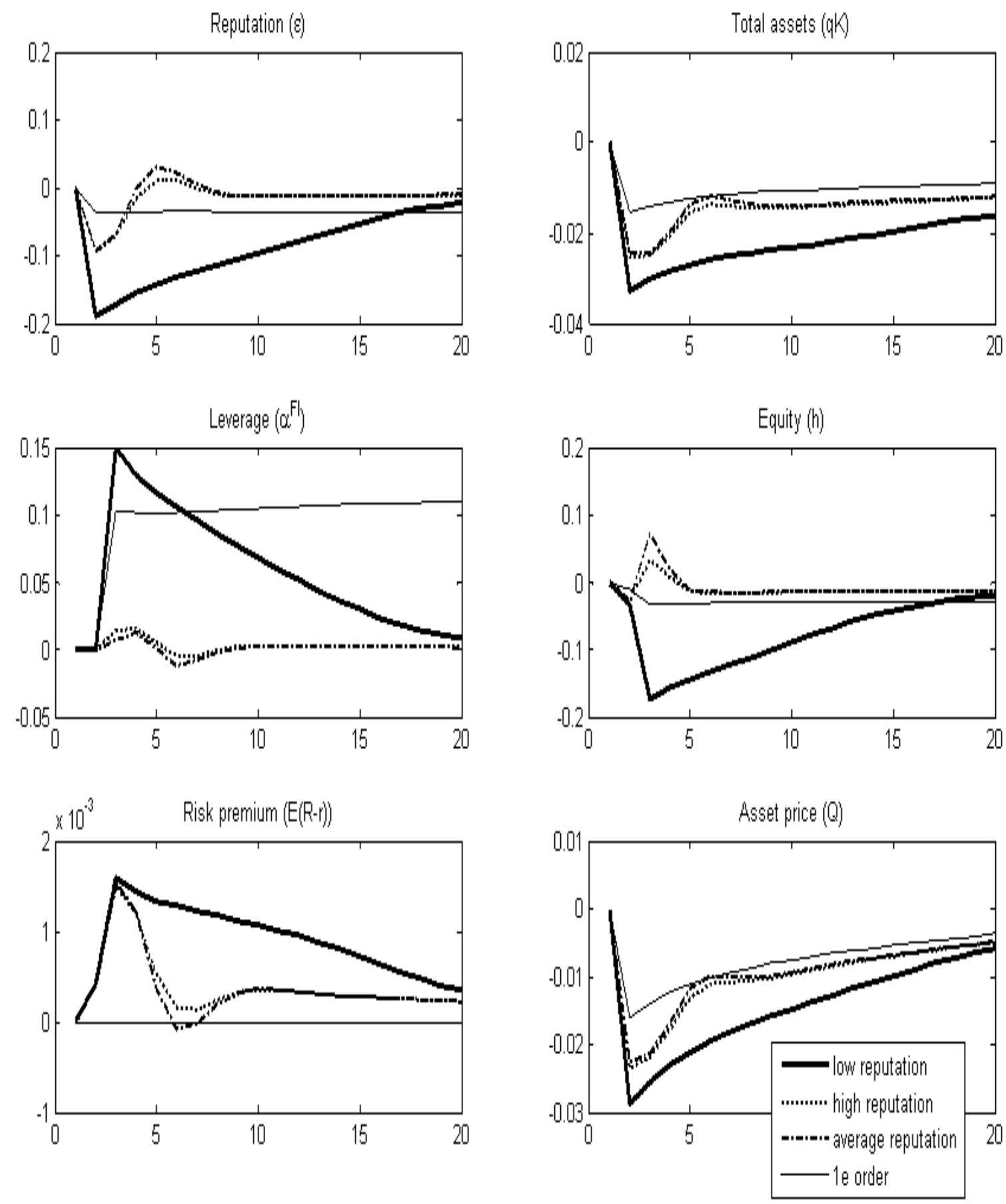
Figure 9: IRF ANALYSis of the DSGE MOdel: MACRO VARIABLES
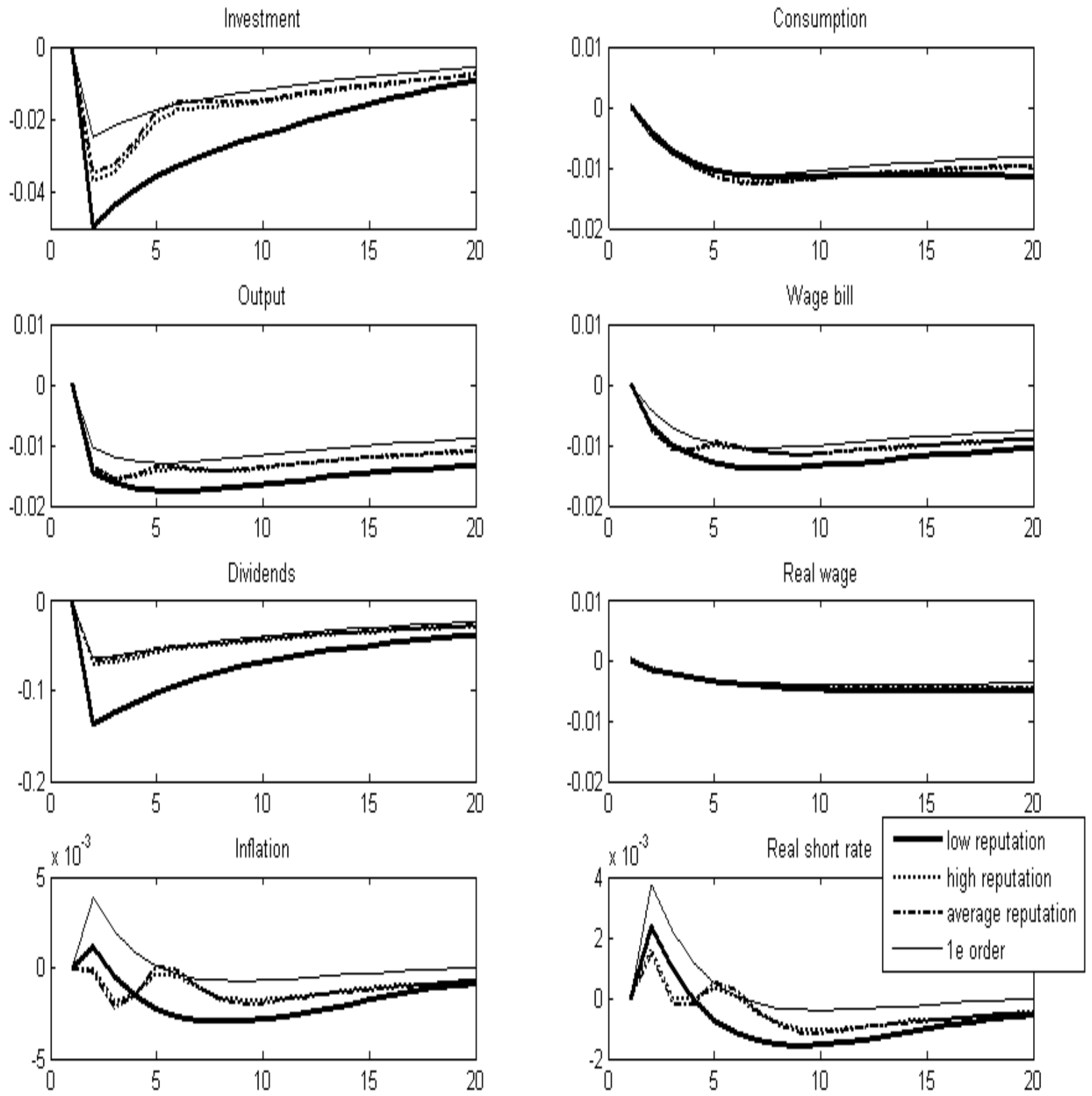
Figure 10: Model-IMPlied DYNAMiCs OF TFP AND FINANCIAL INTERMEDIATION: HISTORICAL DECOMPOSITION

Exogenous total factor productivity process

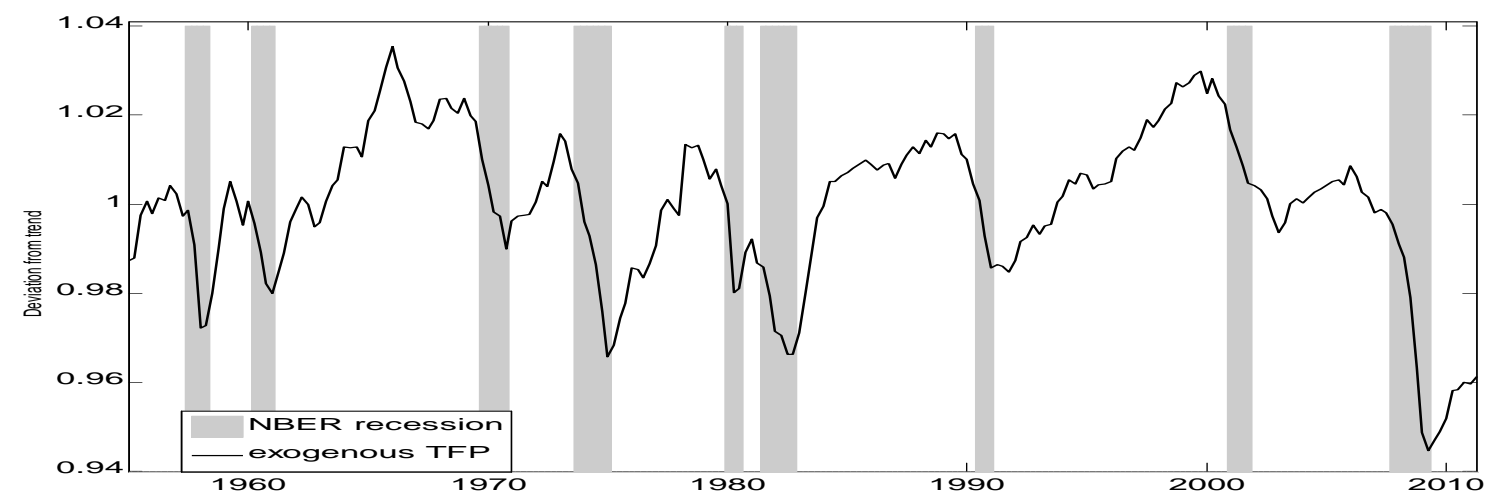

Reputation/total assets

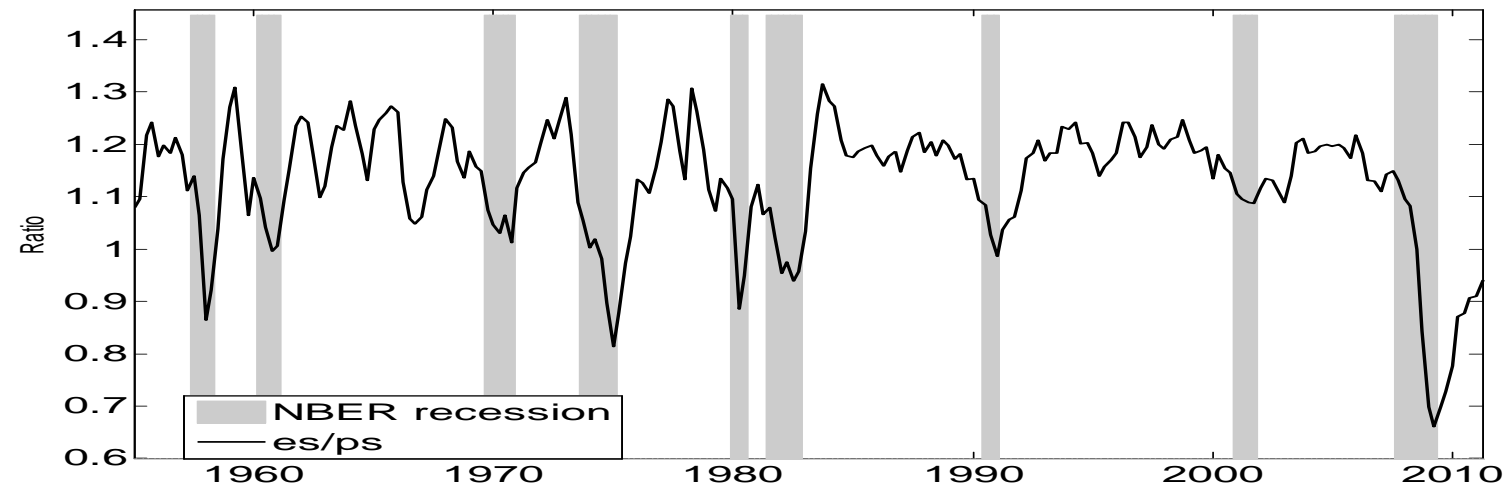

Leverage

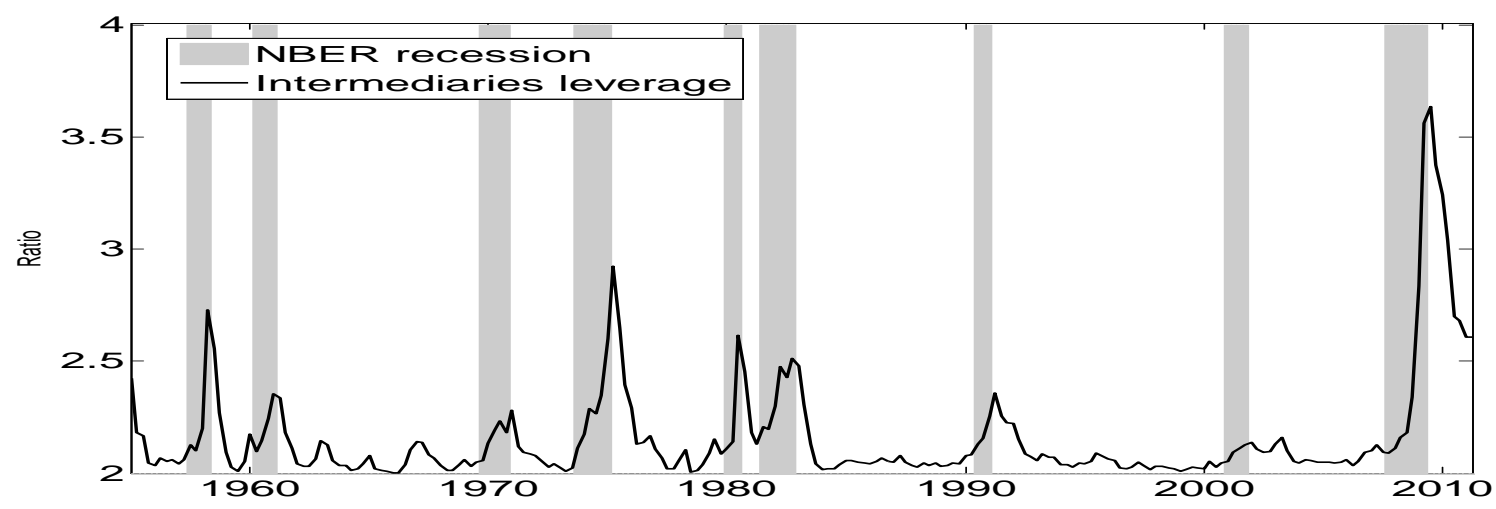

Risk premium

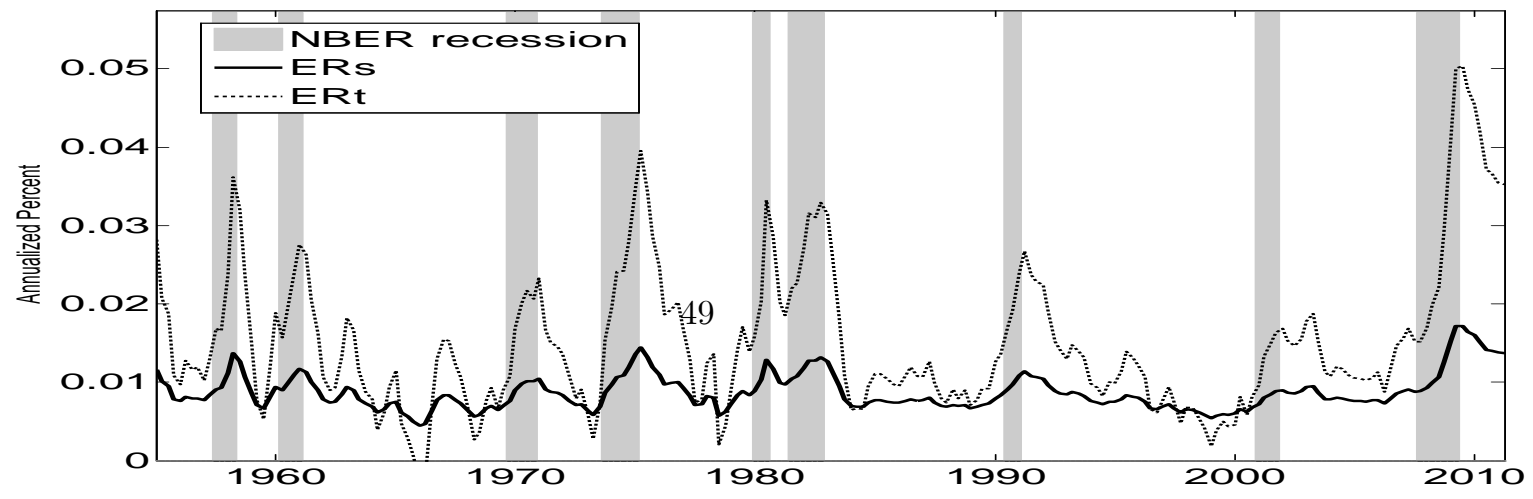


Figure 11: Contribution of Risk Channel to asset PRICE AND InVESTMEnt Dynamics: CounTERFACTUAL SIMULATION

Asset price (first difference)

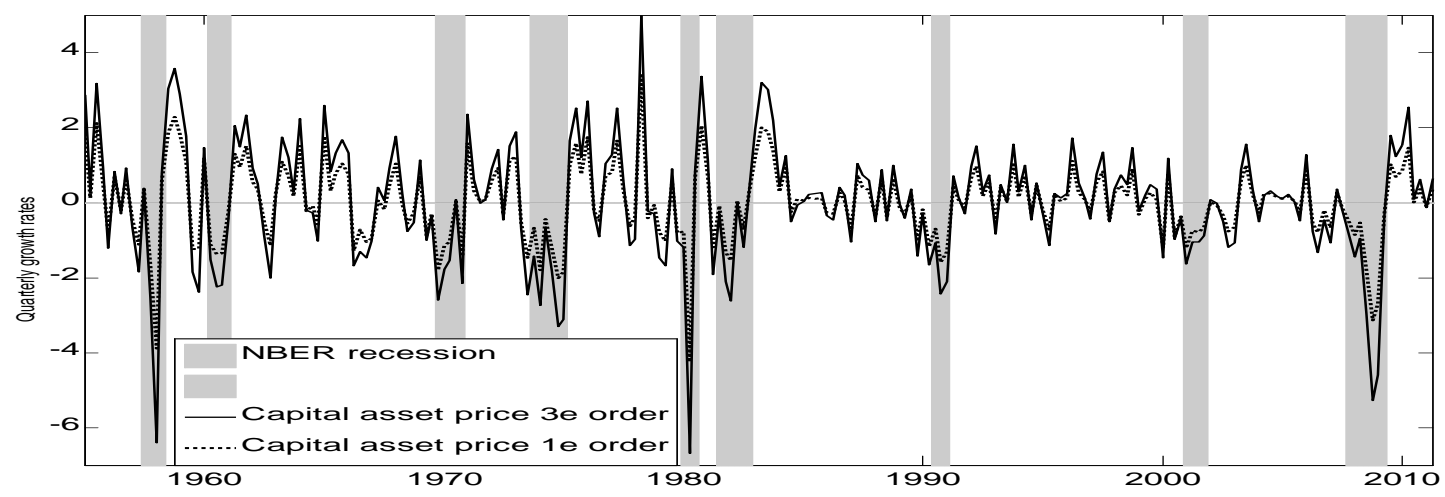

Investment (growth rate)

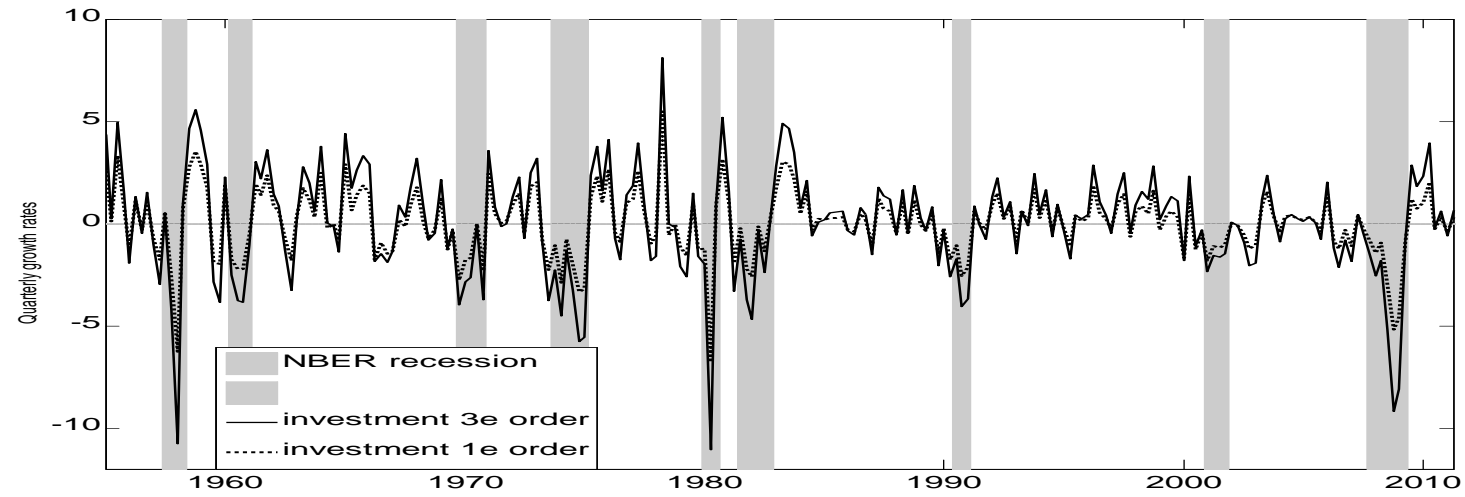

Investment (rate)

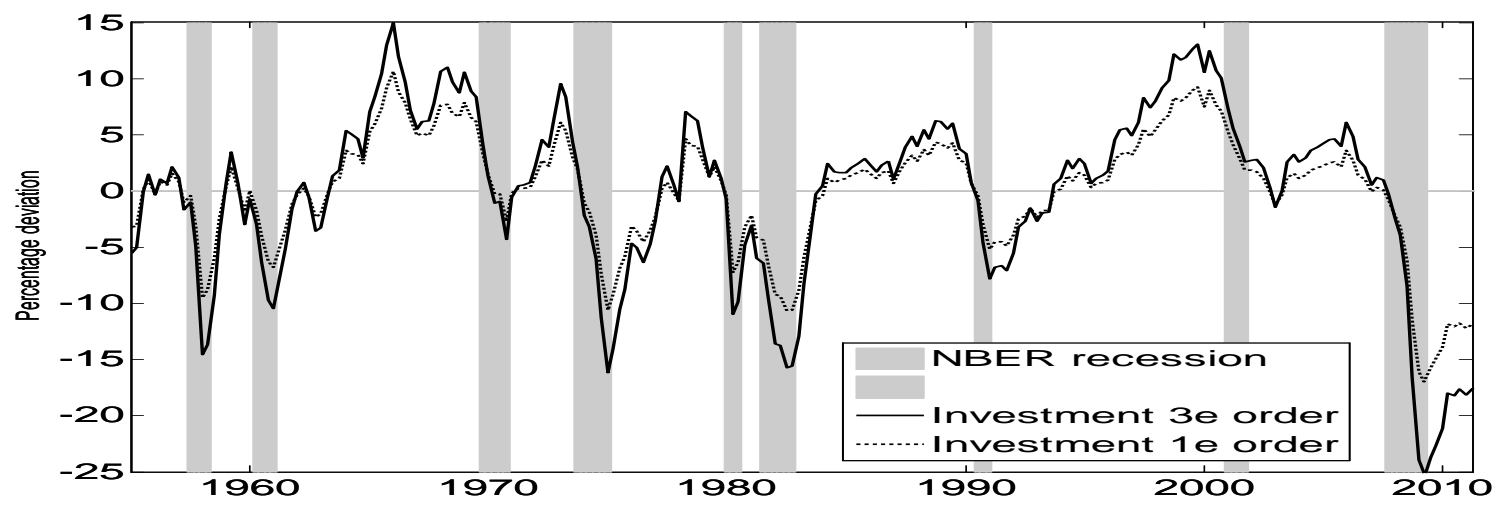

Output (deviation from trend growth rate)

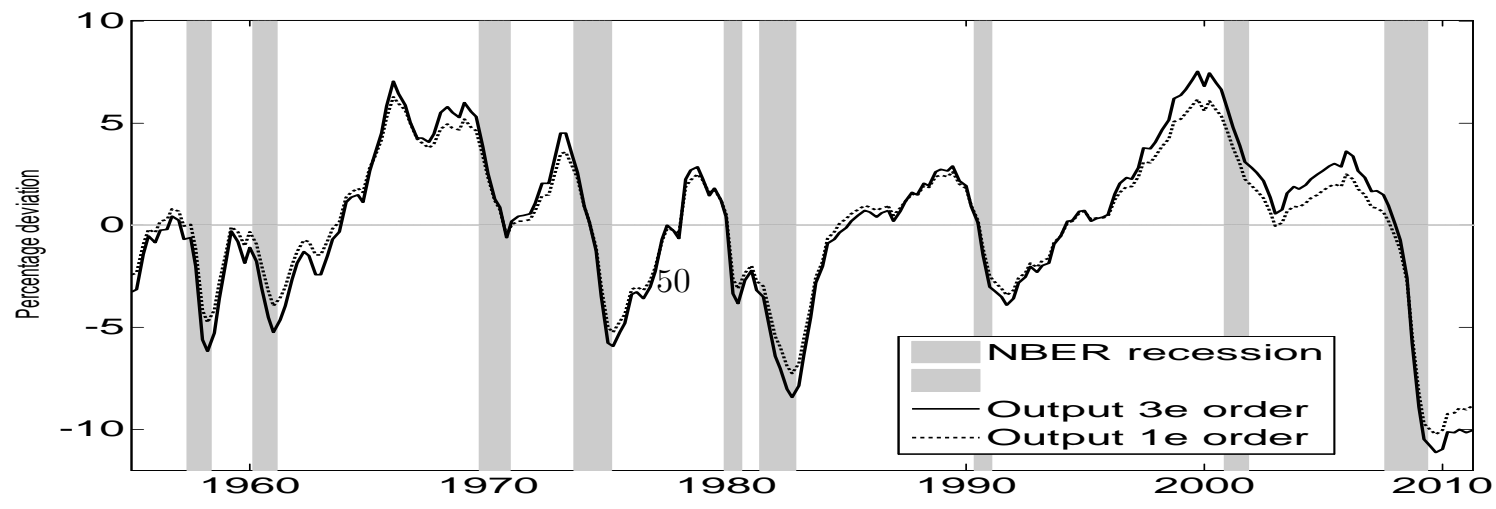


Figure 12: Contribution of Risk Channel to maCroeconomic Dynamics: Counterfactual SIMULATION

Output (deviation from trend growth rate)

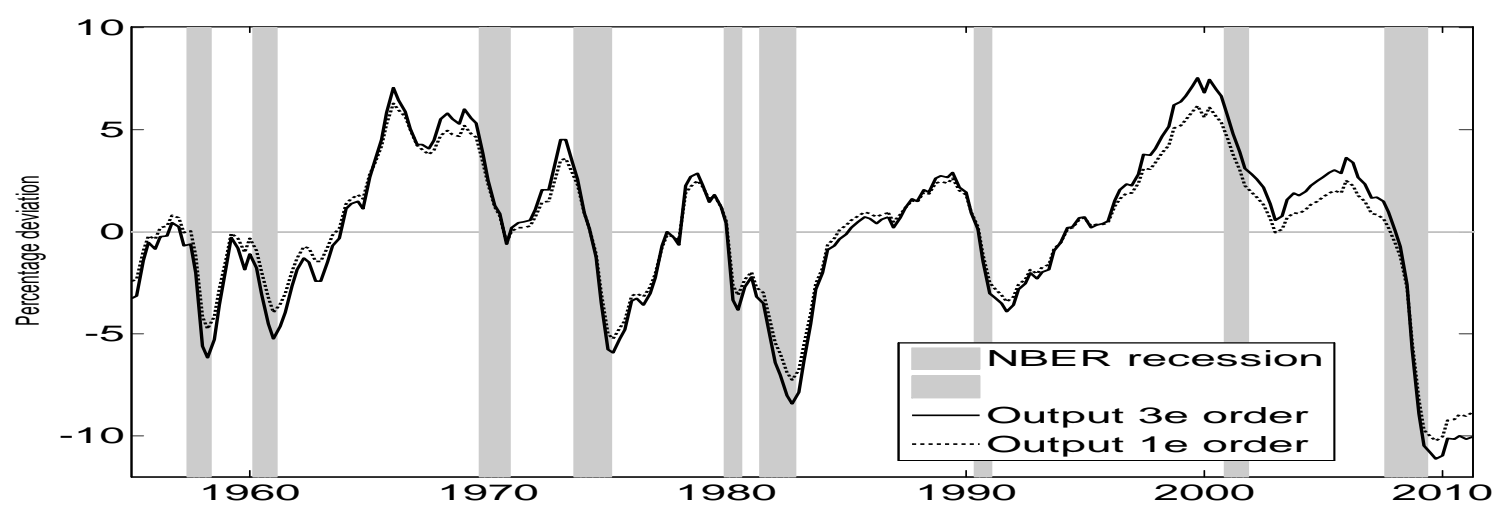

Inflation

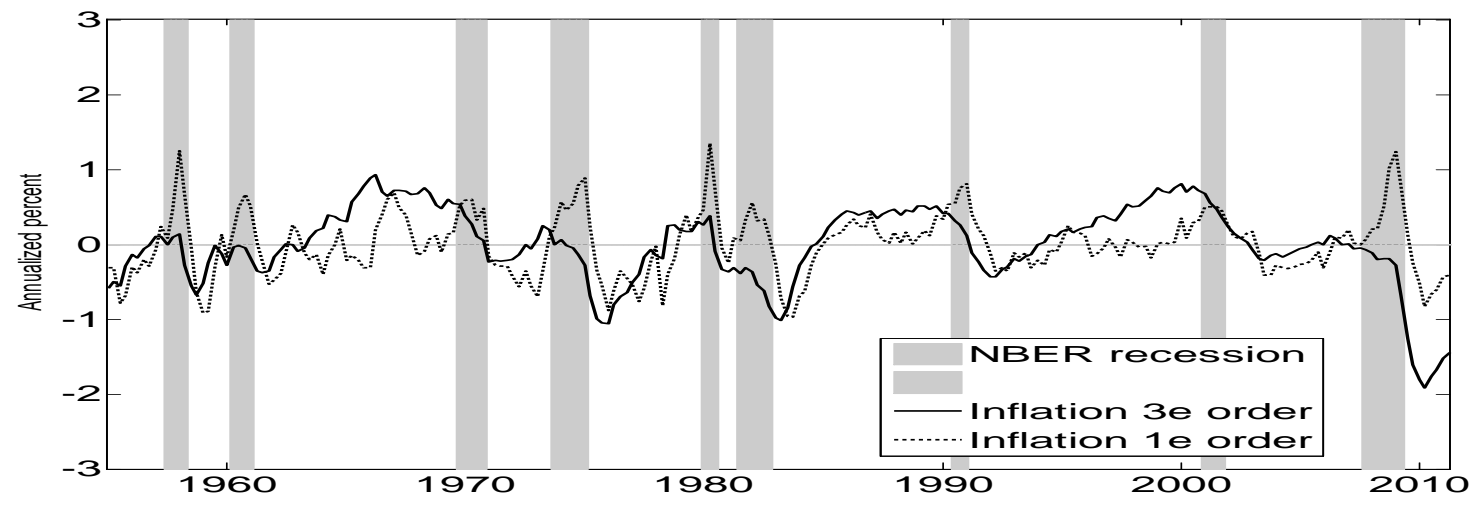

Nominal short rate

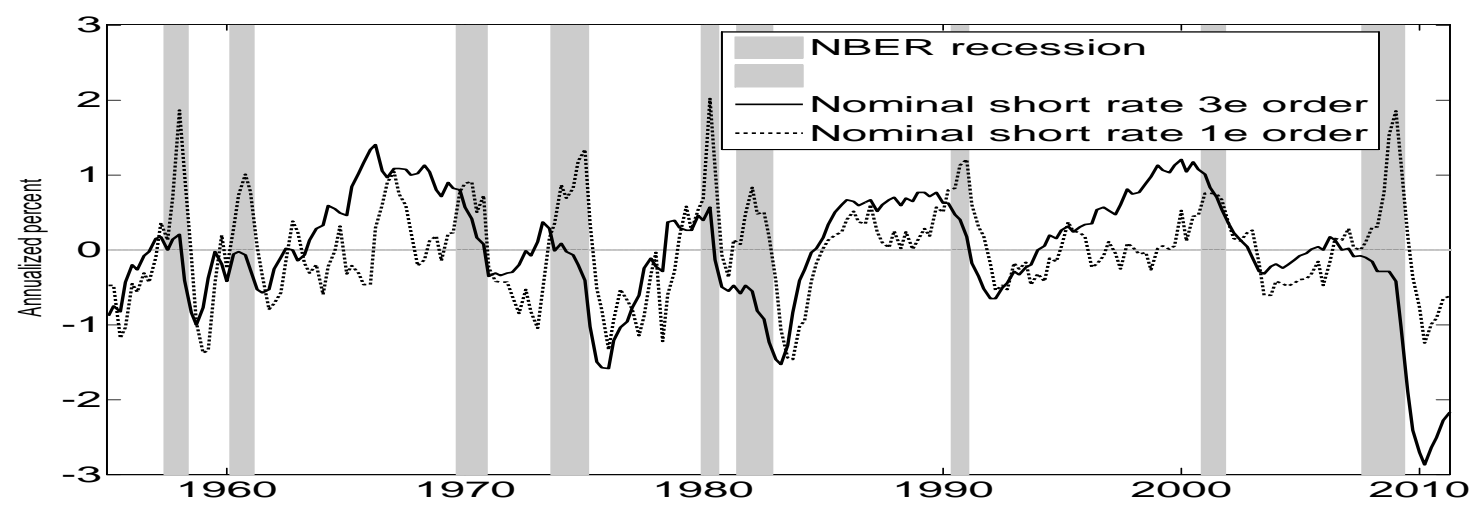

Real short rate

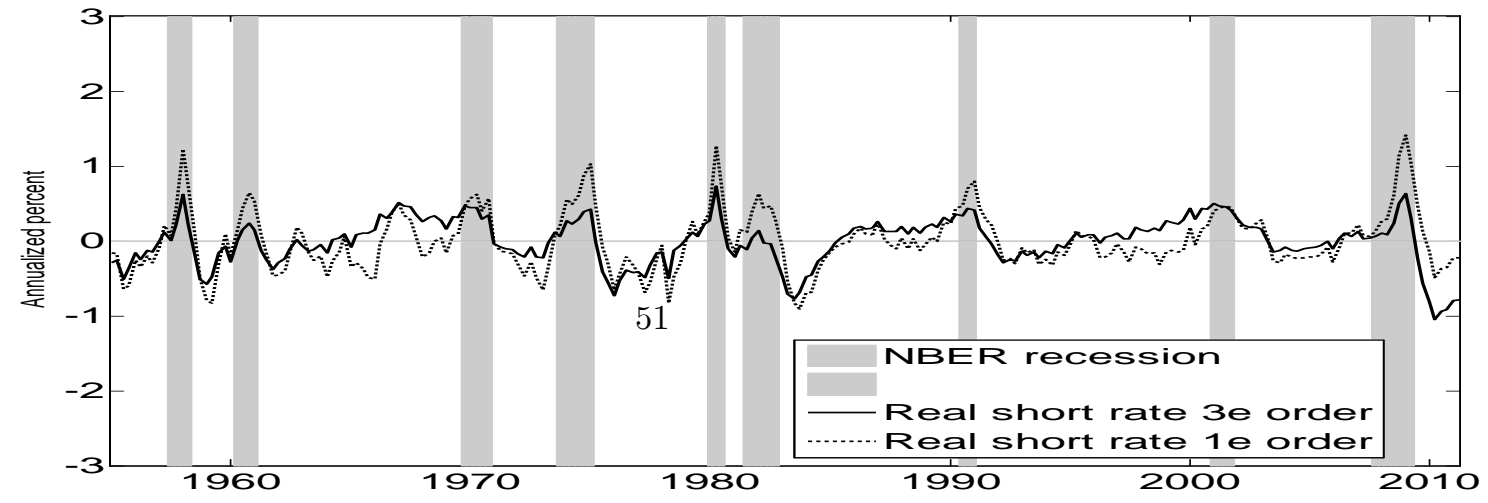





\section{NATIONAL BANK OF BELGIUM - WORKING PAPERS SERIES}

1. "Model-based inflation forecasts and monetary policy rules", by M. Dombrecht and R. Wouters, Research Series, February 2000.

2. "The use of robust estimators as measures of core inflation", by L. Aucremanne, Research Series, February 2000.

3. "Performances économiques des Etats-Unis dans les années nonante", by A. Nyssens, P. Butzen and P. Bisciari, Document Series, March 2000.

4. "A model with explicit expectations for Belgium", by P. Jeanfils, Research Series, March 2000.

5. "Growth in an open economy: Some recent developments", by S. Turnovsky, Research Series, May 2000.

6. "Knowledge, technology and economic growth: An OECD perspective", by I. Visco, A. Bassanini and S. Scarpetta, Research Series, May 2000.

7. "Fiscal policy and growth in the context of European integration", by P. Masson, Research Series, May 2000.

8. "Economic growth and the labour market: Europe's challenge", by C. Wyplosz, Research Series, May 2000.

9. "The role of the exchange rate in economic growth: A euro-zone perspective", by R. MacDonald, Research Series, May 2000.

10. "Monetary union and economic growth", by J. Vickers, Research Series, May 2000.

11. "Politique monétaire et prix des actifs: le cas des États-Unis", by Q. Wibaut, Document Series, August 2000.

12. "The Belgian industrial confidence indicator: Leading indicator of economic activity in the euro area?", by J.-J. Vanhaelen, L. Dresse and J. De Mulder, Document Series, November 2000.

13. "Le financement des entreprises par capital-risque", by C. Rigo, Document Series, February 2001.

14. "La nouvelle économie" by P. Bisciari, Document Series, March 2001.

15. "De kostprijs van bankkredieten", by A. Bruggeman and R. Wouters, Document Series, April 2001.

16. "A guided tour of the world of rational expectations models and optimal policies", by Ph. Jeanfils, Research Series, May 2001.

17. "Attractive prices and euro - Rounding effects on inflation", by L. Aucremanne and D. Cornille, Documents Series, November 2001.

18. "The interest rate and credit channels in Belgium: An investigation with micro-level firm data", by P. Butzen, C. Fuss and Ph. Vermeulen, Research series, December 2001.

19. "Openness, imperfect exchange rate pass-through and monetary policy", by F. Smets and R. Wouters, Research series, March 2002.

20. "Inflation, relative prices and nominal rigidities", by L. Aucremanne, G. Brys, M. Hubert, P. J. Rousseeuw and A. Struyf, Research series, April 2002.

21. "Lifting the burden: Fundamental tax reform and economic growth", by D. Jorgenson, Research series, May 2002.

22. "What do we know about investment under uncertainty?", by L. Trigeorgis, Research series, May 2002.

23. "Investment, uncertainty and irreversibility: Evidence from Belgian accounting data" by D. Cassimon, P.-J. Engelen, H. Meersman and M. Van Wouwe, Research series, May 2002.

24. "The impact of uncertainty on investment plans", by P. Butzen, C. Fuss and Ph. Vermeulen, Research series, May 2002.

25. "Investment, protection, ownership, and the cost of capital", by Ch. P. Himmelberg, R. G. Hubbard and I. Love, Research series, May 2002.

26. "Finance, uncertainty and investment: Assessing the gains and losses of a generalised non-linear structural approach using Belgian panel data", by M. Gérard and F. Verschueren, Research series, May 2002.

27. "Capital structure, firm liquidity and growth", by R. Anderson, Research series, May 2002.

28. "Structural modelling of investment and financial constraints: Where do we stand?", by J.-B. Chatelain, Research series, May 2002.

29. "Financing and investment interdependencies in unquoted Belgian companies: The role of venture capital", by S. Manigart, K. Baeyens, I. Verschueren, Research series, May 2002.

30. "Development path and capital structure of Belgian biotechnology firms", by V. Bastin, A. Corhay, G. Hübner and P.-A. Michel, Research series, May 2002.

31. "Governance as a source of managerial discipline", by J. Franks, Research series, May 2002.

32. "Financing constraints, fixed capital and R\&D investment decisions of Belgian firms", by M. Cincera, Research series, May 2002. 
33. "Investment, R\&D and liquidity constraints: A corporate governance approach to the Belgian evidence", by P. Van Cayseele, Research series, May 2002.

34. "On the origins of the Franco-German EMU controversies", by I. Maes, Research series, July 2002.

35. "An estimated dynamic stochastic general equilibrium model of the euro area", by F. Smets and R. Wouters, Research series, October 2002.

36. "The labour market and fiscal impact of labour tax reductions: The case of reduction of employers' social security contributions under a wage norm regime with automatic price indexing of wages", by K. Burggraeve and Ph. Du Caju, Research series, March 2003.

37. "Scope of asymmetries in the euro area", by S. Ide and Ph. Moës, Document series, March 2003.

38. "De autonijverheid in België: Het belang van het toeleveringsnetwerk rond de assemblage van personenauto's", by F. Coppens and G. van Gastel, Document series, June 2003.

39. "La consommation privée en Belgique", by B. Eugène, Ph. Jeanfils and B. Robert, Document series, June 2003.

40. "The process of European monetary integration: A comparison of the Belgian and Italian approaches", by I. Maes and L. Quaglia, Research series, August 2003.

41. "Stock market valuation in the United States", by P. Bisciari, A. Durré and A. Nyssens, Document series, November 2003.

42. "Modeling the term structure of interest rates: Where do we stand?", by K. Maes, Research series, February 2004.

43. "Interbank exposures: An ampirical examination of system risk in the Belgian banking system", by H. Degryse and G. Nguyen, Research series, March 2004.

44. "How frequently do prices change? Evidence based on the micro data underlying the Belgian CPI", by L. Aucremanne and E. Dhyne, Research series, April 2004.

45. "Firms' investment decisions in response to demand and price uncertainty", by C. Fuss and Ph. Vermeulen, Research series, April 2004.

46. "SMEs and bank lending relationships: The impact of mergers", by H. Degryse, N. Masschelein and J. Mitchell, Research series, May 2004.

47. "The determinants of pass-through of market conditions to bank retail interest rates in Belgium", by F. De Graeve, O. De Jonghe and R. Vander Vennet, Research series, May 2004.

48. "Sectoral vs. country diversification benefits and downside risk", by M. Emiris, Research series, May 2004.

49. "How does liquidity react to stress periods in a limit order market?", by H. Beltran, A. Durré and P. Giot, Research series, May 2004.

50. "Financial consolidation and liquidity: Prudential regulation and/or competition policy?", by P. Van Cayseele, Research series, May 2004.

51. "Basel II and operational risk: Implications for risk measurement and management in the financial sector", by A. Chapelle, Y. Crama, G. Hübner and J.-P. Peters, Research series, May 2004.

52. "The efficiency and stability of banks and markets", by F. Allen, Research series, May 2004.

53. "Does financial liberalization spur growth?", by G. Bekaert, C.R. Harvey and C. Lundblad, Research series, May 2004.

54. "Regulating financial conglomerates", by X. Freixas, G. Lóránth, A.D. Morrison and H.S. Shin, Research series, May 2004.

55. "Liquidity and financial market stability", by M. O'Hara, Research series, May 2004.

56. "Economisch belang van de Vlaamse zeehavens: Verslag 2002", by F. Lagneaux, Document series, June 2004.

57. "Determinants of euro term structure of credit spreads", by A. Van Landschoot, Research series, July 2004.

58. "Macroeconomic and monetary policy-making at the European Commission, from the Rome Treaties to the Hague Summit", by I. Maes, Research series, July 2004.

59. "Liberalisation of network industries: Is electricity an exception to the rule?", by F. Coppens and D. Vivet, Document series, September 2004.

60. "Forecasting with a Bayesian DSGE model: An application to the euro area", by F. Smets and R. Wouters, Research series, September 2004.

61. "Comparing shocks and frictions in US and euro area business cycle: A Bayesian DSGE approach", by F. Smets and R. Wouters, Research series, October 2004.

62. "Voting on pensions: A survey", by G. de Walque, Research series, October 2004.

63. "Asymmetric growth and inflation developments in the acceding countries: A new assessment", by S. Ide and P. Moës, Research series, October 2004.

64. "Importance économique du Port Autonome de Liège: rapport 2002", by F. Lagneaux, Document series, November 2004. 
65. "Price-setting behaviour in Belgium: What can be learned from an ad hoc survey", by L. Aucremanne and M. Druant, Research series, March 2005.

66. "Time-dependent versus state-dependent pricing: A panel data approach to the determinants of Belgian consumer price changes", by L. Aucremanne and E. Dhyne, Research series, April 2005.

67. "Indirect effects - A formal definition and degrees of dependency as an alternative to technical coefficients", by F. Coppens, Research series, May 2005.

68. "Noname - A new quarterly model for Belgium", by Ph. Jeanfils and K. Burggraeve, Research series, May 2005.

69. "Economic importance of the Flemish maritime ports: Report 2003", by F. Lagneaux, Document series, May 2005.

70. "Measuring inflation persistence: A structural time series approach", by M. Dossche and G. Everaert, Research series, June 2005.

71. "Financial intermediation theory and implications for the sources of value in structured finance markets", by J. Mitchell, Document series, July 2005.

72. "Liquidity risk in securities settlement", by J. Devriese and J. Mitchell, Research series, July 2005.

73. "An international analysis of earnings, stock prices and bond yields", by A. Durré and P. Giot, Research series, September 2005.

74. "Price setting in the euro area: Some stylized facts from Individual Consumer Price Data", by E. Dhyne, L. J. Álvarez, H. Le Bihan, G. Veronese, D. Dias, J. Hoffmann, N. Jonker, P. Lünnemann, F. Rumler and J. Vilmunen, Research series, September 2005.

75. "Importance économique du Port Autonome de Liège: rapport 2003", by F. Lagneaux, Document series, October 2005.

76. "The pricing behaviour of firms in the euro area: New survey evidence, by S. Fabiani, M. Druant, I. Hernando, C. Kwapil, B. Landau, C. Loupias, F. Martins, T. Mathä, R. Sabbatini, H. Stahl and A. Stokman, Research series, November 2005.

77. "Income uncertainty and aggregate consumption", by L. Pozzi, Research series, November 2005.

78. "Crédits aux particuliers - Analyse des données de la Centrale des Crédits aux Particuliers", by H. De Doncker, Document series, January 2006.

79. "Is there a difference between solicited and unsolicited bank ratings and, if so, why?", by P. Van Roy, Research series, February 2006.

80. "A generalised dynamic factor model for the Belgian economy - Useful business cycle indicators and GDP growth forecasts", by Ch. Van Nieuwenhuyze, Research series, February 2006.

81. "Réduction linéaire de cotisations patronales à la sécurité sociale et financement alternatif", by Ph. Jeanfils, L. Van Meensel, Ph. Du Caju, Y. Saks, K. Buysse and K. Van Cauter, Document series, March 2006.

82. "The patterns and determinants of price setting in the Belgian industry", by D. Cornille and M. Dossche, Research series, May 2006.

83. "A multi-factor model for the valuation and risk management of demand deposits", by H. Dewachter, M. Lyrio and K. Maes, Research series, May 2006.

84. "The single European electricity market: A long road to convergence", by F. Coppens and D. Vivet, Document series, May 2006.

85. "Firm-specific production factors in a DSGE model with Taylor price setting", by G. de Walque, F. Smets and R. Wouters, Research series, June 2006.

86. "Economic importance of the Belgian ports: Flemish maritime ports and Liège port complex - Report 2004", by F. Lagneaux, Document series, June 2006.

87. "The response of firms' investment and financing to adverse cash flow shocks: The role of bank relationships", by C. Fuss and Ph. Vermeulen, Research series, July 2006.

88. "The term structure of interest rates in a DSGE model", by M. Emiris, Research series, July 2006.

89. "The production function approach to the Belgian output gap, estimation of a multivariate structural time series model", by Ph. Moës, Research series, September 2006.

90. "Industry wage differentials, unobserved ability, and rent-sharing: Evidence from matched worker-firm data, 1995-2002", by R. Plasman, F. Rycx and I. Tojerow, Research series, October 2006.

91. "The dynamics of trade and competition", by N. Chen, J. Imbs and A. Scott, Research series, October 2006.

92. "A New Keynesian model with unemployment", by O. Blanchard and J. Gali, Research series, October 2006.

93. "Price and wage setting in an integrating Europe: Firm level evidence", by F. Abraham, J. Konings and S. Vanormelingen, Research series, October 2006.

94. "Simulation, estimation and welfare implications of monetary policies in a 3-country NOEM model", by J. Plasmans, T. Michalak and J. Fornero, Research series, October 2006. 
95. "Inflation persistence and price-setting behaviour in the euro area: A summary of the Inflation Persistence Network evidence ", by F. Altissimo, M. Ehrmann and F. Smets, Research series, October 2006.

96. "How wages change: Micro evidence from the International Wage Flexibility Project", by W.T. Dickens, L. Goette, E.L. Groshen, S. Holden, J. Messina, M.E. Schweitzer, J. Turunen and M. Ward, Research series, October 2006.

97. "Nominal wage rigidities in a new Keynesian model with frictional unemployment", by V. Bodart, G. de Walque, O. Pierrard, H.R. Sneessens and R. Wouters, Research series, October 2006.

98. "Dynamics on monetary policy in a fair wage model of the business cycle", by D. De la Croix, G. de Walque and R. Wouters, Research series, October 2006.

99. "The kinked demand curve and price rigidity: Evidence from scanner data", by M. Dossche, F. Heylen and D. Van den Poel, Research series, October 2006.

100. "Lumpy price adjustments: A microeconometric analysis", by E. Dhyne, C. Fuss, H. Peseran and P. Sevestre, Research series, October 2006.

101. "Reasons for wage rigidity in Germany", by W. Franz and F. Pfeiffer, Research series, October 2006.

102. "Fiscal sustainability indicators and policy design in the face of ageing", by G. Langenus, Research series, October 2006.

103. "Macroeconomic fluctuations and firm entry: Theory and evidence", by V. Lewis, Research series, October 2006.

104. "Exploring the CDS-bond basis", by J. De Wit, Research series, November 2006.

105. "Sector concentration in loan portfolios and economic capital", by K. Düllmann and N. Masschelein, Research series, November 2006.

106. "R\&D in the Belgian pharmaceutical sector", by H. De Doncker, Document series, December 2006.

107. "Importance et évolution des investissements directs en Belgique", by Ch. Piette, Document series, January 2007.

108. "Investment-specific technology shocks and labor market frictions", by R. De Bock, Research series, February 2007.

109. "Shocks and frictions in US business cycles: A Bayesian DSGE approach", by F. Smets and R. Wouters, Research series, February 2007.

110. "Economic impact of port activity: A disaggregate analysis. The case of Antwerp", by F. Coppens, F. Lagneaux, H. Meersman, N. Sellekaerts, E. Van de Voorde, G. van Gastel, Th. Vanelslander, A. Verhetsel, Document series, February 2007.

111. "Price setting in the euro area: Some stylised facts from individual producer price data", by Ph. Vermeulen, D. Dias, M. Dossche, E. Gautier, I. Hernando, R. Sabbatini, H. Stahl, Research series, March 2007.

112. "Assessing the gap between observed and perceived inflation in the euro area: Is the credibility of the HICP at stake?", by L. Aucremanne, M. Collin and Th. Stragier, Research series, April 2007.

113. "The spread of Keynesian economics: A comparison of the Belgian and Italian experiences", by I. Maes, Research series, April 2007.

114. "Imports and exports at the level of the firm: Evidence from Belgium", by M. Muûls and M. Pisu, Research series, May 2007.

115. "Economic importance of the Belgian ports: Flemish maritime ports and Liège port complex - Report 2005", by F. Lagneaux, Document series, May 2007.

116. "Temporal distribution of price changes: Staggering in the large and synchronization in the small", by E. Dhyne and J. Konieczny, Research series, June 2007.

117. "Can excess liquidity signal an asset price boom?", by A. Bruggeman, Research series, August 2007.

118. "The performance of credit rating systems in the assessment of collateral used in Eurosystem monetary policy operations", by F. Coppens, F. González and G. Winkler, Research series, September 2007.

119. "The determinants of stock and bond return comovements", by L. Baele, G. Bekaert and K. Inghelbrecht, Research series, October 2007.

120. "Monitoring pro-cyclicality under the capital requirements directive: Preliminary concepts for developing a framework", by N. Masschelein, Document series, October 2007.

121. "Dynamic order submission strategies with competition between a dealer market and a crossing network", by H. Degryse, M. Van Achter and G. Wuyts, Research series, November 2007.

122. "The gas chain: Influence of its specificities on the liberalisation process", by C. Swartenbroekx, Document series, November 2007.

123. "Failure prediction models: Performance, disagreements, and internal rating systems", by J. Mitchell and P. Van Roy, Research series, December 2007.

124. "Downward wage rigidity for different workers and firms: An evaluation for Belgium using the IWFP procedure", by Ph. Du Caju, C. Fuss and L. Wintr, Research series, December 2007.

125. "Economic importance of Belgian transport logistics", by F. Lagneaux, Document series, January 2008. 
126. "Some evidence on late bidding in eBay auctions", by L. Wintr, Research series, January 2008.

127. "How do firms adjust their wage bill in Belgium? A decomposition along the intensive and extensive margins", by C. Fuss, Research series, January 2008.

128. "Exports and productivity - Comparable evidence for 14 countries", by The International Study Group on Exports and Productivity, Research series, February 2008.

129. "Estimation of monetary policy preferences in a forward-looking model: A Bayesian approach", by P. Ilbas, Research series, March 2008.

130. "Job creation, job destruction and firms' international trade involvement", by M. Pisu, Research series, March 2008.

131. "Do survey indicators let us see the business cycle? A frequency decomposition", by L. Dresse and Ch. Van Nieuwenhuyze, Research series, March 2008.

132. "Searching for additional sources of inflation persistence: The micro-price panel data approach", by R. Raciborski, Research series, April 2008.

133. "Short-term forecasting of GDP using large monthly datasets - A pseudo real-time forecast evaluation exercise", by K. Barhoumi, S. Benk, R. Cristadoro, A. Den Reijer, A. Jakaitiene, P. Jelonek, A. Rua, G. Rünstler, K. Ruth and Ch. Van Nieuwenhuyze, Research series, June 2008.

134. "Economic importance of the Belgian ports: Flemish maritime ports, Liège port complex and the port of Brussels - Report 2006", by S. Vennix, Document series, June 2008.

135. "Imperfect exchange rate pass-through: The role of distribution services and variable demand elasticity", by Ph. Jeanfils, Research series, August 2008.

136. "Multivariate structural time series models with dual cycles: Implications for measurement of output gap and potential growth", by Ph. Moës, Research series, August 2008.

137. "Agency problems in structured finance - A case study of European CLOs", by J. Keller, Document series, August 2008.

138. "The efficiency frontier as a method for gauging the performance of public expenditure: A Belgian case study", by B. Eugène, Research series, September 2008.

139. "Exporters and credit constraints. A firm-level approach", by M. Muûls, Research series, September 2008.

140. "Export destinations and learning-by-exporting: Evidence from Belgium", by M. Pisu, Research series, September 2008.

141. "Monetary aggregates and liquidity in a neo-Wicksellian framework", by M. Canzoneri, R. Cumby, B. Diba and D. López-Salido, Research series, October 2008.

142 "Liquidity, inflation and asset prices in a time-varying framework for the euro area, by Ch. Baumeister, E. Durinck and G. Peersman, Research series, October 2008.

143. "The bond premium in a DSGE model with long-run real and nominal risks", by G. D. Rudebusch and E. T. Swanson, Research series, October 2008.

144. "Imperfect information, macroeconomic dynamics and the yield curve: An encompassing macro-finance model", by H. Dewachter, Research series, October 2008.

145. "Housing market spillovers: Evidence from an estimated DSGE model", by M. lacoviello and S. Neri, Research series, October 2008.

146. "Credit frictions and optimal monetary policy", by V. Cúrdia and M. Woodford, Research series, October 2008.

147. "Central Bank misperceptions and the role of money in interest rate rules", by G. Beck and V. Wieland, Research series, October 2008.

148. "Financial (in)stability, supervision and liquidity injections: A dynamic general equilibrium approach", by G. de Walque, O. Pierrard and A. Rouabah, Research series, October 2008.

149. "Monetary policy, asset prices and macroeconomic conditions: A panel-VAR study", by K. AssenmacherWesche and S. Gerlach, Research series, October 2008.

150. "Risk premiums and macroeconomic dynamics in a heterogeneous agent model", by F. De Graeve, M. Dossche, M. Emiris, H. Sneessens and R. Wouters, Research series, October 2008.

151. "Financial factors in economic fluctuations", by L. J. Christiano, R. Motto and M. Rotagno, Research series, to be published.

152. "Rent-sharing under different bargaining regimes: Evidence from linked employer-employee data", by M. Rusinek and F. Rycx, Research series, December 2008.

153. "Forecast with judgment and models", by F. Monti, Research series, December 2008.

154. "Institutional features of wage bargaining in 23 European countries, the US and Japan", by Ph. Du Caju, E. Gautier, D. Momferatou and M. Ward-Warmedinger, Research series, December 2008.

155. "Fiscal sustainability and policy implications for the euro area", by F. Balassone, J. Cunha, G. Langenus, B. Manzke, J Pavot, D. Prammer and P. Tommasino, Research series, January 2009.

156. "Understanding sectoral differences in downward real wage rigidity: Workforce composition, institutions, technology and competition", by Ph. Du Caju, C. Fuss and L. Wintr, Research series, February 2009. 
157. "Sequential bargaining in a New Keynesian model with frictional unemployment and staggered wage negotiation", by G. de Walque, O. Pierrard, H. Sneessens and R. Wouters, Research series, February 2009.

158. "Economic importance of air transport and airport activities in Belgium", by F. Kupfer and F. Lagneaux, Document series, March 2009.

159. "Rigid labour compensation and flexible employment? Firm-Level evidence with regard to productivity for Belgium", by C. Fuss and L. Wintr, Research series, March 2009.

160. "The Belgian iron and steel industry in the international context", by F. Lagneaux and D. Vivet, Document series, March 2009.

161. "Trade, wages and productivity", by K. Behrens, G. Mion, Y. Murata and J. Südekum, Research series, March 2009.

162. "Labour flows in Belgium", by P. Heuse and Y. Saks, Research series, April 2009.

163. "The young Lamfalussy: An empirical and policy-oriented growth theorist", by I. Maes, Research series, April 2009.

164. "Inflation dynamics with labour market matching: Assessing alternative specifications", by K. Christoffel, J. Costain, G. de Walque, K. Kuester, T. Linzert, S. Millard and O. Pierrard, Research series, May 2009.

165. "Understanding inflation dynamics: Where do we stand?", by M. Dossche, Research series, June 2009.

166. "Input-output connections between sectors and optimal monetary policy", by E. Kara, Research series, June 2009.

167. "Back to the basics in banking? A micro-analysis of banking system stability", by $\mathrm{O}$. De Jonghe, Research series, June 2009.

168. "Model misspecification, learning and the exchange rate disconnect puzzle", by V. Lewis and A. Markiewicz, Research series, July 2009.

169. "The use of fixed-term contracts and the labour adjustment in Belgium", by E. Dhyne and B. Mahy, Research series, July 2009.

170. "Analysis of business demography using markov chains - An application to Belgian data", by F. Coppens and F. Verduyn, Research series, July 2009.

171. "A global assessment of the degree of price stickiness - Results from the NBB business survey", by E. Dhyne, Research series, July 2009.

172. "Economic importance of the Belgian ports: Flemish maritime ports, Liège port complex and the port of Brussels - Report 2007", by C. Mathys, Document series, July 2009.

173. "Evaluating a monetary business cycle model with unemployment for the euro area", by N. Groshenny, Research series, July 2009.

174. "How are firms' wages and prices linked: Survey evidence in Europe", by M. Druant, S. Fabiani and G. Kezdi, A. Lamo, F. Martins and R. Sabbatini, Research series, August 2009.

175. "Micro-data on nominal rigidity, inflation persistence and optimal monetary policy", by E. Kara, Research series, September 2009.

176. "On the origins of the BIS macro-prudential approach to financial stability: Alexandre Lamfalussy and financial fragility", by I. Maes, Research series, October 2009.

177. "Incentives and tranche retention in securitisation: A screening model", by I. Fender and J. Mitchell, Research series, October 2009.

178. "Optimal monetary policy and firm entry", by V. Lewis, Research series, October 2009.

179. "Staying, dropping, or switching: The impacts of bank mergers on small firms", by H. Degryse, N. Masschelein and J. Mitchell, Research series, October 2009.

180. "Inter-industry wage differentials: How much does rent sharing matter?", by Ph. Du Caju, F. Rycx and I. Tojerow, Research series, October 2009.

181. "Empirical evidence on the aggregate effects of anticipated and unanticipated US tax policy shocks", by K. Mertens and M. O. Ravn, Research series, November 2009.

182. "Downward nominal and real wage rigidity: Survey evidence from European firms", by J. Babecký, Ph. Du Caju, T. Kosma, M. Lawless, J. Messina and T. Rõõm, Research series, November 2009.

183. "The margins of labour cost adjustment: Survey evidence from European firms", by J. Babecký, Ph. Du Caju, T. Kosma, M. Lawless, J. Messina and T. Rõõm, Research series, November 2009.

184. "Discriminatory fees, coordination and investment in shared ATM networks" by S. Ferrari, Research series, January 2010.

185. "Self-fulfilling liquidity dry-ups", by F. Malherbe, Research series, March 2010.

186. "The development of monetary policy in the 20th century - some reflections", by O. Issing, Research series, April 2010.

187. "Getting rid of Keynes? A survey of the history of macroeconomics from Keynes to Lucas and beyond", by M. De Vroey, Research series, April 2010.

188. "A century of macroeconomic and monetary thought at the National Bank of Belgium", by I. Maes, Research series, April 2010. 
189. "Inter-industry wage differentials in EU countries: What do cross-country time-varying data add to the picture?", by Ph. Du Caju, G. Kátay, A. Lamo, D. Nicolitsas and S. Poelhekke, Research series, April 2010.

190. "What determines euro area bank CDS spreads?", by J. Annaert, M. De Ceuster, P. Van Roy and C. Vespro, Research series, May 2010.

191. "The incidence of nominal and real wage rigidity: An individual-based sectoral approach", by J. Messina, Ph. Du Caju, C. F. Duarte, N. L. Hansen, M. Izquierdo, Research series, June 2010.

192. "Economic importance of the Belgian ports: Flemish maritime ports, Liège port complex and the port of Brussels - Report 2008", by C. Mathys, Document series, July 2010.

193. "Wages, labor or prices: how do firms react to shocks?", by E. Dhyne and M. Druant, Research series, July 2010.

194. "Trade with China and skill upgrading: Evidence from Belgian firm level data", by G. Mion, H. Vandenbussche, and L. Zhu, Research series, September 2010.

195. "Trade crisis? What trade crisis?", by K. Behrens, G. Corcos and G. Mion, Research series, September 2010.

196. "Trade and the global recession", by J. Eaton, S. Kortum, B. Neiman and J. Romalis, Research series, October 2010.

197. "Internationalization strategy and performance of small and medium sized enterprises", by J. Onkelinx and L. Sleuwaegen, Research series, October 2010.

198. "The internationalization process of firms: From exports to FDI?", by P. Conconi, A. Sapir and M. Zanardi, Research series, October 2010.

199. "Intermediaries in international trade: Direct versus indirect modes of export", by A. B. Bernard, M. Grazzi and C. Tomasi, Research series, October 2010.

200. "Trade in services: IT and task content", by A. Ariu and G. Mion, Research series, October 2010.

201. "The productivity and export spillovers of the internationalisation behaviour of Belgian firms", by M. Dumont, B. Merlevede, C. Piette and G. Rayp, Research series, October 2010.

202. "Market size, competition, and the product mix of exporters", by T. Mayer, M. J. Melitz and G. I. P. Ottaviano, Research series, October 2010.

203. "Multi-product exporters, carry-along trade and the margins of trade", by A. B. Bernard, I. Van Beveren and H. Vandenbussche, Research series, October 2010.

204. "Can Belgian firms cope with the Chinese dragon and the Asian tigers? The export performance of multiproduct firms on foreign markets" by F. Abraham and J. Van Hove, Research series, October 2010.

205. "Immigration, offshoring and American jobs", by G. I. P. Ottaviano, G. Peri and G. C. Wright, Research series, October 2010.

206. "The effects of internationalisation on domestic labour demand by skills: Firm-level evidence for Belgium", by L. Cuyvers, E. Dhyne, and R. Soeng, Research series, October 2010.

207. "Labour demand adjustment: Does foreign ownership matter?", by E. Dhyne, C. Fuss and C. Mathieu, Research series, October 2010.

208. "The Taylor principle and (in-)determinacy in a New Keynesian model with hiring frictions and skill loss", by A. Rannenberg, Research series, November 2010.

209. "Wage and employment effects of a wage norm: The Polish transition experience" by A. de Crombrugghe and G. de Walque, Research series, February 2011.

210. "Estimating monetary policy reaction functions: A discrete choice approach" by J. Boeckx, Research series, February 2011.

211. "Firm entry, inflation and the monetary transmission mechanism" by V. Lewis and C. Poilly, Research series, February 2011.

212. "The link between mobile telephony arrears and credit arrears" by H. De Doncker, Document series, March 2011.

213. "Development of a financial health indicator based on companies' annual accounts", by D. Vivet, Document series, April 2011.

214. "Wage structure effects of international trade: Evidence from a small open economy", by Ph. Du Caju, F. Rycx and I. Tojerow, Research series, April 2011.

215. "Economic importance of the Belgian ports: Flemish maritime ports, Liège port complex and the port of Brussels - Report 2009", by C. Mathys, Document series, June 2011.

216. "Verti-zontal differentiation in monopolistic competition", by F. Di Comite, J.-F. Thisse and H. Vandenbussche, Research series, October 2011.

217. "The evolution of Alexandre Lamfalussy's thought on the international and European monetary system (1961-1993)" by I. Maes, Research series, November 2011.

218. "Economic importance of air transport and airport activities in Belgium - Report 2009", by X. Deville and S. Vennix, Document series, December 2011. 
219. "Comparative advantage, multi-product firms and trade liberalisation: An empirical test", by C. Fuss and L. Zhu, Research series, January 2012.

220. "Institutions and export dynamics", by L. Araujo, G. Mion and E. Ornelas, Research series, February 2012.

221. "Implementation of EU legislation on rail liberalisation in Belgium, France, Germany and the Netherlands", by X. Deville and F. Verduyn, Document series, March 2012.

222. "Tommaso Padoa-Schioppa and the origins of the euro", by I. Maes, Document series, March 2012.

223. "(Not so) easy come, (still) easy go? Footloose multinationals revisited", by P. Blanchard, E. Dhyne, C. Fuss and C. Mathieu, Research series, March 2012.

224. "Asymmetric information in credit markets, bank leverage cycles and macroeconomic dynamics", by A. Rannenberg, Research series, April 2012.

225. "Economic importance of the Belgian ports: Flemish maritime ports, Liège port complex and the port of Brussels - Report 2010", by C. Mathys, Document series, July 2012.

226. "Dissecting the dynamics of the US trade balance in an estimated equilibrium model", by P. Jacob and G. Peersman, Research series, August 2012.

227. "Regime switches in volatility and correlation of financial institutions", by K. Boudt, J. Daníelsson, S.J. Koopman and A. Lucas, Research series, October 2012.

228. "Measuring and testing for the systemically important financial institutions", by C. Castro and S. Ferrari, Research series, October 2012.

229. "Risk, uncertainty and monetary policy", by G. Bekaert, M. Hoerova and M. Lo Duca, Research series, October 2012.

230. "Flights to safety", by L. Baele, G. Bekaert, K. Inghelbrecht and M. Wei, Research series, October 2012.

231. "Macroprudential policy, countercyclical bank capital buffers and credit supply: Evidence from the Spanish dynamic provisioning experiments", by G. Jiménez, S. Ongena, J.-L. Peydró and J. Saurina, Research series, October 2012.

232. "Bank/sovereign risk spillovers in the European debt crisis", by V. De Bruyckere, M. Gerhardt, G. Schepens and R. Vander Vennet, Research series, October 2012.

233. "A macroeconomic framework for quantifying systemic risk", by Z. He and A. Krishnamurthy, Research series, October 2012.

234. "Fiscal policy, banks and the financial Crisis", by R. Kollmann, M. Ratto, W. Roeger and J. in't Veld, Research series, October 2012.

235. "Endogenous risk in a DSGE model with capital-constrained financial intermediaries", by $\mathrm{H}$. Dewachter and R. Wouters, Research series, October 2012. 
National Bank of Belgium

Limited liability company

RLP Brussels - Company's number: 0203.201.340

Registered office: boulevard de Berlaimont $14-B E-1000$ Brussels

www.nbb.be

\section{Editor}

\section{Jan Smets}

Member of the Board of directors of the National Bank of Belgium

(C) Illustrations: National Bank of Belgium

Layout: Analysis and Research Group Cover: NBB AG - Prepress \& Image

Published in October 2012 